Aus der Poliklinik für Zahnärztliche Prothetik

(Prof. Dr. med. dent. R. Bürgers)

im Zentrum für Zahn-, Mund- und Kieferheilkunde

der Medizinischen Fakultät der Universität Göttingen

\title{
In-vivo-Biofilmakkumulation auf implantatprothetischen Werkstoffen
}

\author{
INAUGURAL-DISSERTATION \\ zur Erlangung des Doktorgrades \\ für Zahnmedizin \\ der Medizinischen Fakultät der \\ Georg-August-Universität zu Göttingen
}

vorgelegt von

Andreas Wiessner

aus

Ischewsk, Russland

Göttingen 2020 
Dekan:

Referent/in

Ko-Referent/in:

Drittreferent/in:
Prof. Dr. med. W. Brück

Prof. Dr. med. dent. R. Bürgers

Prof. Dr. med. dent. T. Rödig

Prof. Dr. hum. biol. M. Schön

Datum der mündlichen Prüfung: 14.07.2021 
Hiermit erkläre ich, die Dissertation mit dem Titel "In-vivoBiofilmakkumulation auf implantatprothetischen Werkstoffen" eigenständig angefertigt und keine anderen als die von mir angegebenen Quellen und Hilfsmittel verwendet zu haben.

Göttingen, den 


\section{Inhaltsverzeichnis}

Abbildungsverzeichnis........................................................................................II

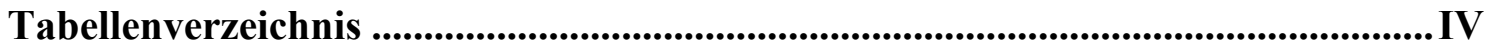

Abkürzungsverzeichnis .......................................................................................................... V

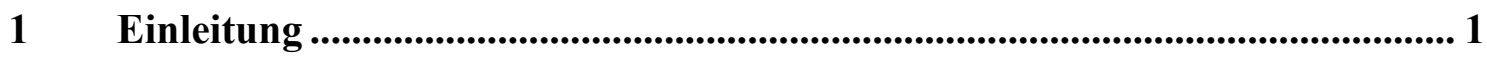

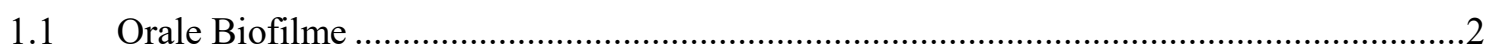

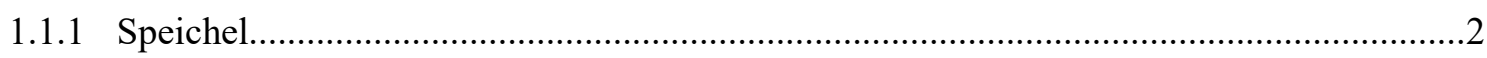

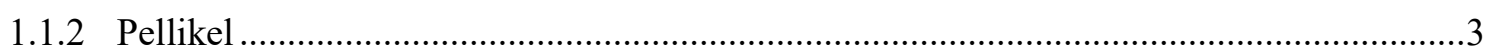

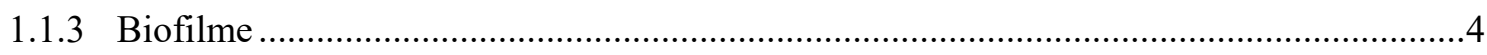

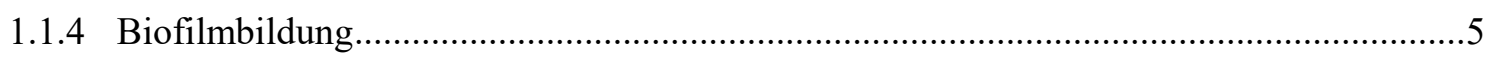

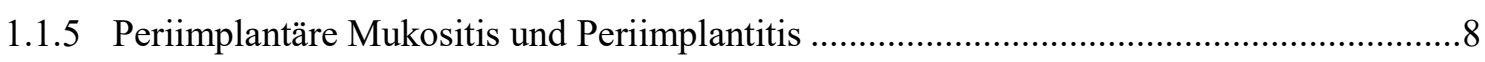

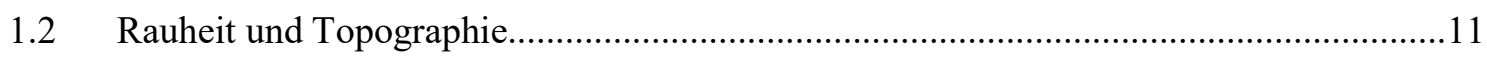

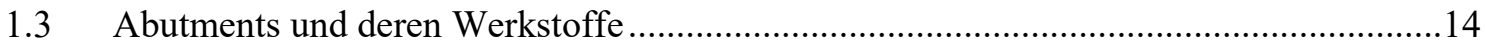

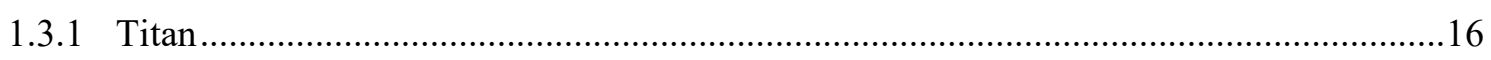

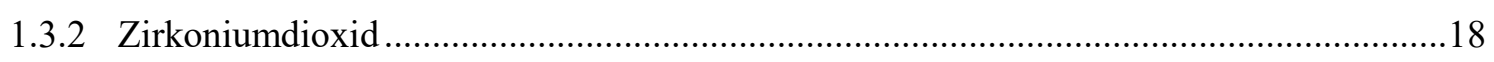

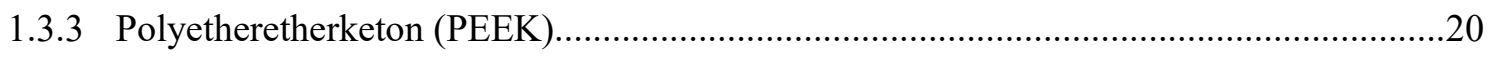

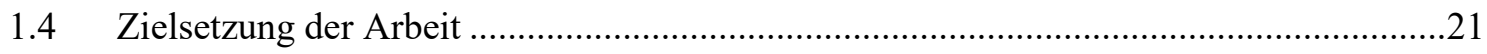

2 Material und Methoden ............................................................................... 22

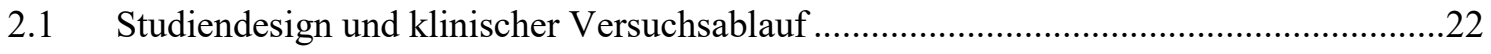

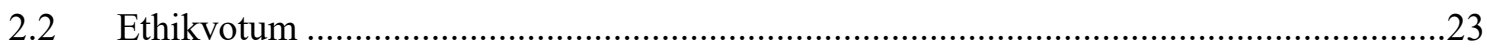

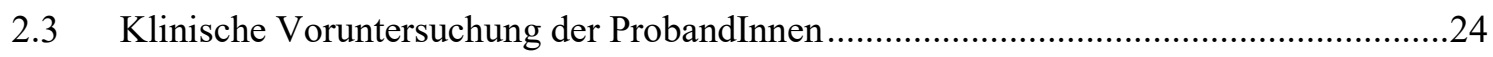

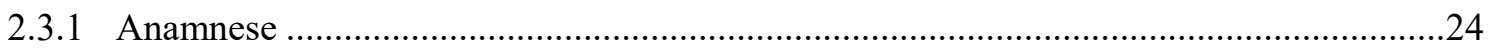

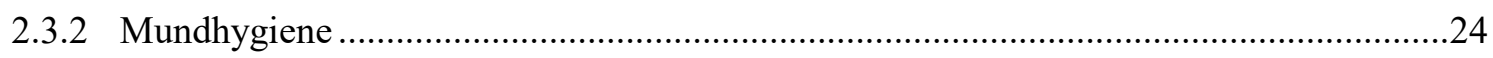

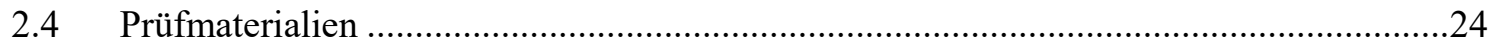

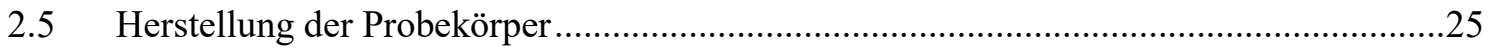

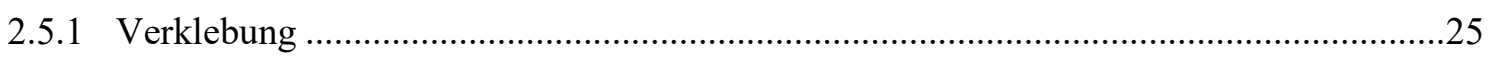

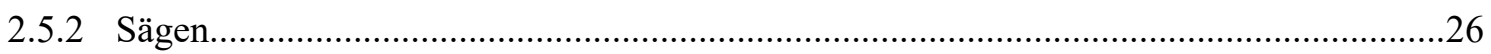

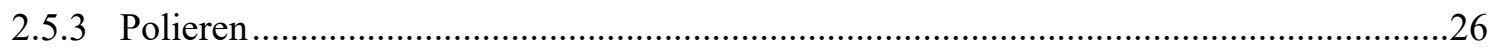

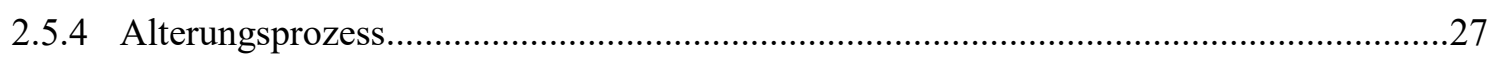

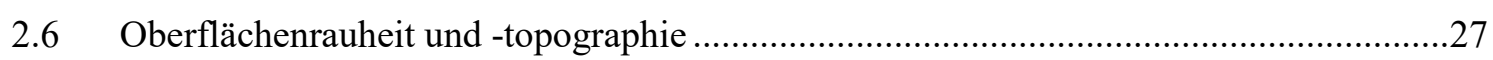

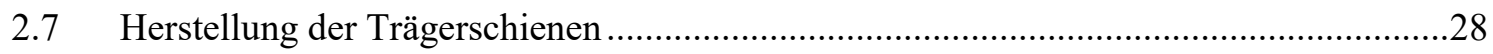

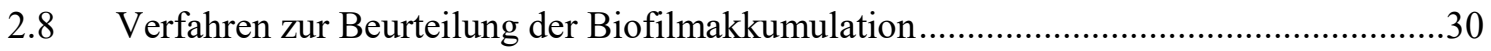

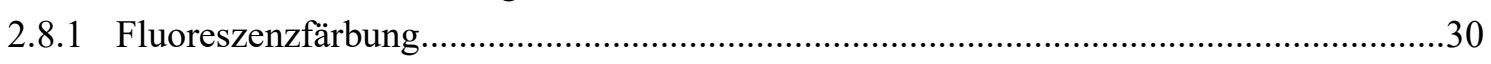

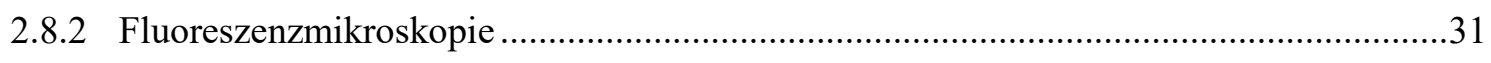

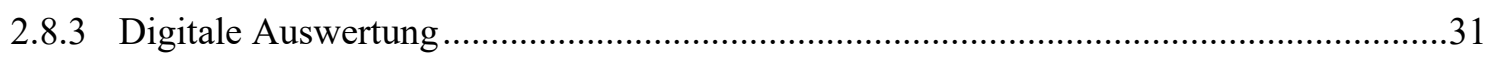

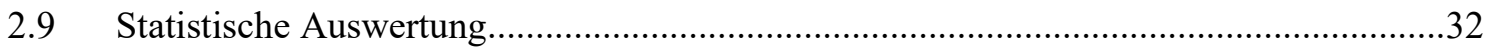




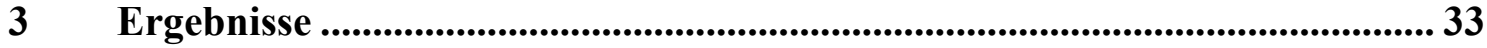

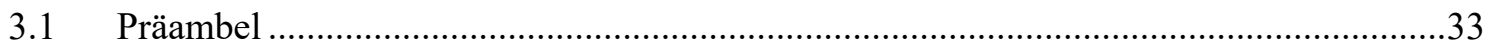

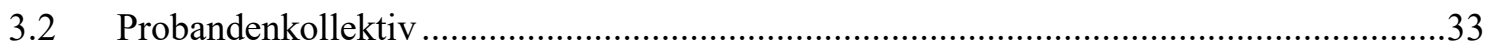

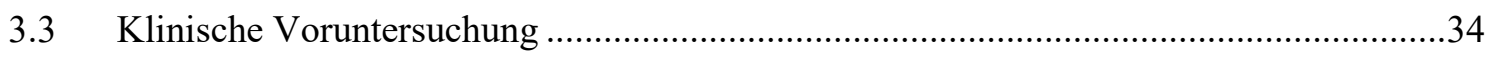

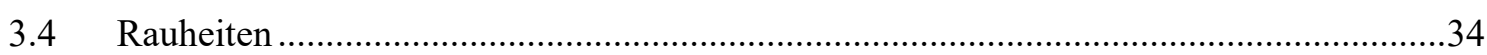

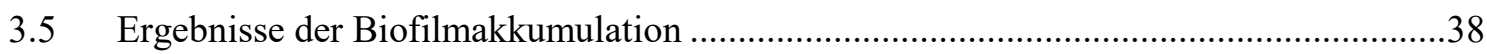

3.5.1 Materialspezifische Biofilmakkumulation im Gesamtkollektiv .........................................38

3.5.2 Biofilmakkumulation in Abhängigkeit von der Materialalterung....................................4

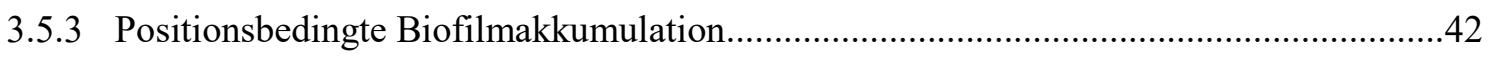

3.5.4 Geschlechterspezifische Biofilmakkumulation .............................................................43

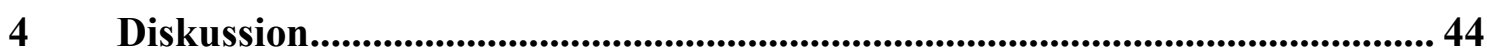

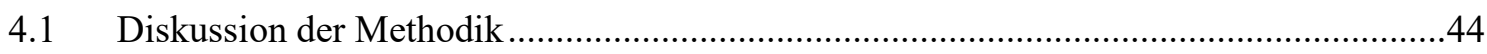

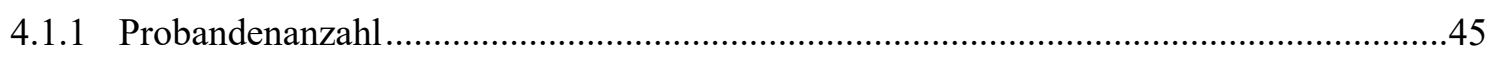

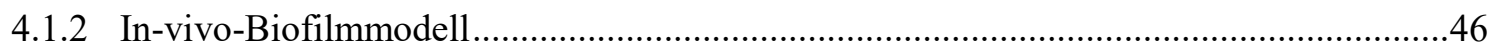

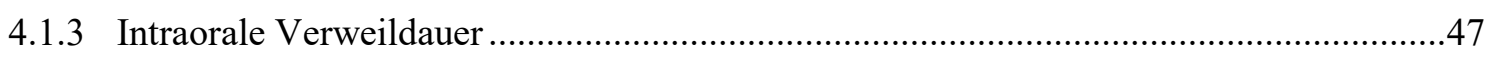

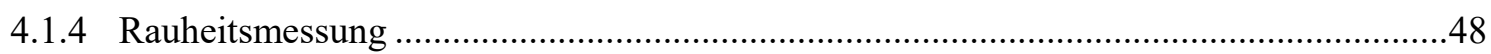

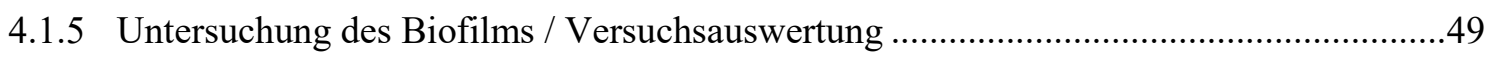

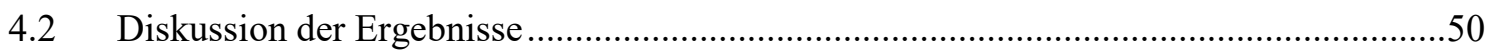

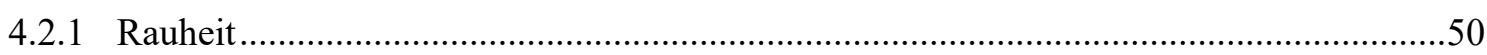

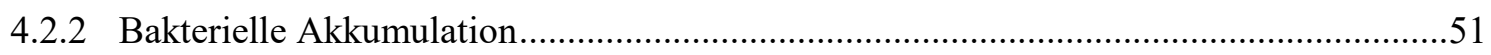

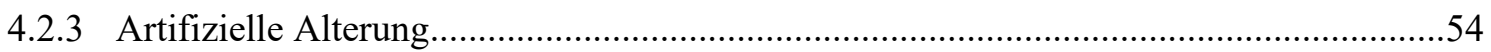

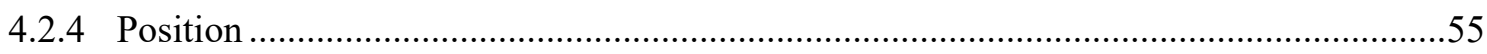

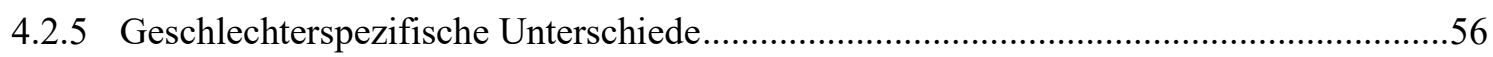

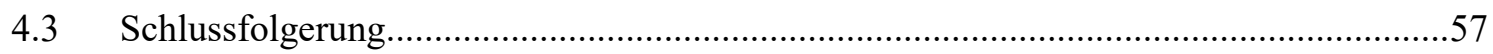

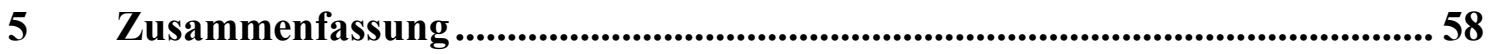

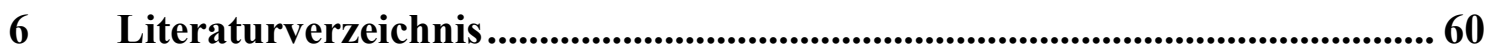




\section{Abbildungsverzeichnis}

Abbildung 1: Theoretisches Modell der Architektur eines reifen Biofilms ................................5

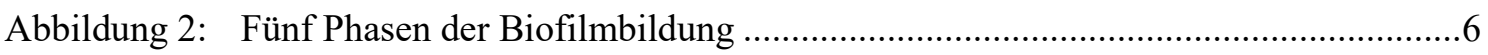

Abbildung 3: Anlagerungsverhalten von Bakterien auf glatten und rauen Oberflächen............11

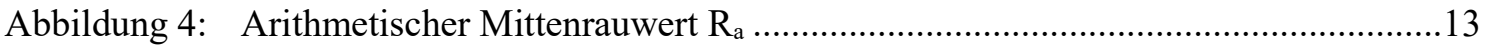

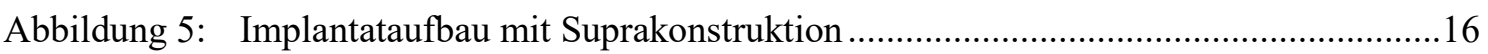

Abbildung 6: $\mathrm{CAD} / \mathrm{CAM}$-gefertigte Abutments aus Zirkoniumdioxid, PEEK und Titan .........16

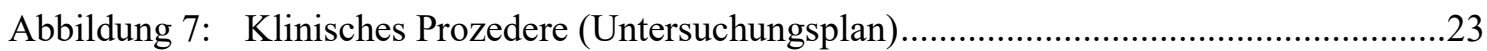

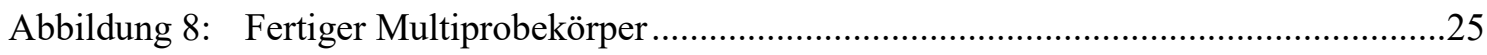

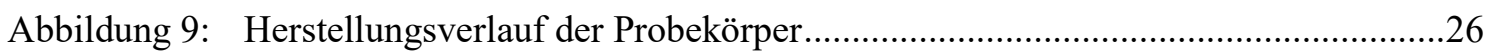

Abbildung 10: Dreidimensionale Darstellung mit dazugehörigem Profilschnitt einer Titanoberfläche im Ausgangszustand.................................................................28

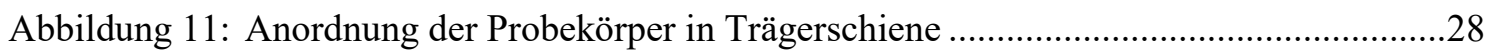

Abbildung 12: Trägerschiene mit Probekörpern auf dem Modell ............................................29

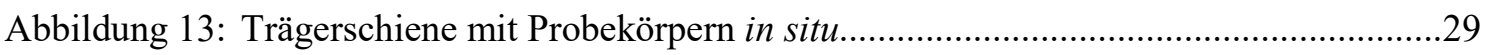

Abbildung 14: 24-Well-Platte mit eingebrachten Probekörpern ................................................

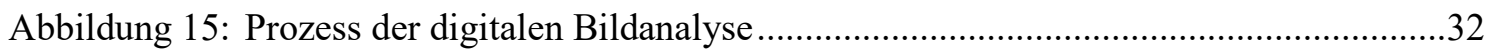

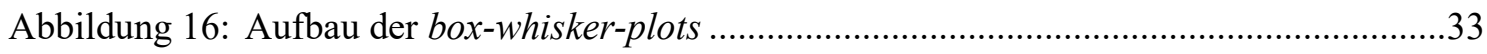

Abbildung 17: Verteilung der arithmetischen Mittenrauwerte $\mathrm{R}_{\mathrm{a}}[\mu \mathrm{m}]$ der Prüfmaterialien in Abhängigkeit vom Alterungszustand ...............................................................35

Abbildung 18: Verteilung der mittleren arithmetischen Höhen $S_{a}[\mu \mathrm{m}]$ der Prüfmaterialien

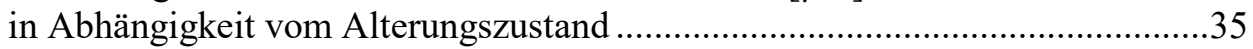

Abbildung 19: Dreidimensionale Darstellung der Oberflächentopographie (550 x $550 \mu \mathrm{m})$ mit dazugehöriger Darstellung des Rauheitsprofils von BioHPP.........................36

Abbildung 20: Dreidimensionale Darstellung der Oberflächentopographie (550 x $550 \mu \mathrm{m})$ mit dazugehöriger Darstellung des Rauheitsprofils von PEEK...........................36

Abbildung 21: Dreidimensionale Darstellung der Oberflächentopographie (550 x $550 \mu \mathrm{m})$ mit dazugehöriger Darstellung des Rauheitsprofils von Titan

Abbildung 22: Dreidimensionale Darstellung der Oberflächentopographie $(550$ x $550 \mu \mathrm{m})$ mit dazugehöriger Darstellung des Rauheitsprofils von Zirkoniumdioxid ..........37

Abbildung 23: Verteilung der Biofilmakkumulation auf den einzelnen Materialoberflächen ....38

Abbildung 24: BioHPP, Fluoreszenzmikroskopische Aufnahme (20-fache Vergrößerung), Hoechst 33342-Färbung ....

Abbildung 25: PEEK, Fluoreszenzmikroskopische Aufnahme (20-fache Vergrößerung), Hoechst 33342-Färbung

Abbildung 26: Titan, Fluoreszenzmikroskopische Aufnahme (20-fache Vergrößerung), Hoechst 33342-Färbung

Abbildung 27: Zirkoniumdioxid, Fluoreszenzmikroskopische Aufnahme (20-fache Vergrößerung), Hoechst 33342-Färbung...

Abbildung 28: Verteilung der Biofilmakkumulation auf den einzelnen Materialoberflächen [\%] in Abhängigkeit vom Alterungszustand

Abbildung 29: Verteilung der Biofilmakkumulation [\%] in Abhängigkeit von den intraoralen Positionen..

Abbildung 30: Verteilung der Biofilmakkumulation auf den einzelnen Materialoberflächen $[\%]$ in Abhängigkeit vom Geschlecht 


\section{Tabellenverzeichnis}

Tabelle 1: $\quad$ Ein- und Ausschlusskriterien zur Studienteilnahme...........................................22

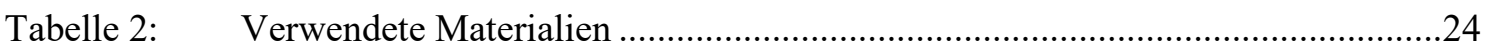

Tabelle 3: Arithmetische Mittenrauwerte $R_{a}$ und $S_{a}[\mu \mathrm{m}]$ für alle Materialien in Abhängigkeit vom Alterungszustand (Median, Q1, Q2)....................................34

Tabelle 4: $\quad$ Ergebnisse (p-Werte) des allgemeinen linearen gemischten Modells für den Einfluss des Materials auf die Biofilmakkumulation ...........................................39

Tabelle 5: $\quad$ Paarvergleiche der gemessenen Biofilmmenge auf den Prüfmaterialien mit entsprechenden $\mathrm{p}$-Werten

Tabelle 6: Verteilung der Biofilmakkumulation auf den einzelnen Materialoberflächen [\%] in Abhängigkeit vom Alterungszustand

Tabelle 7: Verteilung der Biofilmakkumulation auf den einzelnen Materialoberflächen [\%] in Abhängigkeit vom Geschlecht 


\section{Abkürzungsverzeichnis}

$\begin{array}{ll}\text { API } & \text { Approximalraum-Plaque-Index } \\ \text { cp-Ti } & \text { Reintitan } \\ \text { DAPI } & 4^{\prime}, 6 \text {-Diamidin-2-phenylindol } \\ \text { EPS } & \text { Extrazelluläre polymere Substanz } \\ \mathrm{IL} & \text { Interleukin } \\ \mathrm{NaCl} & \text { Natriumchlorid } \\ \mathrm{PBS} & \text { phosphate-buffered Saline, phophatgepufferte Salzlösung } \\ \mathrm{PEEK} & \text { Polyetheretherketon } \\ \mathrm{PFA} & \text { Paraformaldehyd } \\ \mathrm{R}_{\mathrm{a}} & \text { Arithmetischer Mittenrauwert } \\ \mathrm{S}_{\mathrm{a}} & \text { Flächenbezogener arithmetischer Mittenrauwert } \\ \mathrm{SBI} & \text { Sulkus-Blutungs-Index } \\ \text { TiO } & \text { Titandioxid } \\ \text { TNF- } \alpha & \text { Tumornekrosefaktor- } \alpha \\ \text { Zirkon } & \text { Zirkoniumdioxid }\end{array}$




\section{$1 \quad$ Einleitung}

Dentale Implantate sind als Therapie zur Verankerung von festsitzendem und herausnehmbarem Zahnersatz in der Zahnmedizin evidenzbasiert, etabliert und weit verbreitet. Vor allem die hohen klinischen Überlebensraten von Implantaten haben zu einer breiten Akzeptanz als Behandlungsmethode zum Ersatz von fehlenden Zähnen geführt. Der Langzeiterfolg wird jedoch stark von der Besiedlung der Materialoberflächen durch pathogene Biofilme beeinflusst, welche initial zu Entzündungen in der bindegewebigen Umgebung des Implantates führen, die wiederum unbehandelt in eine Periimplantitis münden und dann auch den Alveolarknochen irreversibel schädigen. Die raue Oberfläche von Implantaten begünstigt hierbei die Akkumulation und Strukturierung von Biofilmen. Eine entscheidende Rolle spielt dabei das Implantat-Abutment, welches das transgingivale Bindeglied zwischen dem in den Knochen integrierten Implantatkörper und der prothetischen Suprakonstruktion darstellt und folglich dem periimplantären Weichgewebe direkt anliegt. An diesem Implantataufbau lagert sich größtenteils subgingivaler Biofilm an, der eine hohe Pathogenität aufweist und mit häuslichen Mundhygienemaßnahmen nur schwer zu entfernen ist. Das wiederum begünstigt das Eindringen der Mikroorganismen in das periimplantäre Gewebe, wodurch es zu einer Mukositis bzw. Periimplantitis und schließlich eventuell zum Implantatverlust kommen kann. Es ist deshalb von hoher klinischer Relevanz, Werkstoffe mit einer reduzierten Neigung zur Biofilmakkumulation für die Abutmentherstellung $\mathrm{zu}$ verwenden. Durch die hervorragenden Langzeitergebnisse in der Herstellung prothetischer Retentionselemente hat sich Titan in der Vergangenheit als Abutmentmaterial durchgesetzt. Es wird aber dem zunehmenden Wunsch nach metallfreien, zahnfarbenen Materialien nicht gerecht, weshalb es zur Entwicklung und Einführung neuer Materialien kam. Dabei gewinnen insbesondere keramische Werkstoffe wie beispielsweise Zirkoniumdioxid (Zirkon) oder der Hochleistungskunststoff Polyetheretherketon (PEEK) an Relevanz.

Im Rahmen der vorliegenden Untersuchung sollte die In-vivo-Biofilmbildung auf vier modernen implantatprothetischen Materialien (Titan, Zirkoniumdioxid, PEEK, BioHPP) evaluiert werden. 


\subsection{Orale Biofilme}

\subsubsection{Speichel}

Etwa $90 \%$ der gesamten Speichelmenge wird von den drei großen, paarig angelegten Speicheldrüsen produziert, nämlich den Glandulae parotideae, Glandulae submandibulares und Glandulae sublinguales (Palk et al. 2010; Pedersen et al. 2002). Zusätzlich gibt es zahlreiche kleine Speicheldrüsen durch die zusammen mit den großen täglich etwa 0,6 - 1,5 Liter Speichel gebildet wird (Mese und Matsuo 2007; Murer 2005). Die einzelnen Speicheldrüsen sezernieren Speichel in voneinander abweichender Zusammensetzung, Fließrate und Konsistenz (Humphrey und Williamson 2001). Außerdem unterscheidet man zwischen Ruhespeichel, der einen $\mathrm{pH}-\mathrm{Wert}$ von 6,5-6,9 besitzt und dem Speichel, der unter Stimulation gebildet wird, bei dem sich der pH-Wert auf bis zu 7,2 erhöhen kann (Mandel 1974; Axelsson 2000). Für einen Großteil des Ruhespeichels sind die kleinen Speicheldrüsen, deren Sekret am stärksten mukös ist, sowie die Glandulae submandibulares und sublinguales mit ebenfalls mukösem Sekret, verantwortlich (Eliasson und Carlén 2010; Hand et al. 1999). Unter Stimulation wird vermehrt seröser Speichel von den Glandulae parotideae gebildet (Jensen Kjeilen et al. 1987).

Mit einem Anteil von etwa $99 \%$ besteht Speichel hauptsächlich aus Wasser (Humphrey und Williamson 2001; Lima et al. 2010). Die restlichen Bestandteile setzen sich aus organischen und anorganischen Substanzen zusammen. $\mathrm{Zu}$ den organischen zählen neben Proteinen, Glykoproteinen (Muzine), Enzymen ( $\alpha$-Amylase, Lysozymen, Lipasen) und Immunglobuli auch Harnstoff und Lactat (Mese und Matsuo 2007; Kielbassa 2006; Buddecke 1981; Vacca Smith und Bowen 2000). Der anorganische Bestandteil setzt sich aus Natrium, Kalzium, Chlorid, Kalium, Bicarbonat, Phosphat, Magnesium und Fluorid zusammen (van Rensburg 1994; Buddecke 1981). Außerdem befindlich im Speichel sind Zelltrümmer, Bakterien und Sulkusflüssigkeit (Kielbassa 2006; Walz et al. 2006). Die Speichelsekretion wird von einer Vielzahl von Faktoren beeinflusst; Beispiele sind neben dem Hydratationszustand des Körpers auch mastikatorische und gustatorische Reize sowie visuelle Eindrücke (Hector und Linden 1999; Proctor und Carpenter 2007). Ebenfalls eine große Rolle spielen Faktoren wie die Einnahme bestimmter Medikamente (z. B. Antidepressiva) oder Nikotin- und Drogenkonsum, bei denen als Nebenwirkung Mundtrockenheit, die sogenannte Xerostomie, auftreten kann (Sarapur und Shilpashree 2012; Bardow et al. 2001). 


\subsubsection{Pellikel}

Eine weitere essentielle Aufgabe des Speichels ist die Bildung des Pellikels - auch als Schmelzoberhäutchen oder acquired pellicle bezeichnet (Armstrong 1968; Hannig 1997; Lendenmann et al. 2000). Hierbei handelt es sich um eine strukturlose, azelluläre und bakterienfreie Proteinschicht, deren Dicke in Abhängigkeit von Lokalisation und Reifezeit zwischen 0,1 und 3,0 $\mu \mathrm{m}$ beträgt (Amaechi et al. 1999; Hannig 1999). Die Bildung des Pellikels ist ein hochselektives Verfahren, bei dem nur ein geringer Anteil aller Speichelproteine adsorbiert wird, wie beispielsweise Glykoproteine, saure prolinreiche Enzyme und Immunglobuline (Yao et al. 2001; Hannig 2002; Li et al. 2004). Bei der Proteinadsorption laufen unterschiedliche chemische und physikalische Interaktionen zwischen Zahn- und Werkstoffoberflächen, Flüssigkeit und den freien Proteinen ab (Huang et al. 2011). In der ersten Phase der Pellikelbildung lösen sich einige der im Zahnschmelz vorhandenen Kalziumionen aus dem Hydroxylapatit heraus, wodurch sich eine Kalziumschicht an der Oberfläche des negativ geladenen Zahnschmelzes bildet (Hay 1973; Hannig und Joiner 2006). Eine hohe Anziehung zu dieser besitzen Phosphoproteine des Speichels, weshalb sie auch als Pellikelpräkursoren bezeichnet werden (Hannig und Hannig 2009). Diese interagieren mit den im Schmelz zurückgebliebenen Phosphationen und es entsteht ein Verbund über Kalziumbrücken mit der Schmelzoberfläche (Hannig und Hannig 2007; Embery et al. 1986; Hay 1973). Es wird angenommen, dass die zweite Phase, die der Pellikelproliferation, nach etwa 30 Minuten beginnt und von den Interaktionen zwischen den freien Biopolymeren und den bereits an der Zahnoberfläche haftenden Proteinen abhängig ist (Kuboki et al. 1987; Lamkin et al. 1996; Amaechi et al. 1999). Die protektive Funktion des Pellikels vor Abrasion, Attrition und Erosion ist für die Zahnhartsubstanz von großer Bedeutung (Hannig et al. 2007; Mayhall 1970). Als Diffusionsbarriere kontrolliert es außerdem De- und Remineralisationsprozesse durch Steuerung des Ionenflusses von Fluorid, Kalzium- und Phosphationen (Hannig und Joiner 2006; Zahradnik et al. 1976; Rytömaa et al. 1988; Meurman und Frank 1991). Spezifische adsorbierte Proteine dienen als Rezeptoren für sogenannte frühkolonisierende Bakterien wie Streptococcus oralis, sanguinis und mitis, die die Bakterienadhäsion fördern (Gibbons et al. 1976; Hannig und Hannig 2009; Hannig und Joiner 2006; Müller et al. 2007). 


\subsubsection{Biofilme}

Schon im Jahre 1683 erforschte der Naturwissenschaftler Antoni van Leeuwenhoek die Zusammensetzung des Speichels und beschrieb dabei Bakterien als animalcules (van Leeuwenhoek 1684; Slavkin 1997; Lane 2015). Die detaillierte Beschreibung von mikrobiellen Biofilmen folgte allerdings erst um das Jahr 1940 durch Heukelekian und Heller (1940).

Grundsätzlich wird zwischen zwei mikrobiellen Lebensformen unterschieden, der planktonischen und der Biofilm-assoziierten. Bei der planktonischen Lebensweise flottieren Mikroorganismen frei in einer Suspension, in der sie wachsen und leben (O'Toole et al. 2000). Der Begriff Biofilm wird definiert als Akkumulation von Mikroorganismen an der Fläche zwischen zwei unterschiedlichen Phasen, eingebettet in eine meist hochhydrierte, überwiegend anionische Matrix aus Exopolysacchariden und anderen organischen Makromolekülen (Costerton et al. 1999; Hall-Stoodley und Stoodley 2002). Der Komplex mit einer eigens synthetisierten Matrix aus extrazellulären polymeren Substanzen (EPS) weist im Vergleich zu planktonischen Zellen einen veränderten Phänotypus bezüglich der Wachstumsrate und der Genexpression auf (Donlan und Costerton 2002; O'Toole et al. 2000). Die extrazelluläre Matrix bietet den Bakterien neben mechanischer Stabilität Schutz vor Austrocknung, wechselnden $\mathrm{pH}$ Werten, UV-Licht, Antibiotika und toxischen Substanzen (Costerton 1987; Hoyle et al. 1990; Anwar et al. 1990; Sutherland 2001a). Biofilme reagieren sensibel auf externe Reize und können sich so an Umweltveränderungen anpassen (Costerton et al. 1994; Liljemark et al. 1997). Diese Anpassungsfähigkeit wird hauptsächlich dadurch ermöglicht, dass die vielfältigen Bakterienspezies innerhalb des Biofilms ein komplexes Kommunikationssystem mittels autoinduzierter Signalmoleküle aufbauen, das als quorum sensing bezeichnet wird (Fuqua et al. 1994; Waters und Bassler 2005; Dunne 2002). Durch diese Zell-Zell-Kommunikation sind die Mikroorganismen sozusagen im Stande als ein mehrzelliger Organismus zu agieren (Fux et al. 2003). Über die Sekretion bestimmter chemischer Signalstoffe können die Mikroorganismen die Zelldichte messen und ihre Genexpression entsprechend regulieren (Miller und Bassler 2001; Li und Nair 2012). Bei Über- oder Unterschreitung einer bestimmten Zelldichte kommt es zur Aktivierung spezifischer Gene, die bewirken, dass sich Prozesse durch die Aufteilung auf die bakterielle Gemeinschaft, das sogenannte quorum, effizienter koordinieren lassen (Barnard und Salmond 2004; Duan et al. 2009). Makroskopisch zeichnet sich der reife Biofilm durch eine pilz- oder fingerartige Architektur aus (Bryers 1993; Dunne 2002; 
Klausen et al. 2003) (siehe Abbildung 1). Sie ist durchzogen von Kanälen und Kavernen, wodurch sowohl die konstante Zufuhr von Nährstoffen bis in tiefere Schichten als auch der Abtransport von metabolischen Endprodukten der Zellen stattfinden kann (Stoodley et al. 1994; Costerton 1995; Davey und O'Toole 2000; Overman 2000). In den vergangenen Jahrzehnten ist eine steigende bakterielle Resistenz gegen antibakterielle Noxen in Biofilmen $\mathrm{zu}$ verzeichnen, die wiederum $\mathrm{zu}$ fortschreitenden chronischen Infektionen führte (Lewis 2001; Donlan 2002; Stewart und Costerton 2001). In Bezug auf die Mundhöhle sind Biofilme verantwortlich für verschiedene dentale Erkrankungen wie Karies, Gingivitis, Parodontitis oder Periimplantitis (Lewis et al. 2004; Arciola et al. 2012; Subramani et al. 2009).

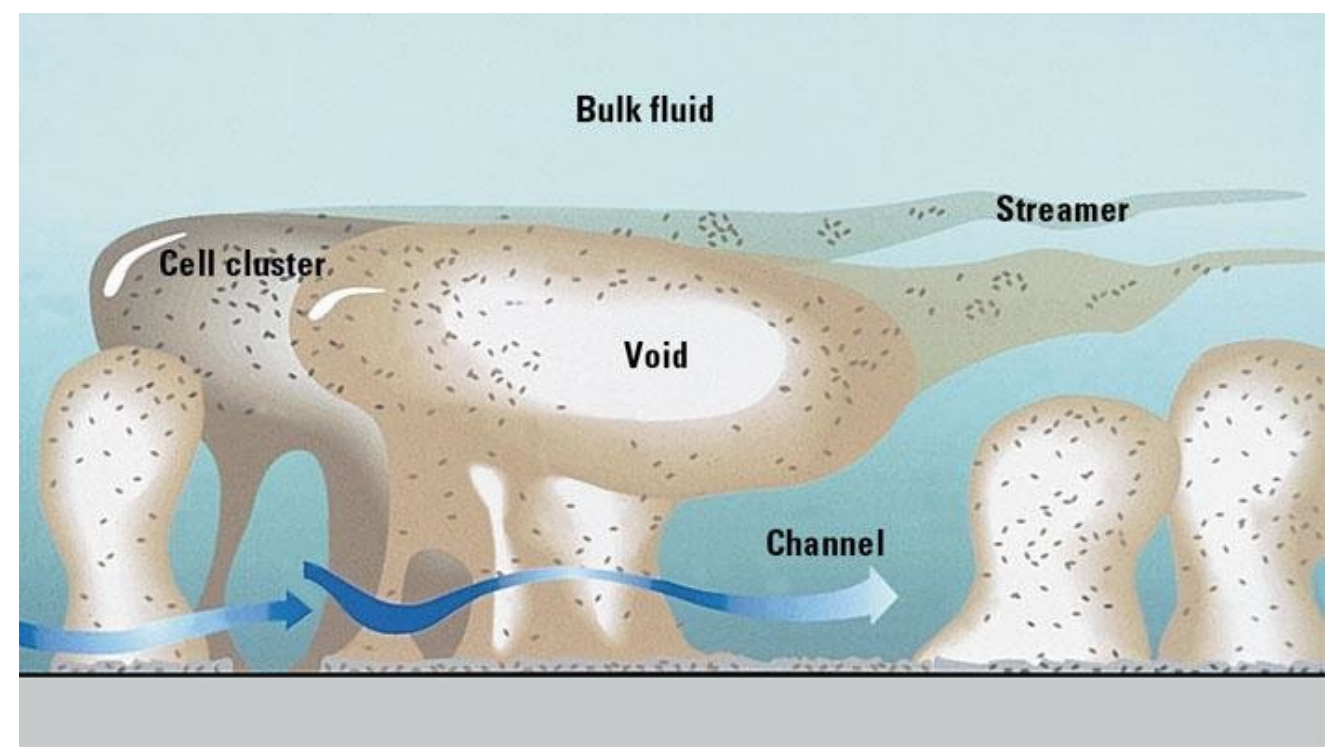

Abbildung 1: Theoretisches Modell der Architektur eines reifen Biofilms (Dirckx 1997; die Verwendung erfolgt mit freundlicher Genehmigung der Montana State University, Center for Biofilm Engineering)

\subsubsection{Biofilmbildung}

Die Entstehung des Biofilms umfasst voneinander abhängige komplexe Vorgänge, die in ihrer Gesamtheit in vitro aufgrund der Variabilität der Zusammensetzung des Biofilms nicht exakt reproduzierbar sind. Trotz der Inhomogenität des Ablaufs lässt sich in der Literatur ein generelles Muster darstellen (van Loosdrecht et al. 1990; Marsh und Bradshaw 1995). Zunächst kommt es zur Entstehung des Pellikels (siehe Kapitel 2.1.2). Anschließend wird die Biofilmbildung grundsätzlich in fünf Stadien unterteilt (Monroe 2007; Marsh 2004; Aparna und Yadav 2008) (siehe Abbildung 2): 


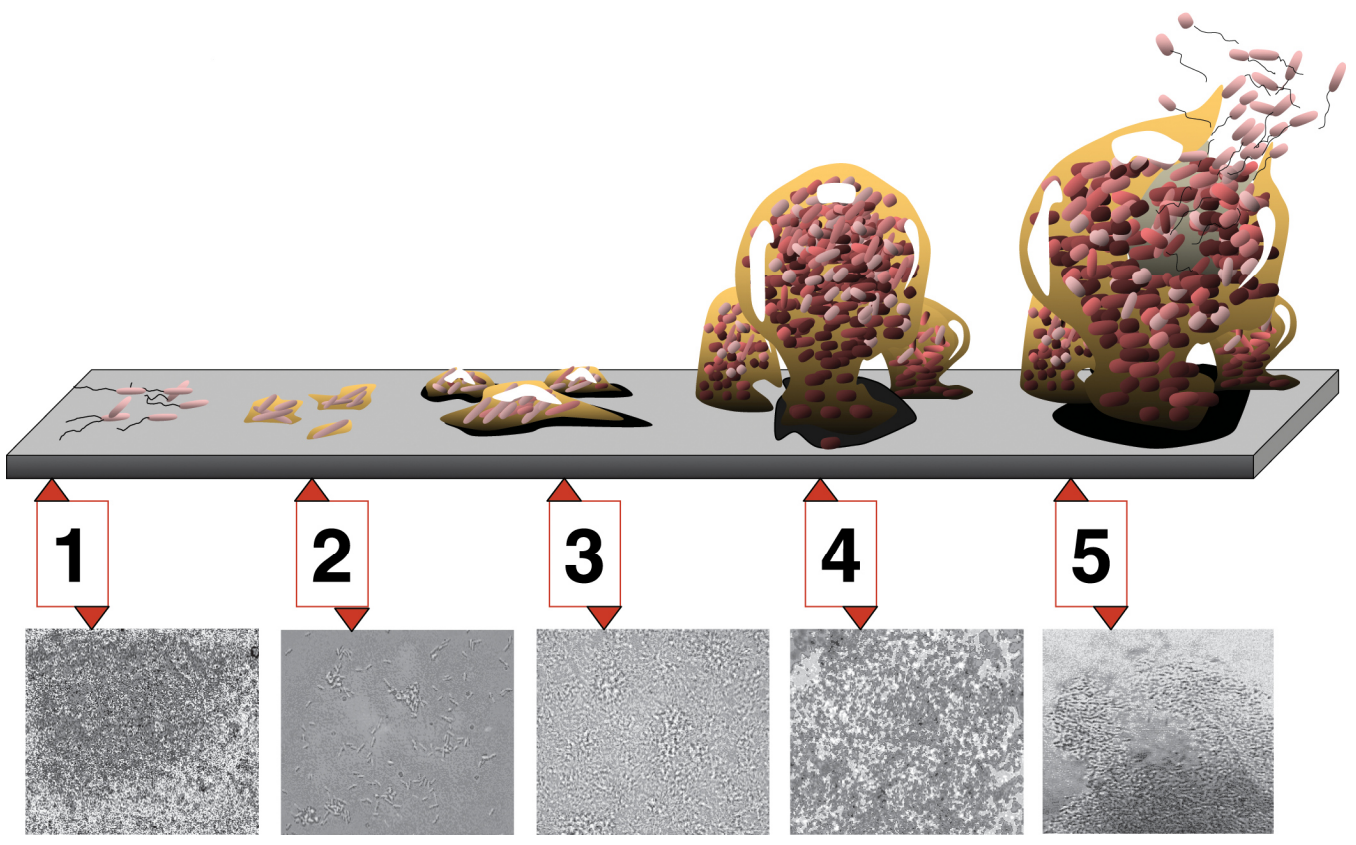

Abbildung 2: Fünf Phasen der Biofilmbildung (Monroe 2007; CC BY 2.5 erstellt durch D. Davis)

\section{Transport (1)}

Im ersten Stadium werden die Voraussetzungen für eine mikrobielle Besiedlung geschaffen, indem planktonische Mikroorganismen auf die Oberfläche gelangen. Der Transport erfolgt passiv einerseits in Form der Brown'schen Bewegung durch Diffusion und andererseits mittels Konvektion infolge von Strömungen im flüssigen Medium (=Speichel). Auch eine aktive Beförderung findet aufgrund der Eigenmotilität der Mikroorganismen, die sogenannte Sedimentation, statt, die durch die verschiedenen Zellanhänge wie Fimbrien, Pili oder Flagellen einiger Bakterien möglich ist (Bos 1999; Teughels et al. 2006; Characklis 1981; Busscher und Weerkamp 1987; Scheie 1994).

\section{Reversible Adhäsion (2)}

Im nächsten Schritt folgt die initiale Anheftung der Mikroorganismen an die Substratoberfläche. In der Regel binden diese nicht direkt an die inerte Oberfläche, sondern an einen sogenannten conditioning film, auch aquirred pellicle genannt, der im oralen Bereich entsteht (siehe Kapitel 2.1.2) (Costerton 1995; Sogn et al. 1973). Durch ihre metabolische Aktivität bieten sie nachfolgenden Mikroorganismen adäquate Lebensbedingungen (Sanderink et al. 2004). Pionierkeime haften über physikochemische Wechselwirkungen initial nur schwach und reversibel an der konditionierten Oberfläche, sodass sie durch leichte Scherkräfte abgelöst werden können (Busscher et al. 1992; Busscher und van der Mei 1997; Marsh und Bradshaw 1995). Zu den Erstbesiedlern 
(Pionierkeime) zählen im oralen Milieu insbesondere Kokken (Streptococcus oralis, Streptococcus sanguinis, Streptococcus mitis) und Aktinomyzeten (Actinomyces naeslundii) (Diaz et al. 2006; Hannig und Joiner 2006; Douglas 1983; 1994).

\section{Irreversible Adhäsion (3)}

Verschiedene Effekte führen nach einigen Minuten $\mathrm{zu}$ einer irreversiblen Adhäsion (Flemming und Wingender 2001b). Die Erstbesiedler tragen Adhäsine auf ihren Oberflächen, diese gehen über stereochemische Wechselwirkungen eine irreversible Bindung mit bestimmten Rezeptoren auf dem conditioning film ein (Marsh et al. 2011; Sanderink et al. 2004; Marsh und Bradshaw 1995). Zusätzlich kommt es auch während der Adhäsion zur Produktion der EPS durch die Bakterien. Die EPS lagert sich zwischen den Mikroorganismen ab und bildet so die stabilisierende dreidimensionale Struktur des Biofilms (Limoli et al. 2015; Romaní et al. 2008). Diese polymere Matrix besteht maßgeblich aus Wasser, Polysacchariden, Proteinen, Nukleinsäuren sowie Lipiden und gewährleistet den mikrobiellen Zellen neben dem interbakteriellen Zusammenhalt eine verbesserte Funktionalität (Marshall et al. 1989; Ahn et al. 2007). Innerhalb dieser Glykokalix leben die verschiedenen Bakterienspezies in einem symbiotischen Verbund sie können interzellulär kommunizieren (quorum sensing) sowie Nähr- und Abbaustoffe austauschen (Skillman et al. 1999). Die Zellen werden dadurch beispielsweise mit Informationen über die Zelldichte in der Umgebung versorgt und reagieren gegebenenfalls mit einer Umstellung ihrer physiologischen Eigenschaften. Zusätzlich bietet die EPS den Erregern Schutz vor äußeren mechanischen oder chemischen Einflüssen (Sutherland 2001b; Flemming und Wingender 2001a; Romaní et al. 2008). Durch die Vermehrung der Mikroorganismen und die aktive Dynamik der Zellen (twitching motility) entstehen Mikrokolonien (O'Toole und Kolter 1998).

\section{Reifung (4)}

Im Verlauf der sich anschließenden Kolonisations- und Reifungsphase entwickeln sich die Mikrokolonien zu einem „reifen“ Biofilm. Durch Koadhäsions- und Koaggregationsprozesse schreitet die Akkumulation weiterer Bakterien fort (Kolenbrander und London 1993; Bos et al. 1994; Bos et al. 1996). Koadhäsion beschreibt die Adhäsion von Mikroorganismen untereinander und damit an die bereits mikrobiell besiedelte Oberfläche, während bei der Koaggregation genetisch unterschiedliche Bakterienspezies an diese adhärieren (Busscher und van der Mei 1997; Ellen et al. 1994; Kolenbrander und London 1992; Kolenbrander et al. 2010). Den wesentlichen Aspekt des 
Biofilmwachstums stellt jedoch die Zellteilung dar (Bloomquist et al. 1996). Die erhöhte Expression von EPS führt zu einer gesteigerten Zellanbindung. Nach Kolenbrander und London (1993) können die Bakterien eines Biofilms in drei Gruppen unterteilt werden: die Frühkolonisierer, die Spätkolonisierer und dessen Verbindungsglieder, den Brückenkeimen. Die mikrobiellen Zwischenglieder, insbesondere das Fusobacterium nucleatum, werden benötigt, weil Früh- und Spätbesiedler keine Koaggregation miteinander eingehen können und die unterschiedlichen Frühbesiedler in ihrer Koadhäsion miteinander limitiert sind (Gibbons und Nygaard 1970; Rickard et al. 2003; Bradshaw et al. 1998). Durch die verschiedenen Interaktionen und Koadhäsionen entsteht ein komplexer Biofilm. Der Anteil der Streptokokken nimmt stetig ab und verschiebt sich in Richtung der Anaerobier, wodurch die Pathogenität des Biofilms erhöht wird (Marsh et al. 2003).

\section{Ablösung (5)}

In der finalen Phase erreicht der „reife“ Biofilm, auch als Plaque bezeichnet, eine PlateauPhase, die durch ein Gleichgewicht zwischen Progression und Ablösung entsteht (Flemming und Wingender 2001b). Die Ablösung kommt passiv durch externe Scherkräfte zustande, wodurch einzelne Zellen (Erosion) oder ganze Biofilmanteile (sloughing) abgesondert werden (Li et al. 2001; Stoodley et al. 2001). Zusätzlich können die Bakterien aktiv als „Schwärmerzellen“ den Biofilm verlassen, sich auf andere Bereiche niederlassen oder die Biofilmbildung erneut initialisieren (Hammer und Bassler 2003; Rowe et al. 2010; Sauer et al. 2004).

\subsubsection{Periimplantäre Mukositis und Periimplantitis}

Als periimplantäre Mukositis bzw. Periimplantitis werden entzündliche Veränderungen in der direkten Umgebung dentaler Implantate bezeichnet (Khammissa et al. 2012; Albrektsson und Isidor 1994; Berglundh et al. 2004; Eke et al. 1998; Leonhardt et al. 1993). Die periimplantäre Mukositis beschreibt eine reversible, durch Bakterien induzierte Entzündung, die sich auf das periimplantäre Weichgewebe beschränkt, wohingegen die Periimplantitis mit zusätzlichen irreversiblen Knochendestruktionen einhergeht (Berglundh et al. 2015; Wilson 2013; Papaioannou et al. 1996; Schwarz et al. 2008; Lang und Berglundh 2011). Die Biofilmbildung an Implantaten verläuft zu großen Teilen analog zu der an natürlichen Zähnen (Pontoriero et al. 1994). Die auf der Implantatoberfläche anhaftende Plaque enthält Bakterien, die sowohl durch direkten 
Kontakt zum periimplantären Weichgewebe als auch durch ihre Stoffwechselprodukte Entzündungsreaktionen auslösen können (Leonhardt et al. 1992; Pontoriero et al. 1994). Dabei kommt es neben der Einwanderung von neutrophilen Granulozyten in das periimplantäre Sulkusepithel zu einer erhöhten Exprimierung von Sulkusfluid (Berglundh et al. 2004; Klinge et al. 2005). Die von den pathogenen Keimen produzierten Stoffwechselprodukte bewirken über eine Auflösung der desmosomalen Interzellularverbindungen und der hemidesmosomalen Verbindungen zum Implantat eine Auflockerung des Saumepithels (Lang et al. 2011a; Lindhe et al. 1992; Ikeda et al. 2000). Den Bakterien wird so das Vordringen nach apikal erleichtert und es kommt zur Bildung einer tiefen Tasche um das Implantat, wodurch das sogenannte Taschenepithel entsteht (Seymour et al. 2015). Klinisch äußert sich dieser Entzündungsgrad durch Rötung, Schwellung und erhöhte Blutungsneigung der Mukosa und entspricht einer periimplantären Mukositis (Papaioannou et al. 1996; Schwarz et al. 2008). Bei rechtzeitiger Behandlung nach klinischer Manifestation der Symptomatik ist es möglich, eine Restitutio ad integrum herzustellen (Albrektsson und Isidor 1994; Schwarz et al. 2006a; Figuero et al. 2014; Berglundh et al. 2004; Leonhardt et al. 1992; Liskmann et al. 2007).

Wird die periimplantäre Mukositis jedoch nicht adäquat therapiert, kommt es zur Progression der Entzündung mit Knochendestruktionen, was in letzter Instanz zum Verlust des Implantates führen kann (Tonetti 1999; Esposito et al. 1998; Lasserre et al. 2018). Bedingt durch das anaerobe Milieu in der periimplantären Tasche verändert sich die Keimflora, die mit einer Zunahme von Spirochäten, Actinobacillus actinomycetemcomitans, Prevotella intermedia und Porphyromonas gingivalis einhergeht (Mombelli und Lang 1998; Rutar et al. 2001; Heitz-Mayfield et al. 2015). Diese Erreger sezernieren wiederum Proteasen, Kollagenasen sowie Lipopolysaccharide (LPS) und bewirken die Anregung von Makrophagen, die dann Interleukine (insbesondere IL-1, IL-6, IL-8, IL-17/12) und Tumornekrosefaktor- $\alpha$ (TNF- $\alpha$ ) freisetzen (Javed et al. 2011; Severino et al. 2011). Durch die Zerstörung von subepithelialen Kollagenfasergerüsten führt die erhöhte Menge an TNF- $\alpha$ zur Aktivierung von Osteoklasten, die mit der Resorption des periimplantären Knochenfaches beginnen (Berglundh et al. 2004; Zitzmann et al. 2006; Nguyen-Hieu et al. 2012). Neben den klinischen Parametern des positiven BOP (Bleeding on Probing), Rötung, Schwellung und Pus, deutet eine Sondierungstiefe von mehr als $4 \mathrm{~mm}$ auf eine Periimplantitis hin (Lindhe und Meyle 2008). Dennoch ist die röntgenologische Bildgebung zur 
Verifizierung des periimplantären Knochenverlustes obligat, der charakteristisch das physiologische Maß von $2 \mathrm{~mm}$ Knochenumbau (bone remodeling) während der funktionellen Belastungsphase übersteigt (Schwarz et al. 2006b; Zitzmann et al. 2006; Lang et al. 2000; Ferreira et al. 2006; Brägger et al. 1996; Zitzmann und Berglundh 2008). Die Periimplantitis ist ähnlich der Parodontitis eine multifaktorielle Erkrankung, die durch eine insuffiziente Mundhygiene ausgelöst werden kann (Tomasi und Derks 2012; Heitz-Mayfield 2008).

Ein bedeutender Risikofaktor zur Entstehung periimplantärer Destruktionen ist das Rauchen, da es sowohl die körpereigene Immunantwort als auch den Stoffwechsel des periimplantären Weich- und Hartgewebes negativ beeinflusst (Mombelli et al. 2012; Tsigarida et al. 2015). Auch systemische Erkrankungen wie Diabetes mellitus, Immundefizienzen oder genetische Risikofaktoren haben einen negativen Effekt auf die Entstehung und den Verlauf von periimplantären Entzündungen (Zitzmann et al. 2001; Kronström et al. 2001; Gruica et al. 2004). Des Weiteren spielen parodontale Erkrankungen in der Pathogenese der Periimplantitis eine Rolle, weil parodontopathogene Keime von den natürlichen Zähnen auf die Implantate übergehen können (Quirynen et al. 2002; Karoussis et al. 2003; Malmstrom et al. 1990). Allerdings wurde gezeigt, dass die Keimflora einer Periimplantitis nicht im vollen Umfang der einer Parodontitis entspricht (Listgarten und Lai 1999; Albertini et al. 2015). Neben den parodontopathogenen Keimen wurden zahlreiche weitere Bakterien identifiziert, die nur in geringem oder keinem Ausmaß mit parodontalen Erkrankungen assoziiert werden (Hultin et al. 2002; Persson und Renvert 2014). Periimplantäre Entzündungen weisen im Gegensatz zur Gingivitis und Parodontitis eine schnellere Progredienz in die Tiefe auf (Sanz et al. 1991). Ursächlich hierfür ist die verringerte Blutversorgung der periimplantären Strukturen, da sie durch das fehlende Desmodont ausschließlich über das Periost versorgt werden (Buser et al. 1992; Listgarten et al. 1992). Zudem verfügt das periimplantäre Bindegewebe über eine narbenähnliche Struktur mit einem hohen Kollagenanteil und einer geringen Anzahl an Fibroblasten, sodass der Stoffwechsel herabgesetzt ist (Berglundh et al. 1991; Berglundh et al. 1994; Moon et al. 1999). Die Kollagenfaserbündel strahlen nicht, wie es am natürlichen Zahn der Fall ist, in das azelluläre Zement ein, sondern verlaufen lediglich parallel zu der Implantatoberfläche, wodurch eine geringere strukturelle Barriere für die bakterielle Infiltration besteht (Rogge und Kielbassa 2004; Sculean et al. 2014; Schroeder et al. 1981). 


\subsection{Rauheit und Topographie}

Die Topographie einer Oberfläche wird - neben ihrer Form und Welligkeit - maßgeblich durch ihre Rauheit bestimmt (Crawford et al. 2012; Antonio et al. 2012). Definiert wird diese als oberflächliche Ungleichmäßigkeit, die die Oberfläche um den Faktor 2 bis 3 vergrößert und somit auch Bakterien eine größere Grenzfläche zur Anheftung bietet (Zhang et al. 2013; Quirynen und Bollen 1995). Rauheiten sind de facto keine bevorzugten Anhaftungspunkte, schützen die initial adhärenten Keime jedoch verstärkt vor Scherkräften und direkter mechanischer Zerstörung (Teughels et al. 2006; Newman 1974; Bollen et al. 1997) (siehe Abbildung 3). Im oralen Milieu konnte festgestellt werden, dass die initiale Bakterienadhäsion vor allem in Fissuren, Perikymatien und Zahnhartsubstanzdefekten beginnt (Nyvad und Fejerskov 1987; Quirynen und Bollen 1995; Hannig 1999).

a)
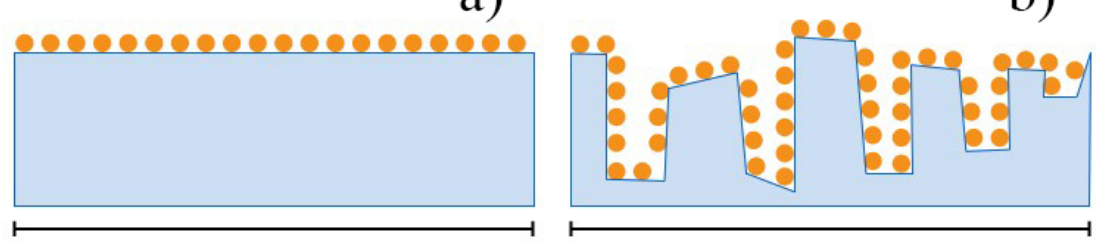

c)
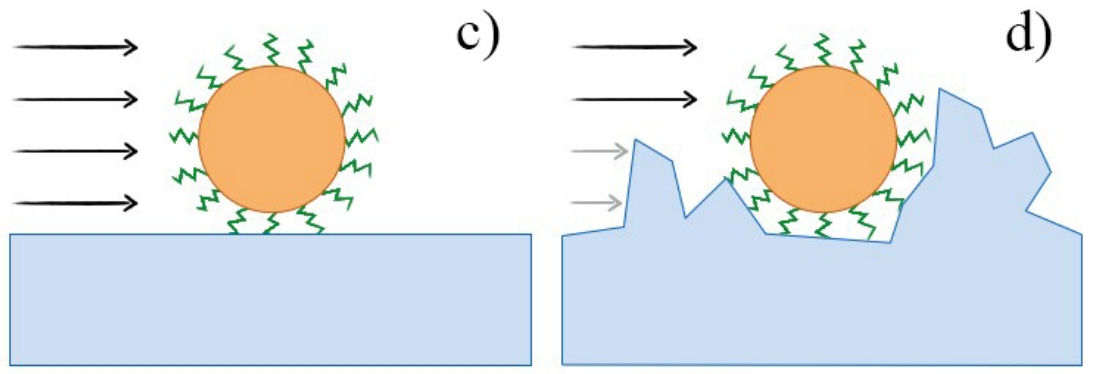

Abbildung 3: Anlagerungsverhalten von Bakterien auf glatten und rauen Oberflächen

a) eine geringere Anzahl an Bakterien $(n=20)$ auf einer ebenen Oberfläche

b) das Aufrauen einer Oberfläche erhöht die Anzahl der anhaftenden Mikroorganismen $(\mathrm{n}=50)$

c-d) die Aufrauung der Oberfläche führt zu einer vergrößerten Kontaktfläche zwischen Bakterium und Untergrund/Substrat sowie einer Verringerung der Scherkräfte (Pfeile)

Die werkstoffkundliche Charakterisierung des Rauheitsprofils einer Werkstückoberfläche kann mit Hilfe unterschiedlicher Messmethoden durchgeführt werden, bei denen man taktile (z. B. Tastschnittverfahren), optische (z. B. 
Konfokalmikroskopie, Laser-Scanning-Mikroskopie, Rasterelektronenmikroskopie) und pneumatische Messtechniken voneinander unterscheidet (Zhang et al. 2013; Wang et al. 2015; Crawford et al. 2012; Kocher et al. 2002; Park et al. 2015). Die Tastschlittenmethode wird in der Literatur als Standardverfahren zur Rauheitsmessung beschrieben (Kocher et al. 2002; Gevatter und Grünhaupt 2006; Keferstein und Marxer 2015). Bei dieser wird eine bestimmte Oberflächenstrecke mittels einer Diamant- oder Saphirspitze mechanisch abgetastet und durch Auslenkung in vertikaler Richtung in elektrische Signale umgewandelt, die daraufhin digital ausgewertet werden (Sander 1991; Rai und Gupta 2013). Als optische Messverfahren konnten sich neuere Methoden etablieren wie beispielsweise die Konfokalmikroskopie und die Laser-ScanningMikroskopie (Paddock und Eliceiri 2014; Bayguinov et al. 2018). Ein computergestütztes Konfokalmikroskop ist ein spezielles Lichtmikroskop, bei dem nur ein kleiner Ausschnitt der Oberfläche beleuchtet und digital erfasst wird (Lange et al. 1993). Nach vollständiger Abrasterung des Präparates werden die einzelnen Segmente zusammengesetzt und es entsteht eine kontrastreichere Gesamtaufnahme (Xiao et al. 1988). Bei der LaserScanning-Mikroskopie wird ein fokussierter Laserpunkt über die Oberfläche geführt, Punkt für Punkt erfasst und anschließend ebenfalls zusammengesetzt (Reddy et al. 2007; Stout 2002).

Das Tastschnittverfahren bietet im Methodenvergleich einige Vorteile: neben ausgeprägter Präzision und Zuverlässigkeit weist es als Referenzmesssystem hohe Erfahrungswerte auf (Gevatter und Grünhaupt 2006). Dennoch sollte bei empfindlichen oder nachgiebigen Materialien ein berührungsloses Verfahren angewandt werden, da es bei der taktilen Messtechnik zu Beschädigungen der Oberfläche und dadurch zu Ungenauigkeiten im Messergebnis kommen kann (Tan 2016). Zudem ist die Tastschnittmethode zur Erfassung der Oberflächentopographie langsamer als optische Messverfahren (Bhushan 2001). Allerdings kann es bei optischen Verfahren insbesondere auf Werkstoffen wie Keramiken oder Kunststoffen zur Streuung des Lichts kommen, was wiederum zu Messfehlern führen kann (Gevatter und Grünhaupt 2006). Um die topographische Bilderstellung zu beschleunigen, kam es zu einer Weiterentwicklung der computergestützten Konfokalmikroskopie, indem eine rotierende Scheibe mit mehreren Lochblenden hinzugefügt und mit der Weitfeldmikroskopie kombiniert wurde (Leach 2011). Diese ermöglicht eine schnelle, zuverlässige und reproduzierbare Oberflächenmessung (Schubert et al. 2019b). 
Zur quantitativen Bewertung der Rauheit stehen verschiedene standardisierte Parameter zur Verfügung:

\section{Arithmetischer Mittenrauwert $\mathbf{R}_{\mathbf{a}}$}

Der arithmetische Mittenrauwert $\mathrm{R}_{\mathrm{a}}$ ist ein Linienrauheitsparameter, der von der Lage des Profilschnittes abhängig ist (An und Friedman 1998). Er wird definiert als Mittelwert aller Abweichungen entlang einer konstruierten Mittellinie (M) mit flächenmäßig gleicher Unterteilung der Unebenheiten in beide Richtungen (Schuth und Buerakov 2017) (siehe Abbildung 4). Ein Nachteil des Parameters ist seine niedrige Sensitivität (Crawford et al. 2012; Gadelmawla et al. 2002). Außerdem differenziert er nicht zwischen Höhen und Tiefen innerhalb des Profils, wodurch Unterschiede zwischen verschiedenen Oberflächenbeschaffenheiten nur unzureichend charakterisiert werden (An und Friedman 1998).

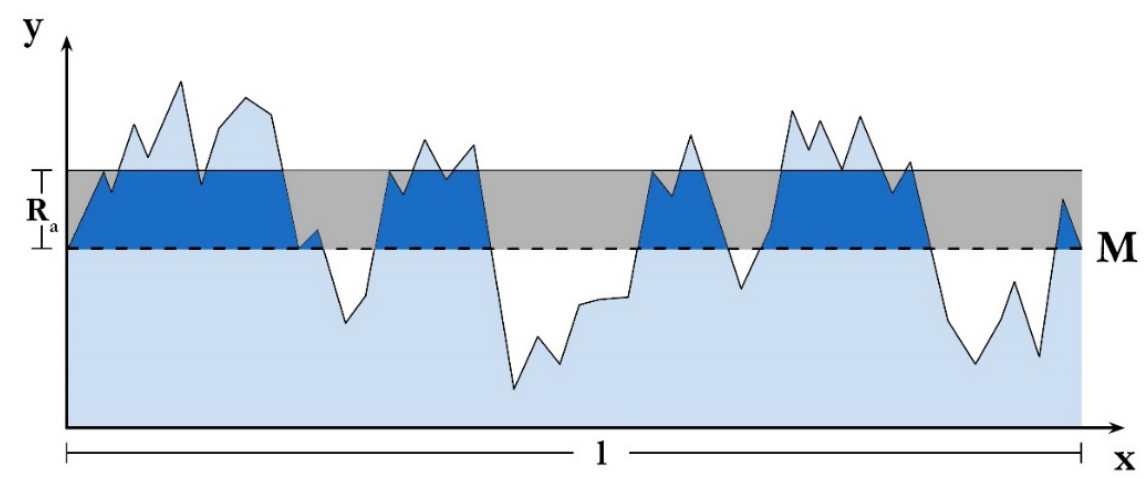

Abbildung 4: Arithmetischer Mittenrauwert $\mathrm{R}_{\mathrm{a}}$

\section{Flächenbezogener arithmetischer Mittenrauwert $\mathbf{S}_{\mathbf{a}}$}

Der Parameter $\mathrm{S}_{\mathrm{a}}$ stellt das Analogon zu $\mathrm{R}_{\mathrm{a}}$ für die Beschreibung dreidimensionaler Eigenschaften von Oberflächen dar und ermöglicht so die Berücksichtigung der Gesamtoberfläche (Crawford et al. 2012; Gadelmawla et al. 2002).

Die Literatur beschreibt eine direkte Korrelation von Rauheit und der Biofilmakkumulation (Elter et al. 2008; Rimondini et al. 1997). Im Jahre 1997 veröffentlichten Bollen et al. (1997) eine Studie, die den Zusammenhang zwischen dem Mittenrauwert $\mathrm{R}_{\mathrm{a}}$ und der Plaqueadhäsion auf Titanabutments bestätigt. Sie stellten fest, dass bei einer Glättung der Oberfläche und der damit einhergehenden Verringerung des Mittenrauwertes $\mathrm{R}_{\mathrm{a}}$ auf einen Schwellenwert von unter $0,2 \mu \mathrm{m}$ keine weitere Reduktion der Biofilmadhäsion und -transformation erreicht werden kann (Quirynen et al. 1990; 
Bollen et al. 1996; Quirynen et al. 1996). Folglich lassen sich die beschriebenen Rauheitsparameter durch Glättung der Oberfläche (z. B. Politur) gewissermaßen modulieren und führen so zu einer Reduktion der Biofilmformation (Ionescu et al. 2012). Bürgers et al. (2010a) zeigten sowohl in vivo als auch in vitro, dass eine raue Titanoberfläche hingegen zu einer Steigerung der bakteriellen Anlagerung führt. Gemäß Albrektsson und Wennerberg (2004) gelten Implantatoberflächen ab einem $\mathrm{S}_{\mathrm{a}^{-}}$ Wert $<0,5 \mu \mathrm{m}$ als ,glatt“. Rimondini et al. (1997) empfehlen für transgingivale Implantatbestandteile eine Oberflächenrauheit von $\mathrm{R}_{\mathrm{a}} \leq 0,088 \mu \mathrm{m}$. Al-Ahmad et al. (2010) kamen in einer In-vivo-Untersuchung zu dem Resultat, dass die Biofilmdicke mit der Materialrauheit korreliert, jedoch der Einfluss nach fünf Tagen signifikant abnimmt. Auf raueren Oberflächen bildet sich nach mehreren Tagen ungestörter Biofilmbildung eine reifere Plaque mit einem erhöhten Anteil an beweglichen Mikroorganismen und Spirochäten (Quirynen et al. 2002). Laut Pier-Francesco et al. (2006) findet auf glatten Oberflächen eine signifikant verringerte Adhäsion von einem der Leitkeime für periimplantäre Erkrankungen (Porphyromonas gingivalis) statt. Im Zusammenhang mit dentalen Implantaten bedeutet eine erhöhte Oberflächenrauheit neben einer beschleunigten Biofilmausbildung allerdings auch eine verbesserte Osseointegration des Implantates, da dies zu einer verstärkten Anhaftung, Differenzierung und Proliferation der Osteoblasten führt (Buser et al. 1991; Buser et al. 1999; Gotfredsen et al. 1992; Subramani 2010). Zudem bietet die raue Oberfläche eine Vergrößerung der Materialoberfläche, wodurch die initiale Primärstabilität unterstützt wird (Javed et al. 2013; Elias et al. 2012).

\subsection{Abutments und deren Werkstoffe}

Implantatgetragener Zahnersatz setzt sich aus einem enossalen Implantatkörper, einem prothetischen Abutment (Retentionselement) und einer Suprakonstruktion (z. B. Krone, Brücke etc.) zusammen (siehe Abbildung 5), die entweder Bestandteil eines ein- oder eines zweiteiligen Implantatsystems sind (Koeck et al. 2005; Reinhardt und Beikler 2014). Der wesentliche Unterschied liegt darin, dass Implantatbasis und Abutment bei einteiligen Systemen aus einem Werkstück bestehen, während sie bei zweiteiligen über eine Schraube miteinander verbunden werden (Reinhardt und Beikler 2014). Nachteilig ist der Mikrospalt zwischen den beiden Komponenten, der eine Nische vor allem für anaerobe paropathogene Keime bietet (Quirynen und van Steenberghe 1993; Persson et al. 1996; Hermann und Cochran 2005). Das Abutment dient als Verankerung der 
prothetischen Versorgung auf dem Implantat und muss neben ausgezeichneter Biokompatibilität über eine hohe Stabilität, Korrosionsresistenz und chemische Beständigkeit verfügen (Rasperini et al. 1998; Gehrke et al. 2006; Turkoglu et al. 2019). Während in der Vergangenheit überwiegend konfektionierte Retentionselemente verwendet wurden, kann seit der Einführung der individuell gestalteten Abutments mittels CAD/CAM-Verfahren auf patientenbezogene funktionelle und ästhetische Gegebenheiten besser eingegangen werden (Gehrke et al. 2018; Hahnel et al. 2014). Somit können abweichende Implantatpositionen und -angulationen genauer korrigiert, eine verbesserte physiologische Kontur des periimplantären Weichgewebes erzielt und die Entfernung der Zementüberschüsse erleichtert werden (Neugebauer et al. 2014; Happe et al. 2011). Jedoch weisen individuell gestaltete Abutments durch das höhere Emergenzprofil eine vergrößerte Kontaktfläche mit dem umliegenden Weichgewebe auf, wodurch sie eine erhöhte Gefahr für die periimplantäre Gesundheit darstellen (Ramenzoni et al. 2019; Esfahanizadeh et al. 2018; Xing et al. 2015). Die transgingivale Lage des Abutments führt zum unmittelbaren Kontakt zwischen dem verwendeten Werkstoff und der periimplantären Mukosa (Hahnel et al. 2014). Zusätzlich akkumuliert durch diese Topographie vornehmlich subgingivale Plaque, die mit herkömmlichen Mundhygienemaßnahmen kaum entfernbar ist (de Avila et al. 2014). Daraus ergibt sich das Bestreben, Materialien mit einer möglichst geringen Affinität zur Biofilmbildung für die Herstellung von Abutments zu verwenden (Hahnel et al. 2014; Esfahanizadeh et al. 2018). In Anbetracht der Langzeiterfahrungen mit dem Werkstoff Titan werden sie überwiegend aus diesem gefertigt (Kohal et al. 2008; Osman und Swain 2015; Ramenzoni et al. 2019). Dennoch gewinnen neue Materialien wie Zirkoniumdioxid und PEEK aufgrund verbesserter ästhetischer Aspekte zunehmend an Relevanz (Kohal et al. 2008; Hahnel et al. 2014) (siehe Abbildung 6). 

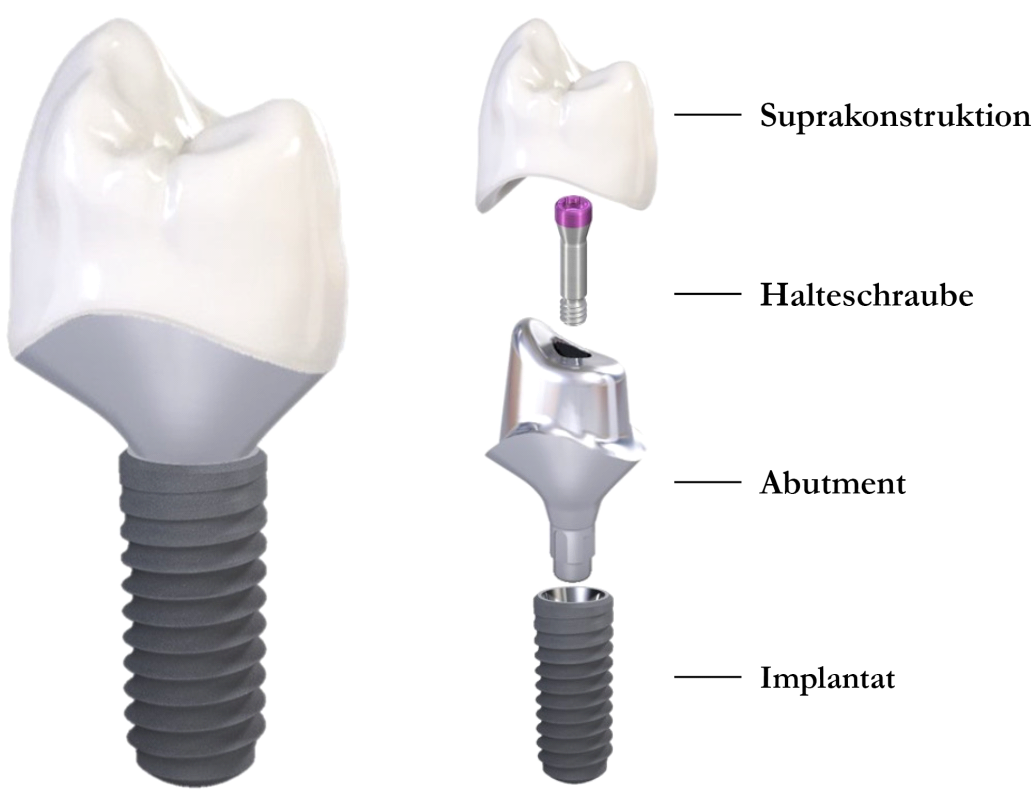

Abbildung 5: Implantataufbau mit Suprakonstruktion (modifizert nach Straumann AG, Basel, Schweiz)
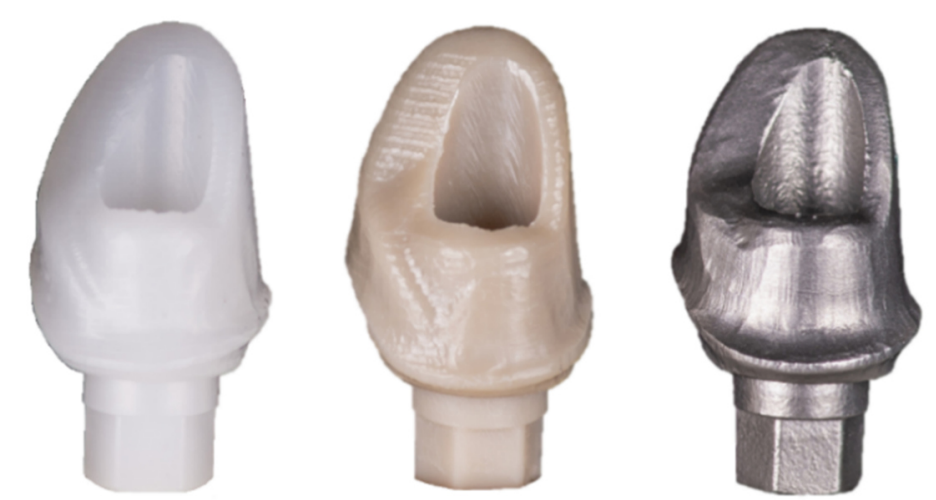

Abbildung 6: $\quad$ CAD/CAM-gefertigte Abutments aus Zirkoniumdioxid, PEEK und Titan

\subsubsection{Titan}

Aktuell gilt Titan als goldener Standard in der Herstellung von dentalen Implantaten und Abutments (Lops et al. 2013; Ottria et al. 2018; Scarano et al. 2018). Außerdem wird es in der Zahnmedizin als Werkstoff für Prothesen, Wurzelstifte, Kronen und Brücken sowie Drähte für festsitzende kieferorthopädische Apparaturen verwendet (Jorge et al. 2013; Gosavi et al. 2013; Ohkubo et al. 2008). Titan besitzt zahlreiche positive Materialeigenschaften, von denen für die Zahnmedizin insbesondere das geringe Gewicht, die 
hohe mechanische Festigkeit, die Korrosions- und Temperaturbeständigkeit sowie die außerordentliche Biokompatibilität von Bedeutung sind (Rodrigues et al. 2013; Yu et al. 2015; Subramani 2010). Die für die Implantologie relevantesten Eigenschaften erhält Titan erst in oxidativer Umgebung, in der es innerhalb von Sekundenbruchteilen zur Ausbildung einer sogenannten Passivierungsschicht kommt, eine $10 \mathrm{~nm}$ dicke, dichte Schicht aus Titandioxid $\left(\mathrm{TiO}_{2}\right.$ ) (Wang und Fenton 1996; Keselowsky et al. 2003; Gosavi et al. 2013). Diese protektive Oxidschicht ist für die hohe Säure- und Korrosionsbeständigkeit des Werkstoffes verantwortlich (Barbieri et al. 2017; Donachie 2000). Zudem unterstützt sie die Osseointegration des Implantates in die umliegenden knöchernen Strukturen und fördert die exzellente Biokompatibilität des Titans durch das Ausbleiben eines Austausches von Metall- mit Wasserstoffionen zwischen Titan und den körpereigenen Geweben (Delgado-Ruiz und Romanos 2018; Zhang et al. 2017). Obwohl Titan dank der dichten Passivierungsschicht eine sehr hohe Korrosionsbeständigkeit aufweist, kann die Kombination aus mikrobiellen Metaboliten, wie Milchsäure und Wasserstoffperoxid $\left(\mathrm{H}_{2} \mathrm{O}_{2}\right)$, hohen Fluoridkonzentrationen und Elektrolyten aus dem Speichel zum Auflösen der $\mathrm{TiO}_{2}-$ Schicht führen (Chaturvedi 2009; Souza et al. 2013; Mabilleau et al. 2006; Guindy et al. 2004). Es wurde nachgewiesen, dass das Vorhandensein von Streptococcus mutans die Korrosionsbeständigkeit von Titan negativ beeinflusst (Beyth et al. 2008; Souza et al. 2013). Zusätzlich kann es durch die bei Belastung entstehenden Mikrobewegungen $\mathrm{zu}$ einer Reibkorrosion (fretting-corrosion) zwischen den Implantatkomponenten kommen, die zu einer Abschilferung der dünnen Oxidschicht führt (Schliephake et al. 1991; Schliephake et al. 1993; Zaffe et al. 2003; Bianco et al. 1996). Die Korrosion von Titan führt zur Freisetzung von Metallionen in das umliegende Gewebe und kann eine Immunreaktion im Gewebe auslösen sowie eine Periimplantitis verursachen (Mouhyi et al. 2012; Schalock et al. 2012; Wang et al. 2007; Urban et al. 2000). Außerdem verursacht die Korrosion einen Materialverlust und führt zu einer dimensionalen Fehlpassung zwischen Abutment, Implantat und prothetischer Versorgung (Souza et al. 2013; Delgado-Ruiz und Romanos 2018).

Die Biofilmbildung auf Titanoberflächen beginnt intraoral analog zur Schmelzoberfläche mit der Bildung eines acquired pellicle (Yeo et al. 2012; Steinberg et al. 1998). Edgerton et al. (1996) verglichen die Pellikelbildung auf Titan- und Schmelzoberflächen in vitro und fanden einige Unterschiede in der Zusammensetzung der beiden Pellikelstrukturen. Nachfolgende Studien zeigten ebenfalls, dass die Biofilmbildung auf diesem Werkstoff der auf natürlicher Zahnhartsubstanz ähnelt, aber Unterschiede im Kolonisationsmuster 
auftreten (Fürst et al. 2007; Yeo et al. 2012; Tanner et al. 1997). In beiden Pellikelarten können $\alpha$-Amylase und hochmolekulare Muzine nachgewiesen werden, hingegen enthalten Titanpellikel keine niedrigmolekularen Muzine und kein Zystatin. Stattdessen stellt das hochmolekulare, prolin-reiche Glykoprotein eine bedeutendere Komponente dar als im Schmelzpellikel (Edgerton et al. 1996; Fisher et al. 1987). Einen Hauptanteil an adsorbierten Speichelproteinen auf Titanoberflächen bildet Albumin (Steinberg et al. 1995; Klinger et al. 1997). Auch Wolinsky et al. (1989) untersuchten in vitro speichelbenetzte Schmelz- und Titanoberflächen. Der Erreger Streptococcus gordonii adhärierte dabei gleichwertig auf beiden Materialien, jedoch konnte eine geringere Menge an Actinomyces viscosus auf der Titanoberfläche nachgewiesen werden (Wolinsky et al. 1989). In einer In-vitro-Studie durch Kuula et al. (2004) konnte eine hohe Affinität von Porphyromonas gingivalis und Prevotella intermedia zu Titan beobachtet werden. Zudem verfügt der Staphylococcus aureus über die Fähigkeit, sich an unterschiedliche Titanoberflächen anzuhaften und ist bei periimplantären Entzündungen von großer Bedeutung (Harris und Richards 2004; Fürst et al. 2007). Leonhard et al. (1995) untersuchten in einer In-vivo-Studie die Biofilmbildung auf Titan-, Amalgam- und Hydroxylapatitoberflächen, konnten jedoch keinen ausschlaggebenden Materialeinfluss auf die frühe Bakterienadhäsion feststellen. In vitro konnte ebenfalls kein signifikanter Unterschied in der Zusammensetzung reifer Biofilme auf Titan und Hydroxylapatitscheiben erfasst werden (Wang et al. 2018). Um den negativen Eigenschaften entgegenzuwirken, erhalten die Implantatoberflächen neben chemischen und elektromechanischen Modifikationen zusätzliche Beschichtungen, wodurch sowohl die Osseointegration verbessert als auch die mikrobielle Akkumulation reduziert wird (Lang et al. 2011b; Rupp et al. 2012; Yoshinari et al. 2000; Thoma et al. 2011).

\subsubsection{Zirkoniumdioxid}

In den vergangenen Jahren legte sich der Fokus in der Implantologie auf den Einsatz von keramischen Abutments aus Zirkoniumdioxid (Zirkonoxid, Zirkon, $\mathrm{ZrO}_{2}$ ), bei dem es sich um einen Werkstoff aus der Gruppe der Oxidkeramiken handelt (Rosentritt et al. 2018; Nakamura et al. 2010; Truninger et al. 2012). Außerdem wird Zirkoniumdioxid zur Herstellung von Implantaten, Kronen, Inlays, Teilkronen, Brücken, Primärteleskopen, Stegen und Wurzelstiften verwendet (Miyazaki et al. 2013; Cionca et al. 2017; Al-Amleh et al. 2010; Rinke et al. 2015). Durch den Einsatz von keramischen Werkstoffen wie Zirkoniumdioxid lässt sich dem zunehmenden Patientenwunsch nach metallfreiem 
Zahnersatz nachkommen (Andreiotelli et al. 2009; Yildirim et al. 2000). Zugrunde liegt diesem Bestreben auch, dass es bei metallischen Implantatversorgungen in Fällen dünner gingivaler Biotypen zum Durchschimmern der dunklen Metalloberfläche des ImplantatAbutments kommen kann (Blatz et al. 2009; Holst et al. 2005; Jemt 1986). Insbesondere kommt dieses Phänomen bei Patienten mit einer erhöhten Lachlinie zum Tragen (Aydin et al. 2010). Für die Zahnmedizin besitzt das Yttrium-stabilisierte Zirkoniumdioxid optimale Eigenschaften, zu denen eine geringe Porosität, eine hohe Dichte sowie eine hohe Biege- und Druckfestigkeit gehören (Cionca et al. 2017; Kelly und Denry 2008; Abd El-Ghany und Sherief 2016).

Zahlreiche Studien konnten die biologische Verträglichkeit des Yttrium-stabilisierten Zirkoniumdioxids belegen, da weder mutagene noch kanzerogene Einflüsse nachgewiesen wurden (Akagawa et al. 1993; Covacci et al. 1999). Die mikrobielle Besiedlung und die Biofilmbildung auf Zirkoniumdioxid wurde im Rahmen zahlreicher In-vivo- und In-vitro-Untersuchungen insbesondere im Vergleich zu Titan analysiert und zeigten kontroverse Ergebnisse (Lee et al. 2011; Al-Ahmad et al. 2010; Roehling et al. 2017). So verglichen Rimondini et al. (2002) beispielsweise in vivo die Adhäsion von Mikroorganismen auf Zirkoniumdioxid- und Titanprobekörpern und berichteten von einer signifikant geringeren Bakterienakkumulation auf den Zirkoniumdioxidoberflächen. Identische Ergebnisse konnten Scarano et al. (2004) in einer In-vivoUntersuchung feststellen. Außerdem wurde auch eine geringere Pathogenität der Kolonisationskeime auf Zirkoniumdioxid bestätigt (Rimondini et al. 2002; Al-Radha et al. 2012). Dennoch konnten einige Untersuchungen keinen Unterschied in der bakteriellen Akkumulation der beiden Materialoberflächen beobachten (Lima et al. 2008; Lee et al. 2011; Rasperini et al. 1998; van Brakel et al. 2011). Wiederum ermittelten Meza-Siccha et al. (2019) in vitro eine höhere mikrobielle Adhäsion auf Zirkoniumdioxidabutments im Vergleich $\mathrm{zu}$ Titanabutments, jedoch zeigte die Titanoberfläche eine höhere bakterielle Viabilität auf. Die bakteriellen Bindungseigenschaften sowie die Pellikelzusammensetzung auf Zirkoniumdioxid und Titan sind zufolge Lima et al. (2008) vergleichbar, weisen aber signifikante Unterschiede zu Hydroxylapatit auf. Es kam zu einer signifikant höheren Adhäsion des Keims Streptococcus mutans auf Zirkoniumdioxid und Titan im Vergleich zur Hydroxylapatitoberfläche. Im Rahmen weiterer Studien zeigte sich eine geringere Menge an entzündlichem Infiltrat im Bereich des periimplantären Weichgewebes von Zirkoniumdioxid verglichen mit Titan (Degidi et al. 2006; Welander et al. 2008). 


\subsubsection{Polyetheretherketon (PEEK)}

Seit einigen Jahren wird der Hochleistungskunststoff Polyetheretherketon (PEEK) als eine Alternative $\mathrm{zu}$ Titan und Zirkoniumdioxid in bestimmten Bereichen der konventionellen Prothetik und Implantatprothetik eingesetzt (Najeeb et al. 2016; Mishra und Chowdhary 2019; Schwitalla und Müller 2013). Der Kunststoff ermöglicht genau wie Zirkoniumdioxid eine metallfreie und zahnfarbene Versorgung (Siewert und Parra 2013; Stawarczyk et al. 2013). In der Zahnmedizin findet PEEK aktuell Verwendung in Form von Einheilkappen (Einheilabutments, Gingivaformer) oder als Prothesenbasis bei herausnehmbarem Zahnersatz (Mishra und Chowdhary 2019; Shafie 2014; Zoidis et al. 2016). Als Basismaterial bietet es durch sein geringeres Gewicht erhöhten Tragekomfort und zeigt verglichen mit alternativen Werkstoffen eine niedrigere Plaqueakkumulation (Zoidis et al. 2016). Durch die Modifizierung des Polymers mit Kohlefasern (18 GPa) $($ CFR-PEEK $=$ carbon-fiber-reinforced PEEK) wird ein E-Modul vergleichbar mit der humanen Kortikalis erzeugt (Sagomonyants et al. 2008; Kurtz 2012). Dies ermöglicht die Abfederung von Kaukräften und bietet Schutz vor Überbelastung des Knochens und noch vorhandenen Zähnen (Schwitalla et al. 2014). Eine weitere Möglichkeit zur Modifizierung von PEEK entsteht durch die Beimischung keramischer Füllstoffe, was ebenfalls $\mathrm{zu}$ einer Adaption des E-Moduls an den Knochen führt (Zoidis und Papathanasiou 2016).

Ein bekannter Werkstoffvertreter dieser Gruppe ist das BioHPP (Bredent GmbH, Senden, Deutschland), das zu $20 \%$ durch keramische Füllstoffe modifiziert ist und ein E-Modul von 4 GPa besitzt (Andrikopoulou et al. 2016). Zahlreiche In-vivo- und In-vitro-Studien konnten eine exzellente Biokompatibilität des Hochleistungskunststoffs PEEK nachweisen (Williams et al. 1987; Brown et al. 1990; Wenz et al. 1990; Morrison et al. 1995). Zwei weitere Untersuchungen konnten keine zytotoxischen, mutagenen oder allergischen Reaktionen feststellen (Morrison et al. 1995; Katzer et al. 2002). Hingegen findet sich nur wenig Literatur zur oralen Biofilmakkumulation auf PEEK (Hahnel et al. 2014; Barkarmo et al. 2019). Hahnel et al. (2014) untersuchten die Biofilmbildung auf verschiedenen Abutmentmaterialien in vitro in Abhängigkeit von der Inkubationszeit und stellten dabei fest, dass nach 20 Stunden zunächst eine signifikant niedrigere bakterielle Akkumulation auf der PEEK-Oberfläche stattfand, jedoch nach 44 Stunden kein Unterschied mehr zwischen der Ablagerung auf PEEK, Zirkoniumdioxid und Titan festgestellt werden konnte. Eine In-vivo-Studie von Volpe et al. (2008) beschäftigte sich mit der periimplantären Konzentration und Variabilität von paropathogenen Keimen auf 
Titan- und PEEK-Abutments und erhielt ähnliche Ergebnisse. Analog dazu konnten weitere Forschungsgruppen keinen Unterschied in der Bakterienkolonisation von PEEK und Titan feststellen (Rochford et al. 2014; Barkarmo et al. 2019). Die Adhäsion und Proliferation von oralen Streptokokken erfolgt auf PEEK und dentalen Kompositmaterialien indes gleichermaßen (Kolbeck et al. 2013).

\subsection{Zielsetzung der Arbeit}

Ziel der vorliegenden In-vivo-Untersuchung war es, die Biofilmbildung auf vier unterschiedlichen implantatprothetischen Werkstoffen $\mathrm{zu}$ quantifizieren und diese miteinander zu vergleichen. Zusätzlich sollte der Einfluss der intraoralen Position der Probekörper sowie einer künstlichen Materialalterung auf die Plaqueakkumulation untersucht werden. Hierfür wurden Multiprobekörper hergestellt und mittels Trägerschienen 24 Stunden bei 20 ProbandInnen eingesetzt. Die quantitative Beurteilung der Biofilme auf den Werkstoffoberflächen sollte mittels Fluoreszenzmikroskopie erfolgen. 


\section{Material und Methoden}

\subsection{Studiendesign und klinischer Versuchsablauf}

Die vorliegende Untersuchung war eine prospektive klinische Studie. Zur Beurteilung der Biofilmakkumulation an den vier unterschiedlichen Prüfmaterialien wurde ein Probandenkollektiv von 20 TeilnehmerInnen ausgewählt. In Tabelle 1 sind die vor Studienbeginn festgelegten Ein- bzw. Ausschlusskriterien aufgeführt.

Tabelle 1: $\quad$ Ein- und Ausschlusskriterien zur Studienteilnahme

\begin{tabular}{|l|l|}
\hline Einschlusskriterien & Ausschlusskriterien \\
\hline - Alter $\geq 18$ Jahre & - Alter $<18$ Jahre \\
- Vollbezahnung (Weisheitszähne & - Antibiose bis zwei Monate vor \\
nicht einbezogen) & Studienbeginn \\
- Gute Mundhygiene (s. Kapitel & - Xerostomie \\
3.4.2) & - Tumorerkrankung mit Radiatio \\
- Keine Antibiose in den & im Kopf-/ Halsbereich \\
vergangenen zwei Monaten & \\
\hline
\end{tabular}

Vor Beginn der Untersuchung wurde die klinische Versuchsdurchführung in einem detaillierten Tages-Zeitplan zusammengefasst. Hierüber wurde jedeR ProbandIn in Kenntnis gesetzt und ausführlich aufgeklärt. Die StudienteilnehmerInnen wurden randomisiert in vier Gruppen mit je fünf TeilnehmernInnen unterteilt. Für jede Gruppe war eine Untersuchungszeit von drei Tagen erforderlich. Die Versuchsabfolge ist in Abbildung 1 dargestellt. 


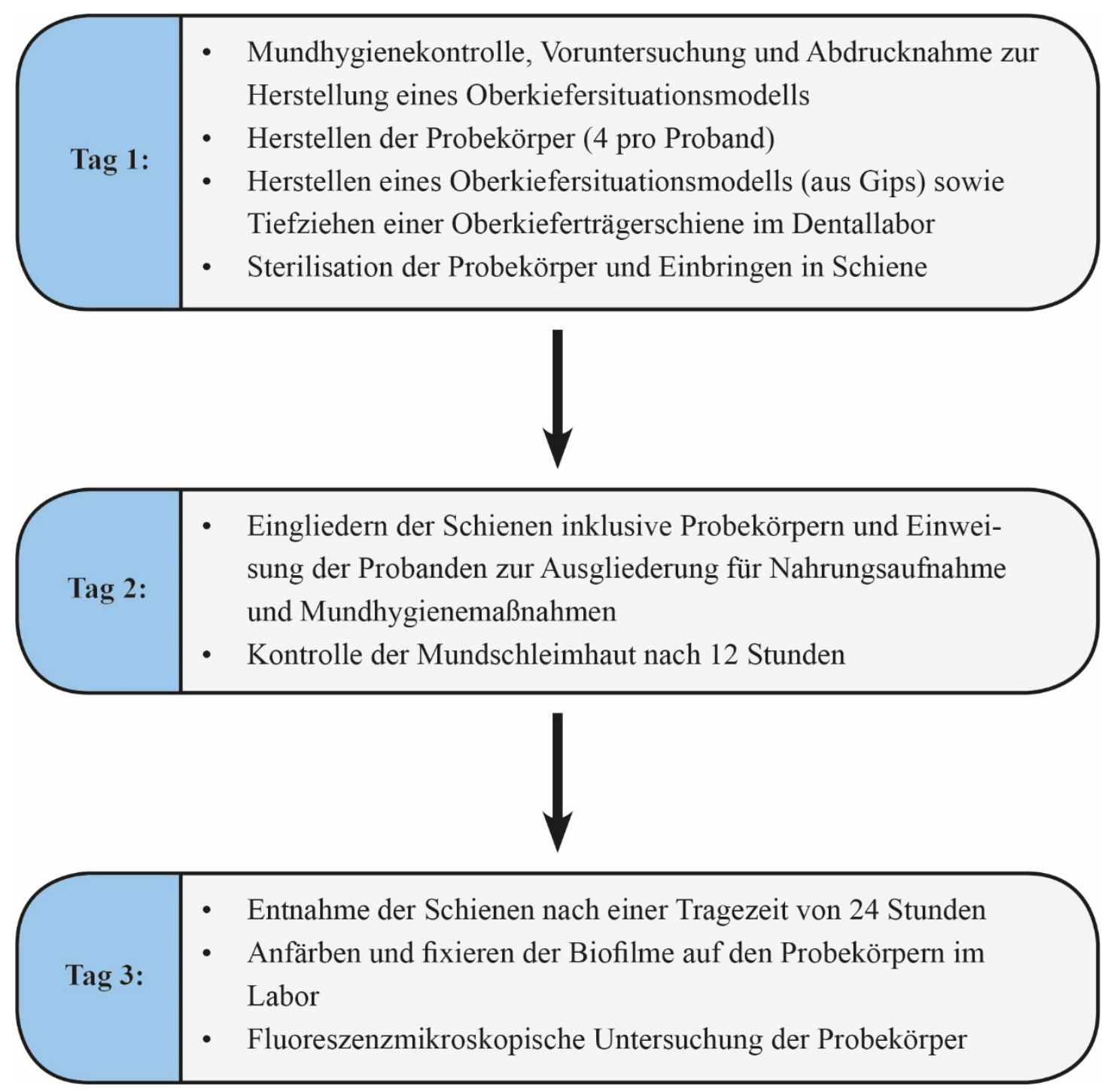

Abbildung 7: Klinisches Prozedere (Untersuchungsplan)

\subsection{Ethikvotum}

Ein positives Votum der Kommission der medizinischen Fakultät Göttingen lag vor (Antragsnummer 17/7/15). JedeR TeilnehmerIn wurde über Studieninhalt, -ablauf und Datenschutzbedingungen in sowohl mündlicher als auch schriftlicher Form aufgeklärt. Dies bestätigte jedeR TeilnehmerIn mit seiner Unterschrift. An der klinischen Studie nahmen 20 ProbandInnen (10 Männer, 10 Frauen) teil. Die Teilnahme an der Studie erfolgte freiwillig und durfte ohne Begründung jederzeit abgebrochen werden. Alle ProbandInnen erhielten eine individuell hergestellte Kunststoffschiene, in die jeweils vier Probekörper integriert wurden. Zusätzlich wurde jede TeilnehmerIn darauf hingewiesen, die Schiene während der 24-stündigen Tragezeit nur für Mundhygienemaßnahmen und zur Nahrungsaufnahme ein- bzw. auszugliedern. 


\subsection{Klinische Voruntersuchung der ProbandInnen}

\subsubsection{Anamnese}

Bei allen ProbandInnen wurde eine allgemeine Anamnese erhoben. Hierbei wurde darauf geachtet, dass bei diesen keine Xerostomie, keine Tumorerkrankung oder Bestrahlung im Kopf-/ Halsbereich vorlag und in den letzten zwei Monaten vor Studienbeginn keine (orale) Antibiose erfolgte. Des Weiteren wurden das Alter und das Geschlecht der TeilnehmerInnen erfasst.

\subsubsection{Mundhygiene}

Nach der Anamnese erfolgte die zahnärztliche Untersuchung zur Beurteilung der Mundhygiene. Es erfolgte das Erheben des SBI (Sulkus-Blutungs-Index) und API (Approximalraum-Plaque-Index). Zur Teilnahme an der Studie musste der SBI bei allen ProbandInnen unter $10 \%$ und der API unter $35 \%$ liegen.

\subsection{Prüfmaterialien}

Die Testmaterialien waren für den zahnmedizinischen Anwendungsbereich zugelassen und finden Verwendung in der dentalen Implantatprothetik. In Tabelle 2 und Abbildung 8 sind die untersuchten Testmaterialien dargestellt.

Tabelle 2: $\quad$ Verwendete Materialien

\begin{tabular}{|l|l|l|}
\hline Material & Hersteller & Materialklasse \\
\hline Titan Grad 2 (Zenotec Ti pur) & $\begin{array}{l}\text { Wieland Dental + } \\
\text { Technik GmbH \& } \\
\text { Co. KG, Pforzheim, DE }\end{array}$ & Titan \\
\hline Zirkon (Cercon base) & $\begin{array}{l}\text { DeguDent GmbH, } \\
\text { Hanau, DE }\end{array}$ & $\begin{array}{l}\text { Zirkoniumdioxid } \\
\text { (Yttrium-stabilisiert) }\end{array}$ \\
\hline BioHPP & $\begin{array}{l}\text { Bredent GmbH \& } \\
\text { Co. KG, Senden, DE }\end{array}$ & $\begin{array}{l}\text { Polyetheretherketon } \\
\text { (PEEK) }\end{array}$ \\
\hline PEEK (VestaKeep MC4420R) & Evonik, Essen, DE & $\begin{array}{l}\text { Polyetheretherketon } \\
\text { (PEEK) }\end{array}$ \\
\hline
\end{tabular}




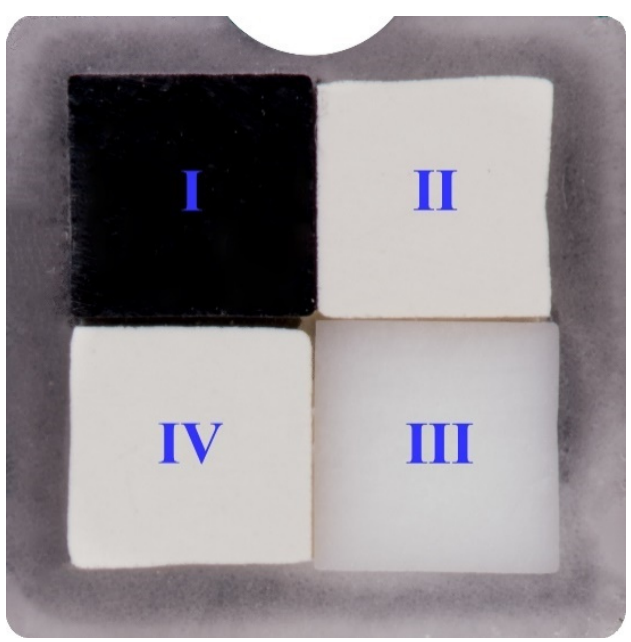

Abbildung 8: Fertiger Multiprobekörper

$\mathrm{I}=$ Titan; II = BioHPP; III = Zirkoniumdioxid; IV = PEEK

\subsection{Herstellung der Probekörper}

\subsubsection{Verklebung}

Für eine optimale Visualisierung und Vergleichbarkeit der Biofilmbildung auf den unterschiedlichen Werkstoffen wurden geteilte Multiprobekörper hergestellt (siehe Abbildung $9 \mathrm{a}-\mathrm{d}$ ). Für die gesamte Studie wurden 80 Probekörper angefertigt (je ProbandIn bzw. Trägerschiene vier). Die Materialien wurden mit den Maßen $30 \times 3 \times 3$ mm (Länge/Breite/Höhe) unter genauer Einhaltung der Herstellerangaben hergestellt (siehe Abbildung 9 a). Von jedem Material wurde jeweils ein Quader miteinander verklebt. Die Verklebung der Materialien miteinander erfolgte mit dem Befestigungskomposit Panavia 21 (Kuraray Noritake Dental Inc., Okayama, Japan). Um den bestmöglichen Haftverbund zwischen den Werkstoffen und dem Befestigungsmaterial zu erzielen, mussten die Oberflächen der Prüfmaterialien einem Silikatisierungs- und Silanisierungsprozess unterzogen werden. Die Silikatisierung erfolgte mittels des Rocatec-Verfahrens (3M ESPE, Seefeld, Deutschland). Daraufhin erfolgte die Silanisierung der Oberfläche mit MonoBond Plus (Ivoclar Vivadent AG, Schaan, Liechtenstein). Anschließend wurden die vier Prüfmaterialien streng nach Herstellerangaben mit dem Befestigungskomposit zu einem Block miteinander verklebt (siehe Abbildung 9b). Zur besseren Stabilität der endgültigen Probekörper sowie einfacheren Eingliederung dieser in die Trägerschiene wurde eine $1 \mathrm{~mm}$ breite Ummantelung hergestellt (siehe Abbildung 9 c). Hierfür wurden die Probekörperblöcke mittig in ein Aluminium-Vierkant-Profil mit den Innenmaßen von $8 \times 8 \mathrm{~mm}$ eingebettet 
und mit einem dünnfließenden, farblosen Orthocryl-Kunststoff (Dentaurum, Ispringen, Deutschland) umhüllt. Zum Polymerisieren wurden diese danach in einem mit Wasser gefüllten Drucktopf bei einer Temperatur von $45^{\circ} \mathrm{C}$ für 15 Minuten gelagert.

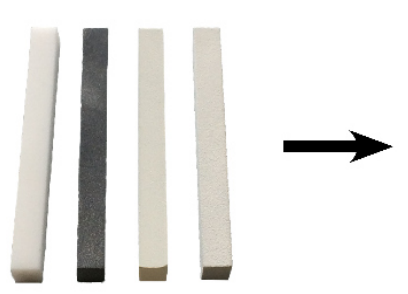

a)

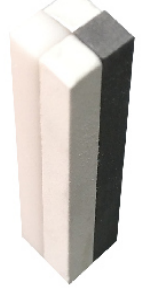

b)

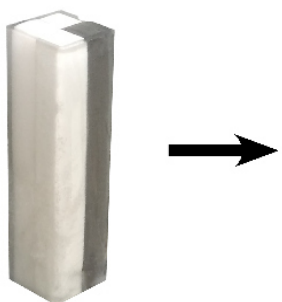

c)

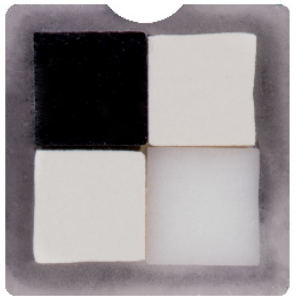

d)

Abbildung 9: Herstellungsverlauf der Probekörper: a) gelieferte Prüfmaterialien, b) verklebte Prüfmaterialien, c) verklebte Prüfmaterialien mit zusätzlicher Ummantelung und d) fertiger Multiprobekörper

\subsubsection{Sägen}

Zum Sägen der einzelnen Probekörper kam eine Diamant-Bandsäge (Exakt 300, Exakt $\mathrm{GmbH}$, Norderstedt, Deutschland) zum Einsatz. Hierdurch konnten die Probekörper, trotz unterschiedlichster Materialeigenschaften und Härtegrade, komplikationsfrei gesägt werden. Der Sägeprozess dauerte etwa 5 Minuten pro Probekörper. Damit die Probekörper intraoral einen gewissen Abstand zur Wange haben, aber dennoch eine gute Festigkeit aufweisen, wurde eine Probekörperdicke von $1 \mathrm{~mm}$ gewählt.

\subsubsection{Polieren}

Das Polierprozedere wurde mit einem Mikro-Schleifgerät (Exakt 400 CS, Exakt GmbH, Norderstedt, Deutschland) durchgeführt. Jeder Probekörper durchlief nacheinander einen Schleifprozess mit jeweils vier unterschiedlichen Körnungsgraden (500, 800, 1200 und 4000). Jeder Schleifvorgang dauerte exakt 5 Minuten bei einer Rotationsgeschwindigkeit von $40 \%$, einer Oszillationsgeschwindigkeit von $30 \%$ und einem Anpressdruck von 400 Gramm. Da nach dem Sägen noch Unebenheiten und Rillen in den Probekörpern ersichtlich waren, wurden diese zunächst mit grobkörnigem Schleifpapier (Körnungsgrad 500 und 800) entfernt und die Oberfläche auf ein einheitliches Niveau gebracht. Für die Vorpolitur wurde ein feineres Schleifpaper (Körnungsgrad 1200) verwendet. Danach folgte die Hochglanzpolitur mit 4000er Schleifpapier. 


\subsubsection{Alterungsprozess}

Nach erfolgreicher Herstellung aller 80 Probekörper wurde die Hälfte der Proben im Thermocycler (Willytec V2.9, SD-Mechatronik GmbH, Feldkirchen-Westerham, Deutschland) einer artifiziellen Alterung unterzogen. Der Prozess bestand aus abwechselnden Tauchbädern in zwei Wasserbecken, gefüllt mit destilliertem Wasser und temperiert auf $5{ }^{\circ} \mathrm{C}$ bzw. $55^{\circ} \mathrm{C}$. Die Probekörper wurden für 5000 Zyklen einer Temperaturdifferenz von somit $50^{\circ} \mathrm{C}$ ausgesetzt. Ein Zyklus setzte sich aus den folgenden Schritten zusammen: 90 Sekunden im Warmbad bei $55^{\circ} \mathrm{C}, 12$ Sekunden Transferzeit (3 Sekunden Abtropfzeit nach jedem Bad inbegriffen) sowie 90 Sekunden im Kaltbad bei $5^{\circ} \mathrm{C}$. Das Thermocycling ermöglichte eine künstliche Alterung der Probekörper, indem die intraoralen Temperaturminima- und maxima und die Hydrolyse reproduziert wurden.

\subsection{Oberflächenrauheit und -topographie}

Zur Beurteilung der Oberflächentopographie der Probekörper wurde ein computergesteuertes Weitfeld-Konfokalmikroskop (Smartproof 5, Carl Zeiss, Oberkochen, Deutschland) mit der Software Zen - Zeiss Efficient Navigation (Carl Zeiss, Oberkochen, Deutschland) und Confomap (Carl Zeiss, Oberkochen, Deutschland) verwendet. Die Messungen erfolgten an den Materialien von jeweils fünf Probekörpern im Ausgangszustand und fünf künstlich gealterten Probekörpern. Letztendlich wurden Aufnahmen bei 20-facher Vergrößerung und einem Teilbereich von 225 x $225 \mu \mathrm{m}$ analysiert. Nach Abschluss der halbautomatischen Bilderfassung konnte die Software eine dreidimensionale Gesamtdarstellung der Oberflächentopographie erstellen. Im Anschluss wurden der arithmetische Mittenrauwert $R_{a}$ und die flächenbezogene mittlere arithmetische Höhe $S_{a}$ für die ausgewählten Teilbereiche vollautomatisch berechnet (siehe Beispiel Abbildung 10). 


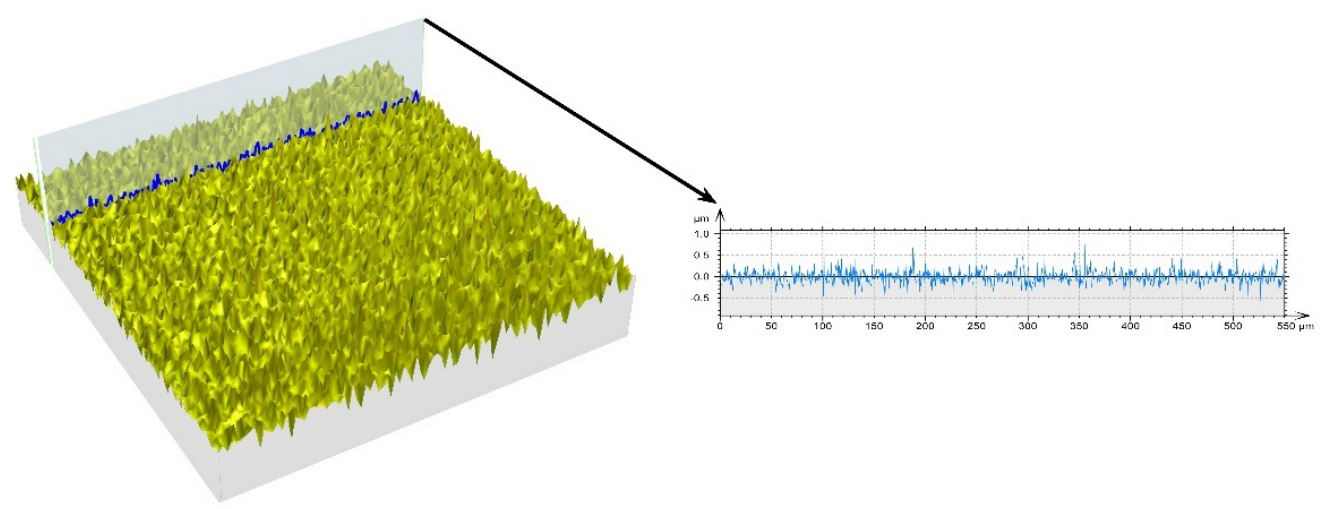

Abbildung 10: Dreidimensionale Darstellung mit dazugehörigem Profilschnitt einer Titanoberfläche im Ausgangszustand

\subsection{Herstellung der Trägerschienen}

Damit für jeden Probanden eine individuelle Schiene hergestellt werden konnte, wurden zunächst Alginatabformungen (Palgat Plus, 3M ESPE, Seefeld, Deutschland) der Oberkiefer jedes Probanden genommen und mit Superhartgips (GC Fujirock EP, GC Europe, Leuven, Belgien) ausgegossen. Die fertigen Modelle wurden getrimmt und die Unterschnitte der Zähne mit Klebewachs (Deiberit, Böhme \& Schöps Dental GmbH, Goslar, Deutschland) ausgeblockt. Als nächstes wurden die Probekörper an den vestibulären Flächen der ersten Molaren und der Eckzähne mit Klebewachs fixiert, die künstlich gealterten Probekörper jeweils vestibulär am Zahn 16 und 23 und die unbearbeiteten Probekörper vestibulär am Zahn 13 sowie 26 (siehe Abbildung 11).

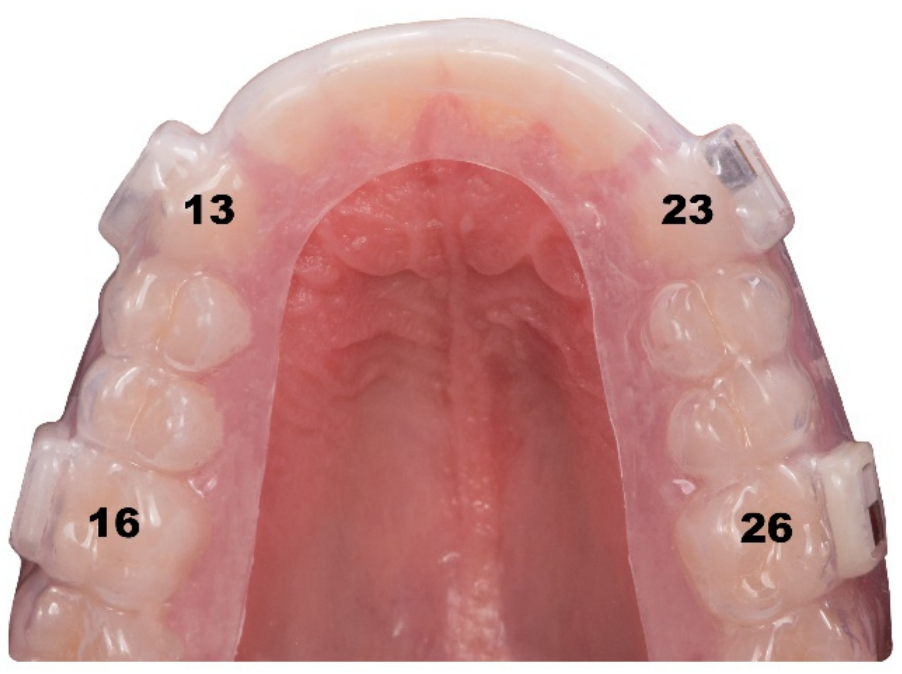

Abbildung 11: Anordnung der Probekörper in Trägerschiene

(Zahnpositionen 13, 16, 23 und 26) 
Mit Hilfe eines Tiefziehgerätes (Erkoform 3D, Erkodent, Deutschland) entstanden die Trägerschienen, indem thermoplastisch verformbare Folien (Erkolen, Erkodent, Pfalzgrafenweiler, Deutschland) der Stärke 1,0 $\mathrm{mm}$ über die vorbereiteten Modelle tiefgezogen wurden (siehe Abbildung 12). Anschließend mussten die Schienen mit einer Schere zugeschnitten und die Probekörper mit einem Skalpell freigelegt werden. Um den Tragekomfort $\mathrm{zu}$ erhöhen erfolgte eine Abrundung der scharfen Ränder mit einer Polierscheibe (Lisko-S, Erkodent, Pfalzgrafenweiler, Deutschland). Schließlich wurden die Schienen bei den ProbandInnen eingegliedert und bei drückenden Stellen oder okklusalen Störkontakten angepasst (siehe Abbildung 13).

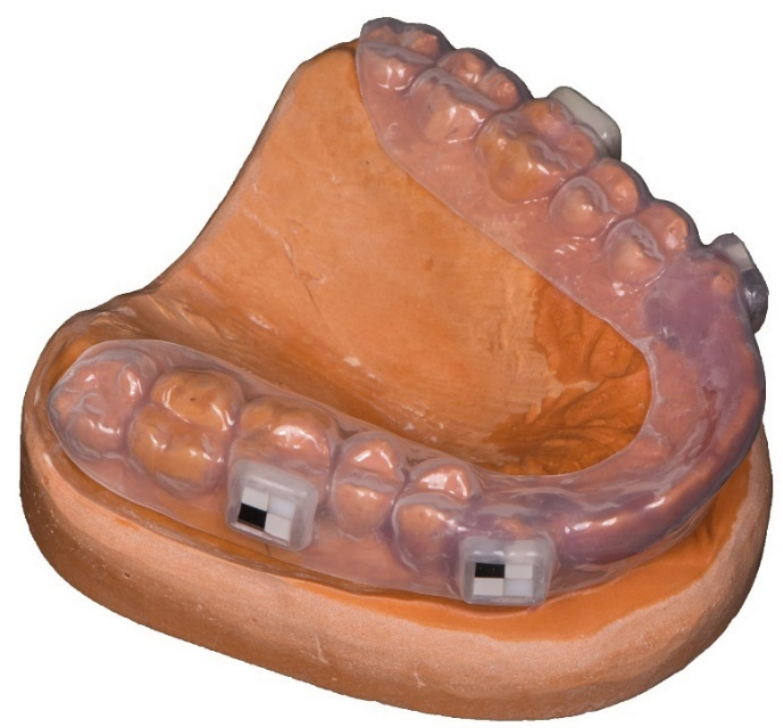

Abbildung 12: Trägerschiene mit Probekörpern auf dem Modell

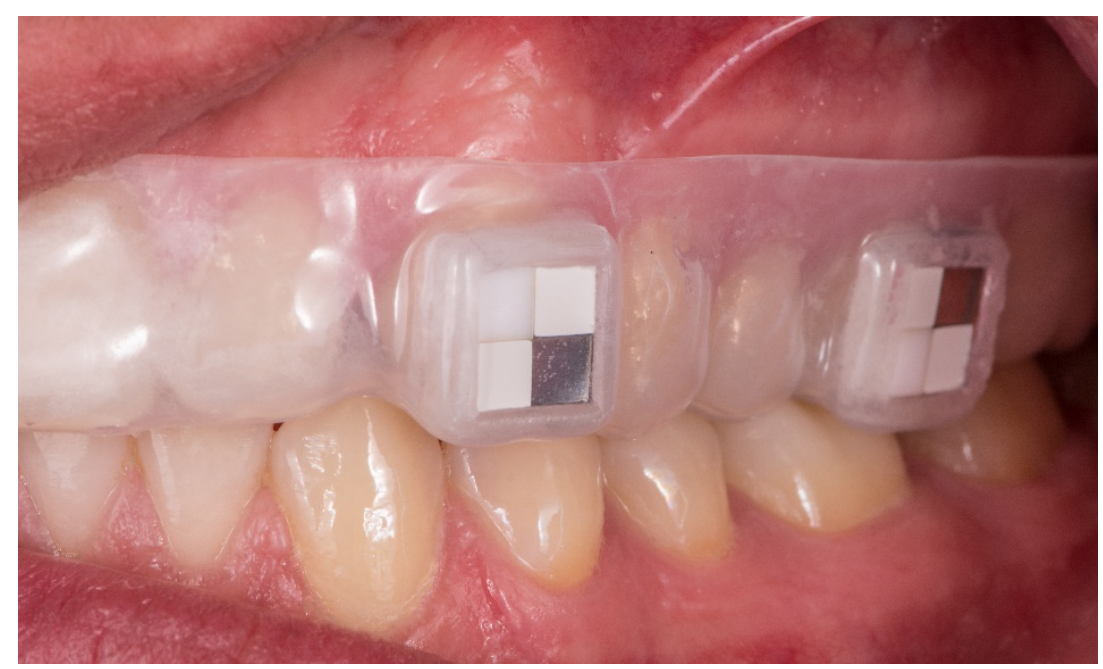

Abbildung 13: Trägerschiene mit Probekörpern in situ 


\subsection{Verfahren zur Beurteilung der Biofilmakkumulation}

\subsubsection{Fluoreszenzfärbung}

Nach einer Tragedauer von 24 Stunden wurden die Trägerschienen entnommen und die Probekörper vorsichtig unter sterilen Bedingungen aus der Schiene gelöst. Alle Arbeitsschritte fanden unter einer mikrobiologischen Werkbank (HERAsafe KS, Thermo Fisher Scientific Inc., Waltham, USA) statt. Vor dem Anfärben und Fixieren des Biofilms mussten die Probekörper zunächst in einer 24-Well-Platte positioniert werden. Zusätzlich wurden die Probekörper zum Schutz vor Aufschwimmen und Drehen bei Suspensionszufuhr in den einzelnen Wells mittels Dubliersilikon (Z-Dupe Shore A-20, Henry Schein Inc., Melville, USA) fixiert (siehe Abbildung 14). Hierfür wurde auf der Unterseite jedes Probekörpers ein Tropfen des Silikons aufgebracht und diese mit der Bakterienseite nach oben mittig in die Wells eingelegt. Es folgte ein Waschprozess mit jeweils $1 \mathrm{ml}$ steriler $0,85 \%$ iger Natriumchlorid $(\mathrm{NaCl})$-Lösung (Merck KGaA, Darmstadt, Deutschland) je Probekörper. Diese wurde am Rand vorsichtig zugegeben und mittels eines Flüssigkeit-Absaugsystems (BVC professional, Vacuubrand $\mathrm{GmbH}$, Wertheim, Deutschland) ebenso vorsichtig wieder entfernt. Der Vorgang wurde wiederholt, die Wells erneut mit jeweils $1 \mathrm{ml}$ steriler 0,85 \%iger NaCl-Lösung aufgefüllt und zum Waschen für $5 \mathrm{~min}$ bei $55 \mathrm{U} / \mathrm{min}$ (Umdrehungen pro Minute) in einen Tischorbitalschüttler (Thermo Scientific MaxQ 4000, Thermo Fisher Scientific Inc., Waltham, USA) eingebracht. Nach Absaugen der NaCl-Lösung erfolgte die Färbung des Biofilms. Hierfür wurde je Probekörper eine Farbsuspension aus $5 \mu \mathrm{l}$ von $1 \mathrm{mg} / \mathrm{ml}$ Hoechst 33342 (Sigma-Aldrich, St. Louis, USA) und $1 \mathrm{ml}$ 0,85 \%iger NaCl-Lösung hinzupipettiert und für $13 \mathrm{~min}$ bei $55 \mathrm{U} / \mathrm{min}$ im Tischorbitalschüttler abgedunkelt inkubiert. Nach Absaugen der Färbelösung wiederholte sich der vorher beschriebene Waschprozess. Die Fixierung des gefärbten Biofilms erfolgte mit $2 \%$ igem Paraformaldehyd (PFA) (Sigma Aldrich, St. Louis, USA). Hierzu wurde 8 \%iges PFA mit phosphatgepufferter Salzlösung (PBS, phosphate-buffered saline) (Sigma Aldrich, Steinheim, Deutschland) im Verhältnis 1:3 vermengt, je Probekörper $1 \mathrm{ml}$ hinzugegeben und für $10 \mathrm{~min}$ bei $55 \mathrm{U} / \mathrm{min}$ wieder im Schüttler abgedunkelt inkubiert. Nach erneutem Waschvorgang wurden die Probekörper mit einer Pinzette aus der Well-Platte entnommen, vom Silikon gelöst und zum Trocknen für 10 min im Dunkeln gelagert. Schließlich kamen die Probekörper mit der Biofilmseite nach unten mittig auf ein Deckglas (24 x 60 mm, Stärke 1; Menzel-Gläser, Braunschweig, Deutschland). 


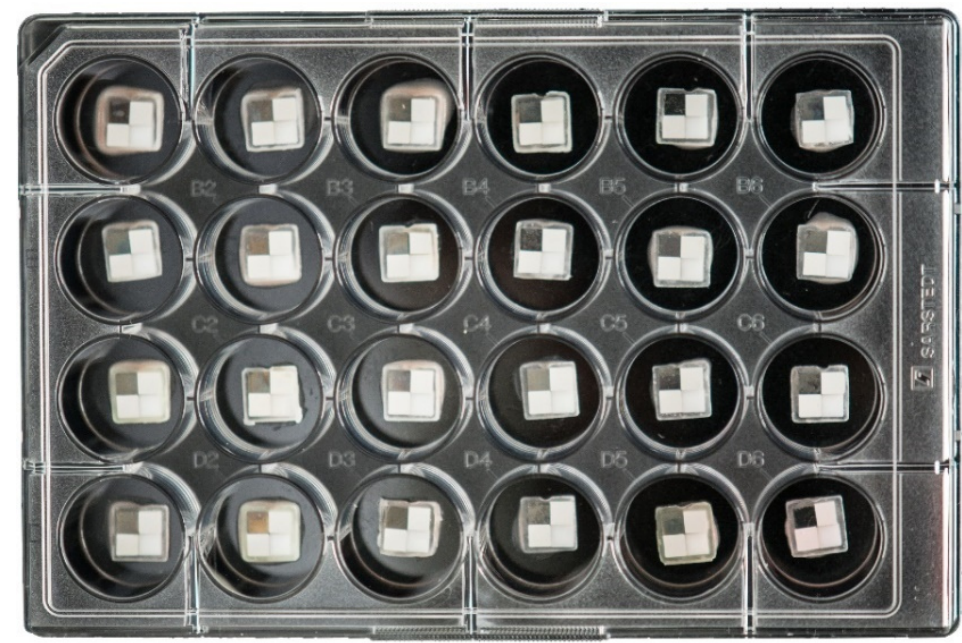

Abbildung 14: 24-Well-Platte mit eingebrachten Probekörpern

\subsubsection{Fluoreszenzmikroskopie}

Nach Anfärben und Fixieren des Biofilms war es möglich, den adhärenten Biofilm mit Hilfe eines Fluoreszenzmikroskops (Keyence BZ-X710, Keyence Corporation, Osaka, Japan) und der entsprechenden Software (BZ-X Analyser, Keyence Corporation, Osaka, Japan) darzustellen und zu visualisieren. Als Fluoreszenzkanal zur Anregung des Farbstoffes Hoechst $33342(355-465 \mathrm{~nm})$ wurde der Kanal 1 (DAPI-Farbstoff, $358-461 \mathrm{~nm}$ ) gewählt, da beide Färbungen in einem ähnlichen Wellenlängenbereich fluoreszieren und somit das Licht im blauen Spektrum emittieren (siehe Abbildung 15 a). Die Position der Probekörper wurde unter 4-facher Vergrößerung festgelegt und bei 20facher Vergrößerung wurden jeweils drei Aufnahmen aus der Mitte jedes Materials frei gewählt und im Dateiformat .tif abgespeichert. Somit sind je Probekörper 12 Bilder und bei einer Anzahl von 20 ProbandInnen insgesamt 960 Bilder entstanden. Die in jedem dieser Bilder dargestellte Fläche besaß eine Größe von $500 \mu \mathrm{m}$ x $750 \mu \mathrm{m}=375.000 \mu \mathrm{m}$, somit wurden insgesamt 4.500.000 $\mu \mathrm{m}$ jedes Probekörpers analysiert. Die Schärfe sowie die Belichtungszeit wurden für jedes Material manuell eingestellt.

\subsubsection{Digitale Auswertung}

Mit Hilfe des Bildbearbeitungs- und Bildverarbeitungsprogramms ImageJ 1.51k Fiji (National Institutes of Health, Maryland, USA) konnte die quantitative Biofilmbesiedlung auf den Probekörpern berechnet werden. Hierfür wurden die mit dem Fluoreszenzmikroskop hergestellten Aufnahmen in das Programm eingefügt und in ein Graustufenbild (8-bit) umgewandelt. Nach individueller Anpassung der Grenzen sowie der Schwellenwerte für die Biofilme konnten die Aufnahmen in Schwarz-Weiß-Bilder 
konvertiert werden. Hierdurch wurde der Biofilm in Weiß und die freie Fläche in Schwarz dargestellt (siehe Abbildung $15 \mathrm{a}-\mathrm{c}$ ). Daraufhin berechnete die Software den prozentualen Anteil an weißen Pixeln in der Gesamtaufnahme. Dies ermöglichte die Gleichsetzung des erhaltenen Prozentwertes mit der quantitativen Biofilmmenge.

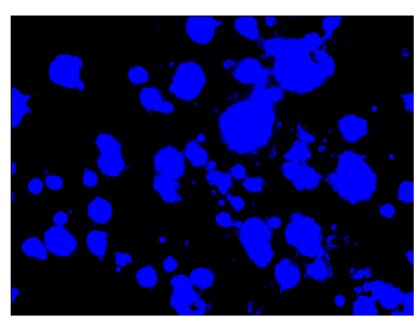

a)

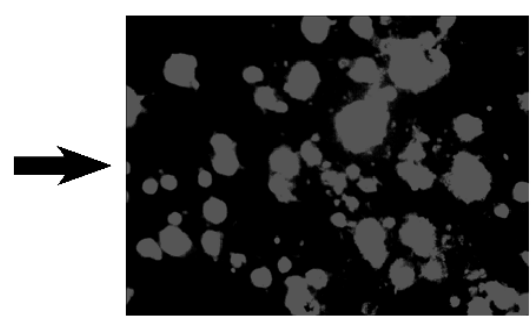

b)

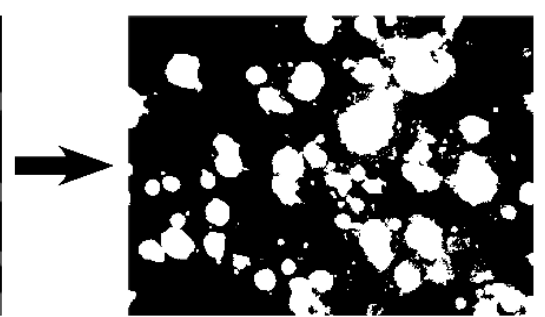

c)

Abbildung 15: Prozess der digitalen Bildanalyse

a) Aufnahme des fluoreszierenden Biofilms, b) Graustufenbild (8-bit),

c) Schwarz-Weiß-Umwandlung

\subsection{Statistische Auswertung}

Die statistische Auswertung der Untersuchungsergebnisse erfolgte mit der Statistiksoftware R (Version 3.4.0, The R Foundation of Statistical Computing (www.rproject.org), Wien, Österreich) in Zusammenarbeit mit dem Institut der Medizinischen Statistik der Universitätsmedizin Göttingen. Für alle statistischen Tests betrug das Signifikanzniveau $\alpha=0,05 \%$. Die Analyse der Biofilmakkumulation erfolgte unter Verwendung des R-Pakets Lme4. Dabei wurden die drei gemessenen Werte (quantitative Plaqueakkumulation in Prozent von der Gesamtfläche) je Werkstoff gemittelt und der statistischen Analyse zugeführt. Auf die abhängige Variable „Fläche in \%“ wurde zur Varianzstabilisierung eine Box-Cox-Transformation angewandt. Um den Einfluss von der Materialart und -alterung, der intraoralen Position, des Geschlechts und des Probandenalters darzustellen, wurde ein allgemeines lineares gemischtes Modell erstellt. Es wurden Interaktionsbedingungen hinzugefügt und jene beibehalten, die zur deutlichen Verbesserung des Modells führten. Zur Ermittlung von topographischen Unterschieden der Materialoberflächen wurden die Daten der Rauheitsmessungen $\left(R_{a}\right.$ und $\left.S_{a}\right)$ mittels Varianzanalyse (ANOVA, analysis of variance) ausgewertet. Signifikante Unterschiede wurden im Anschluss mit Hilfe des Post-hoc-Tests nach Tukey herausgearbeitet. 


\section{Ergebnisse}

\subsection{Präambel}

Die in den Abbildungen ersichtlichen box-whisker-plots (Kastengrafiken) stellen die gemessenen Ergebnisse graphisch dar (siehe Abbildung 16). Die whisker liegen außerhalb der Box und geben den Minimal- und Maximalwert an. Begrenzt wird die Box durch das untere Quartil (Q1) und das obere Quartil (Q3), geteilt wird es durch den Medianwert. Vorhandene Ausreißer werden als Punkte dargestellt.

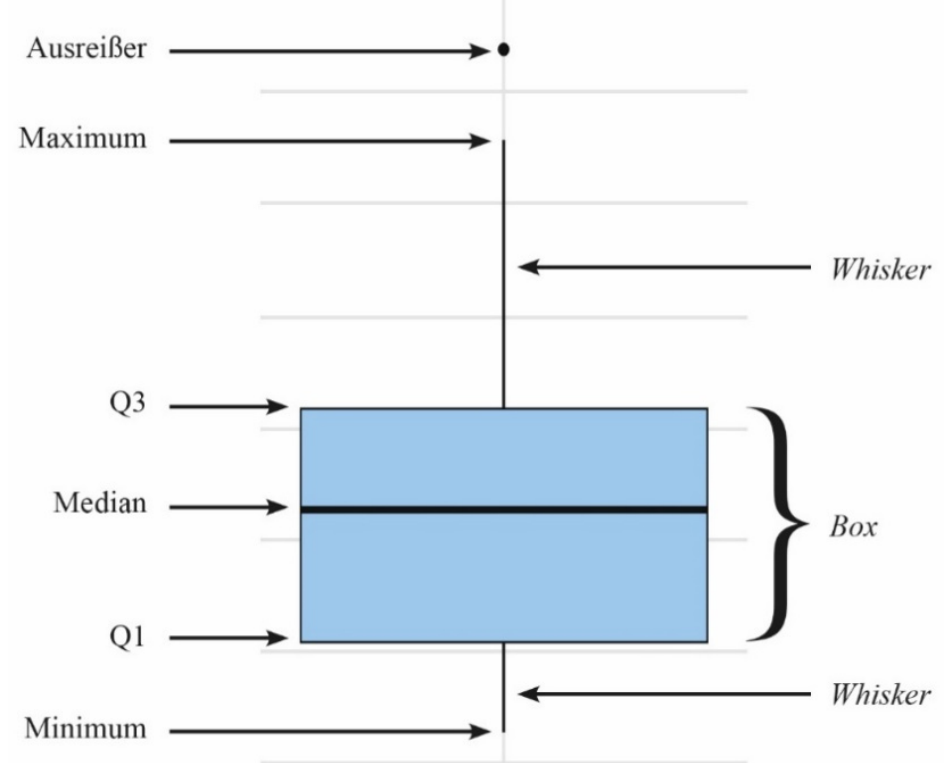

Abbildung 16: Aufbau der box-whisker-plots

\subsection{Probandenkollektiv}

Das Probandenkollektiv umfasste 10 Frauen und 10 Männer. Das Alter der ProbandInnen lag zwischen 22 und 34 Jahren. Daraus ergab sich ein Durchschnittsalter von 25,7 Jahren mit einer Standardabweichung von 3 Jahren. Nach der Tragedauer von 24 Stunden berichtete keinE ProbandIn von unangenehmen Folgen, die durch das Tragen der Trägerschienen entstanden sind, weshalb kein drop-out von Studienteilnehmern stattfand. 


\subsection{Klinische Voruntersuchung}

Alle 20 StudienteilnehmerInnen erfüllten während der Voruntersuchung die Einschlusskriterien für die klinische Studie. Des Weiteren waren alle TeilnehmerInnen vollbezahnt und hatten eine gute Mundhygiene mit SBI $<10 \%$ und API $<35 \%$.

\subsection{Rauheiten}

In Tabelle 3 und Abbildung 17 bzw. Abbildung 18 sind die ermittelten profil- und flächenbezogenen arithmetischen Mittenrauwerte $R_{a}$ und $S_{a}$ für die vier Prüfmaterialien in Abhängigkeit vom Alterungszustand aufgeführt. Eine zweifaktorielle Varianzanalyse (two-way ANOVA) konnte bei den gemessenen Materialoberflächen keinen signifikanten Unterschied für den profilbezogenen arithmetischen Mittenrauwert $R_{a}(p=0,1974)$ und für die mittlere arithmetische Höhe $S_{a}(p=0,1157)$ ermitteln. Die Abbildung 19 - Abbildung 22 zeigen jeweils bespielhaft die dreidimensionale Darstellung der Oberfläche mit dem dazugehörigen Rauheitsprofil für die einzelnen Testmaterialien im Ausgangszustand und gealtert.

Tabelle 3: Arithmetische Mittenrauwerte $R_{a}$ und $S_{a}[\mu \mathrm{m}]$ für alle Materialien in Abhängigkeit vom Alterungszustand (Median, Q1, Q2)

\begin{tabular}{|c|c|c|c|c|}
\hline & \multicolumn{2}{|c|}{ Ausgangszustand } & \multicolumn{2}{c|}{ gealtert } \\
& $\mathbf{R}_{\mathbf{a}}$ & $\mathbf{S}_{\mathbf{a}}$ & $\mathbf{R}_{\mathbf{a}}$ & $\mathbf{S}_{\mathbf{a}}$ \\
\hline \multirow{3}{*}{ BioHPP } & 0,099 & 0,133 & 0,106 & 0,139 \\
& $(0,086 / 0,114)$ & $(0,114 / 0,152)$ & $(0,088 / 0,124)$ & $(0,120 / 0,166)$ \\
\hline \multirow{3}{*}{ PEEK } & 0,100 & 0,130 & 0,102 & 0,129 \\
& $(0,085 / 0,121)$ & $(0,108 / 0,168)$ & $(0,093 / 0,114)$ & $(0,118 / 0,149)$ \\
\hline \multirow{2}{*}{ Titan } & 0,114 & 0,130 & 0,126 & 0,147 \\
& $(0,087 / 0,128)$ & $(0,111 / 0,150)$ & $(0,106 / 0,140)$ & $(0,130 / 0,162)$ \\
\hline \multirow{2}{*}{ Zirkon } & 0,100 & 0,117 & 0,131 & 0,159 \\
& $(0,090 / 0,112)$ & $(0,103 / 0,130)$ & $(0,092 / 0,145)$ & $(0,121 / 0,175)$ \\
\hline
\end{tabular}




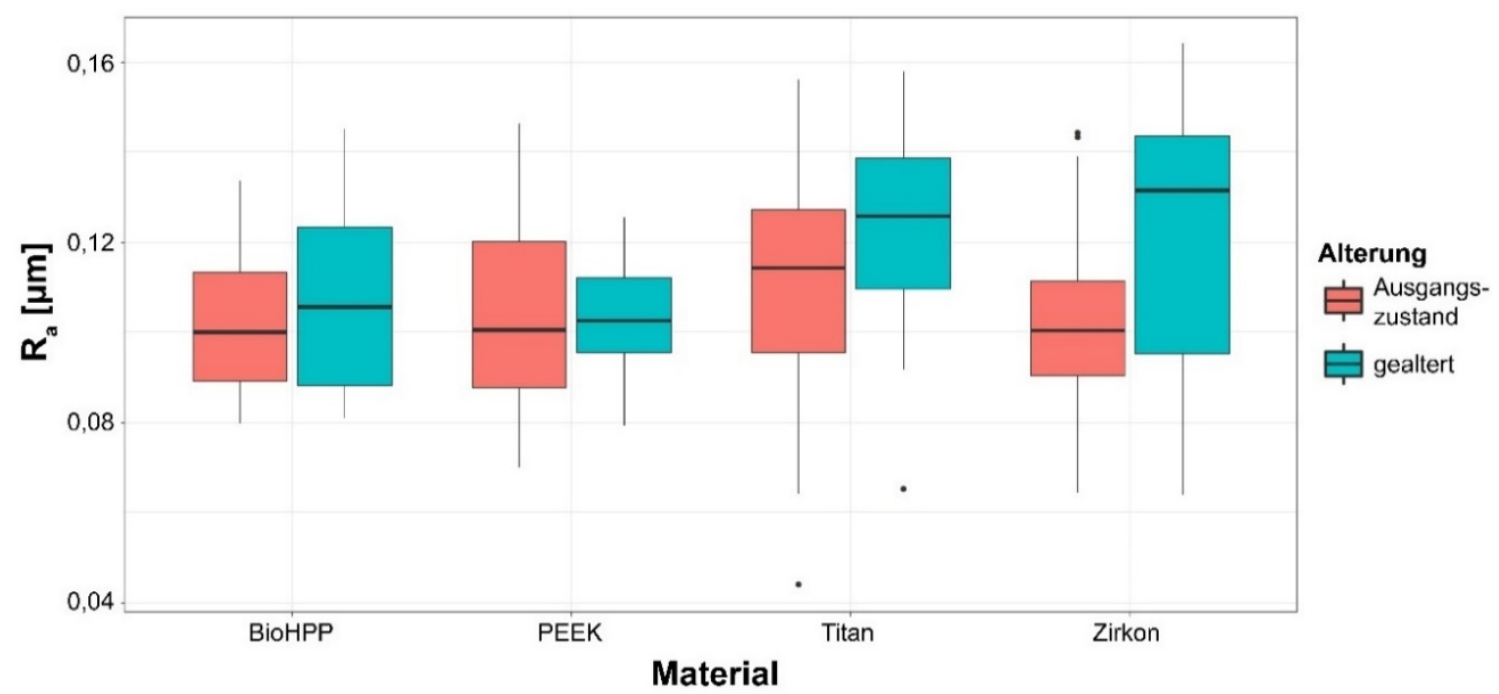

Abbildung 17: Verteilung der arithmetischen Mittenrauwerte $R_{a}[\mu \mathrm{m}]$ der Prüfmaterialien in Abhängigkeit vom Alterungszustand (Maximum, Q3, Median, Q1, Minimum)

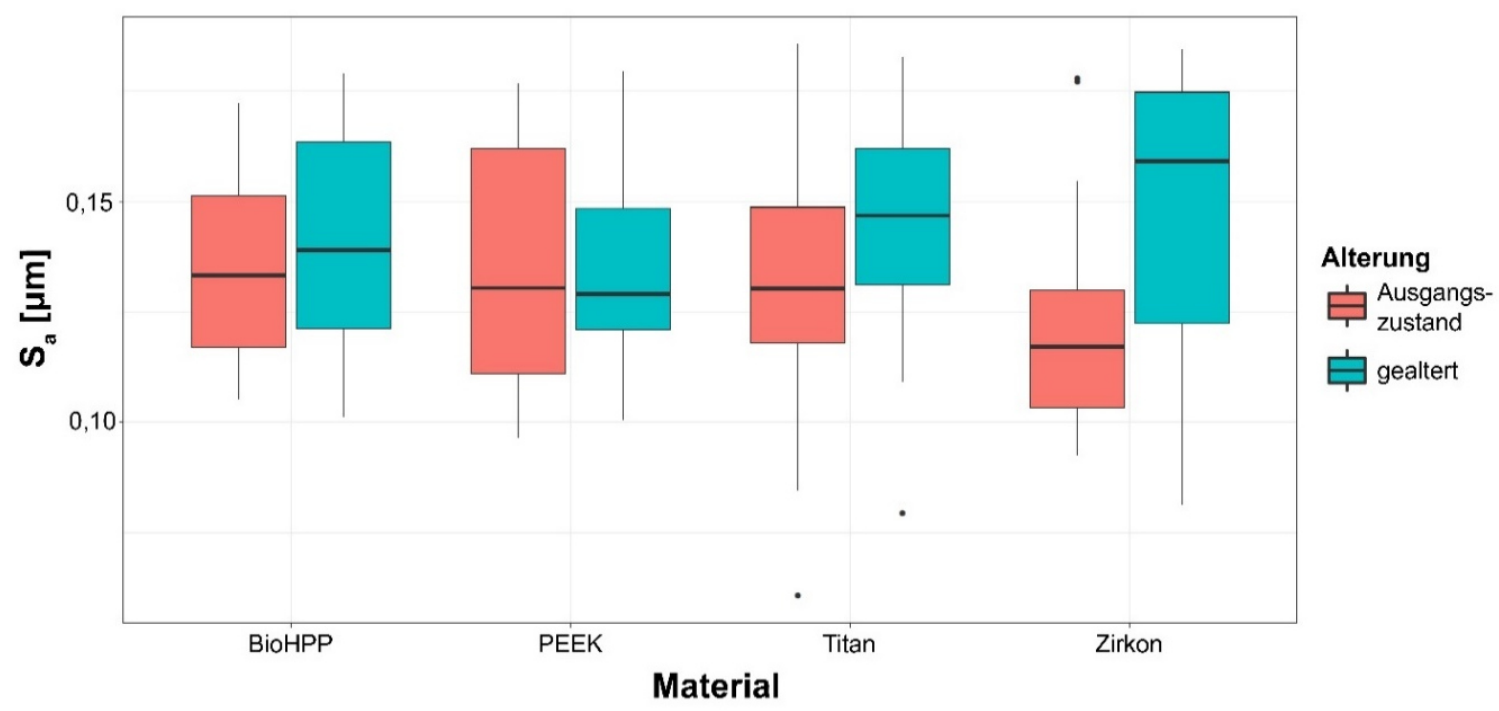

Abbildung 18: Verteilung der mittleren arithmetischen Höhen $S_{a}[\mu \mathrm{m}]$ der Prüfmaterialien in Abhängigkeit vom Alterungszustand (Maximum, Q3, Median, Q1, Minimum) 

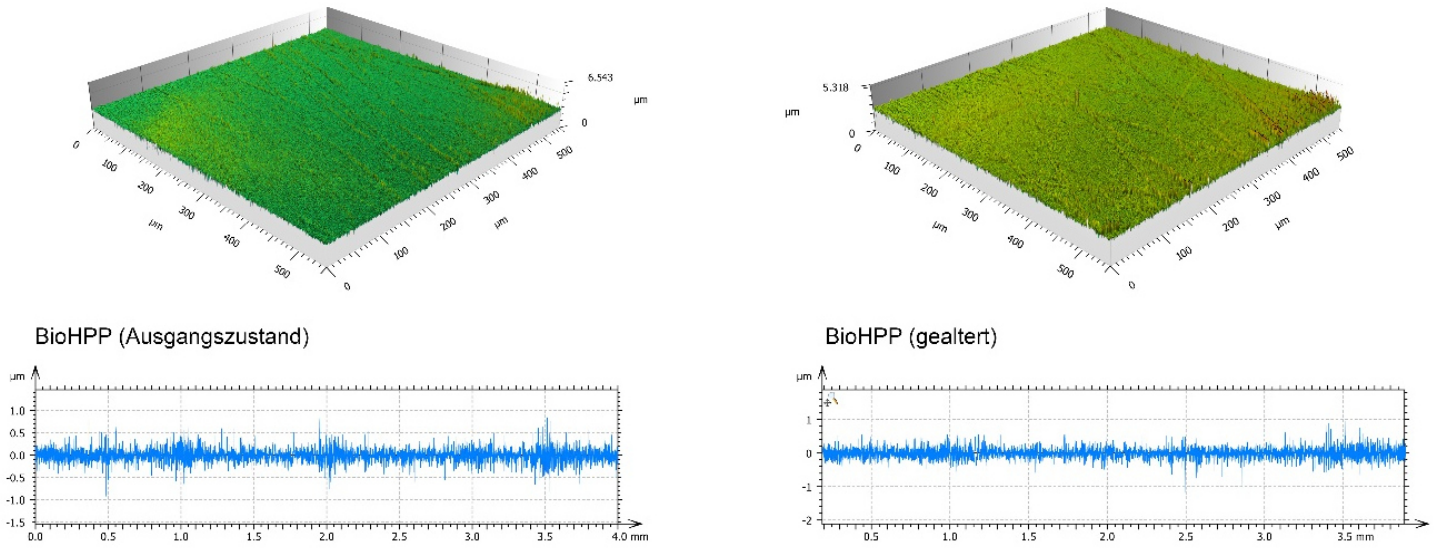

Abbildung 19: Dreidimensionale Darstellung der Oberflächentopographie $(550 \times 550 \mu \mathrm{m}) \mathrm{mit}$ dazugehöriger Darstellung des Rauheitsprofils von BioHPP im Ausgangszustand (links) und nach artifizieller Alterung (rechts)
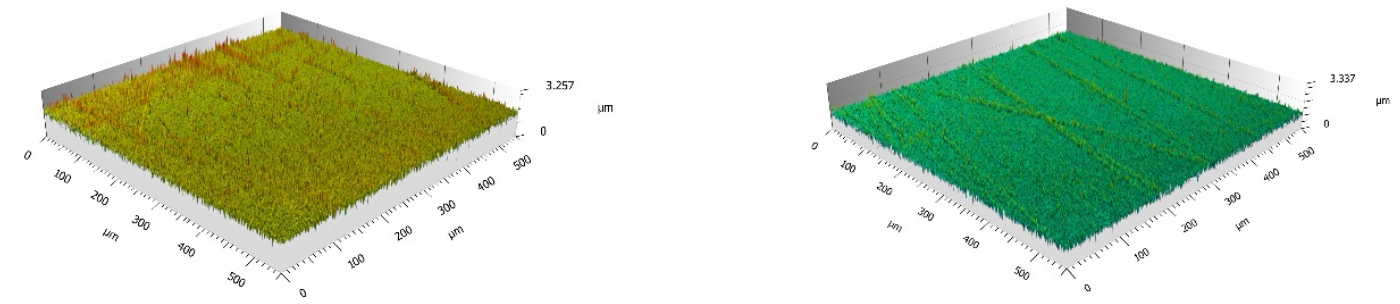

PEEK (Ausgangszustand)

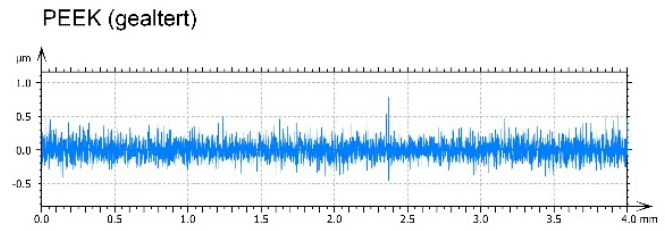

Abbildung 20: Dreidimensionale Darstellung der Oberflächentopographie $(550 \times 550 \mu \mathrm{m}) \mathrm{mit}$ dazugehöriger Darstellung des Rauheitsprofils von PEEK im Ausgangszustand (links) und nach artifizieller Alterung (rechts) 

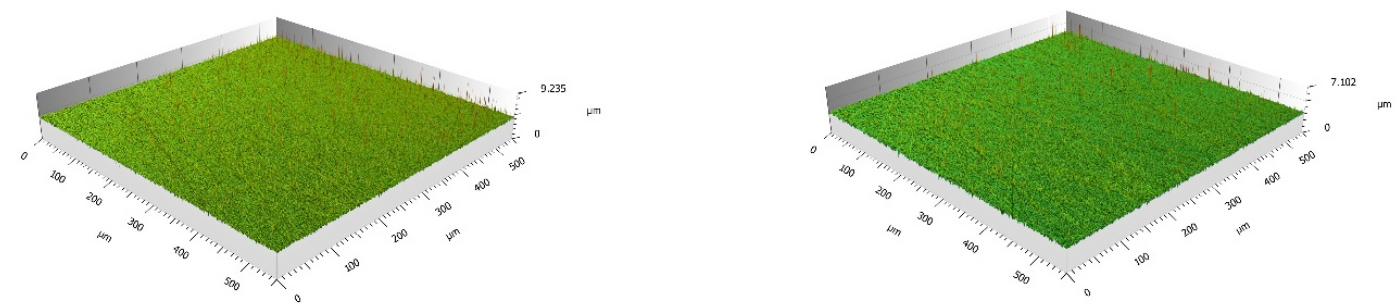

Titan (Ausgangszustand)

Titan (gealtert)
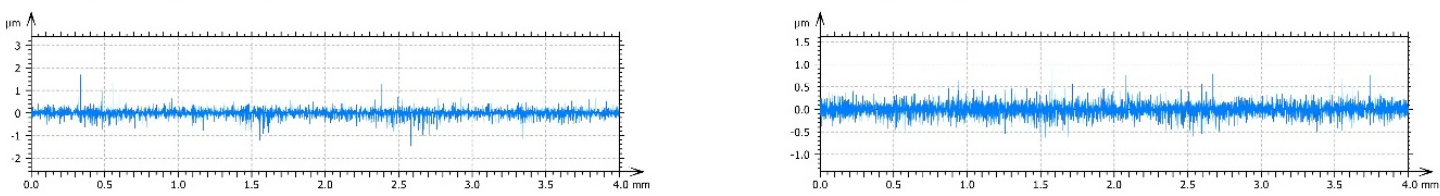

Abbildung 21: Dreidimensionale Darstellung der Oberflächentopographie $(550$ x $550 \mu \mathrm{m}) \mathrm{mit}$ dazugehöriger Darstellung des Rauheitsprofils von Titan im Ausgangszustand (links) und nach artifizieller Alterung (rechts)
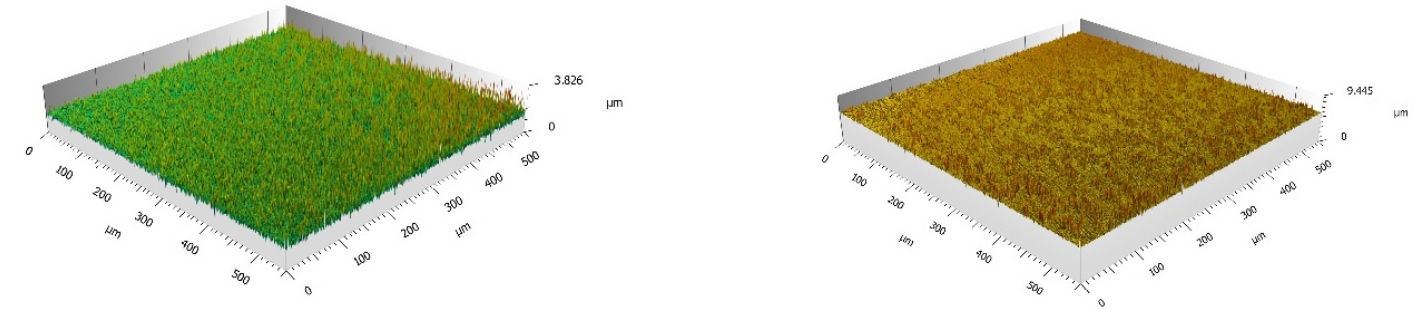

Zirkonium (Ausgangszustand)

Zirkonium (gealtert)
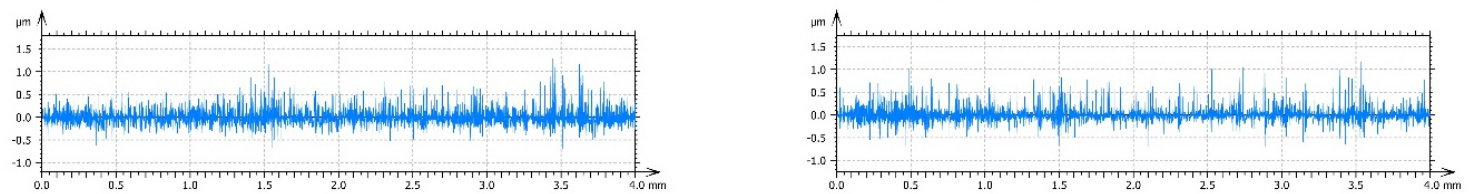

Abbildung 22: Dreidimensionale Darstellung der Oberflächentopographie (550 x $550 \mu \mathrm{m}) \mathrm{mit}$ dazugehöriger Darstellung des Rauheitsprofils von Zirkoniumdioxid im Ausgangszustand (links) und nach artifizieller Alterung (rechts) 


\subsection{Ergebnisse der Biofilmakkumulation}

\subsubsection{Materialspezifische Biofilmakkumulation im Gesamtkollektiv}

Die Quantität der adhärenten Biofilme auf den verschiedenen Testmaterialien ist in Abbildung 23 aufgeführt. Der geringste Medianwert wurde mit 6,5\% auf der Zirkoniumdioxidoberfläche erfasst. Es folgten Titan mit 11,1 \% und PEEK mit 17,8 \%. Den höchsten Medianwert erreichte das Material BioHPP mit 19,7 \%. Die Untersuchung der Probekörper erfolgte mittels Hoechst 33342-Färbung und Fluoreszenzmikroskopie (siehe Bespielaufnahmen Abbildung 24 - Abbildung 27).

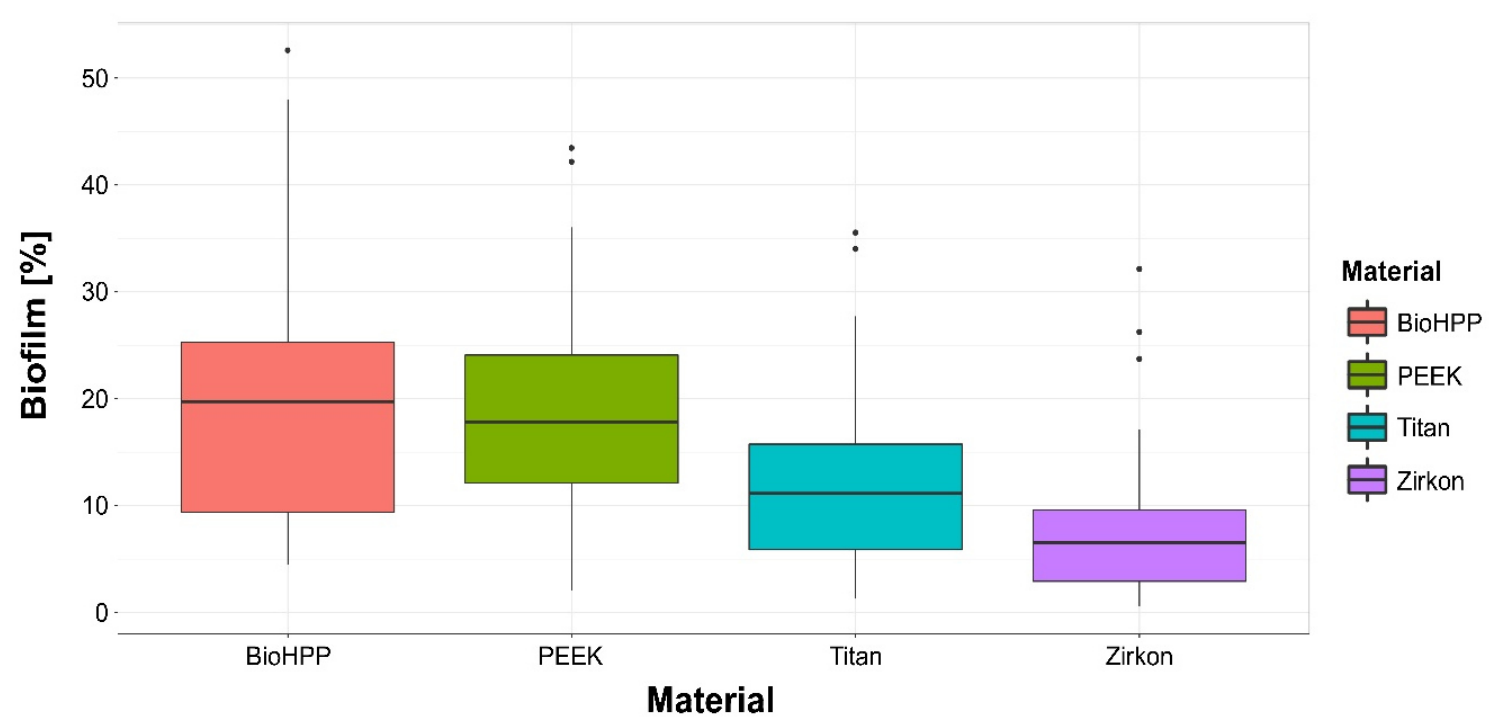

Abbildung 23: Verteilung der Biofilmakkumulation auf den einzelnen Materialoberflächen [\%, besiedelte Oberfläche zu Gesamtoberfläche] (Maximum, Q3, Median, Q1, Minimum)

Bereits im allgemeinen gemischten linearen Modell konnten signifikante Unterschiede in der Biofilmadhäsion zwischen den Materialien festgestellt werden (siehe Tabelle 4). Zur weiteren statistischen Analyse wurde ein Post-hoc-Test nach Tukey mit dem Vergleich der Kleinste-Quadrate-Mittelwerte jedes Materials durchgeführt (siehe Tabelle 5). Lediglich bei der Gegenüberstellung von BioHPP mit PEEK zeigte sich kein signifikanter Unterschied $(p=0,953)$. Alle weiteren paarweisen Vergleiche stellten signifikante Unterschiede dar $(\mathrm{p}<0.001)$. Somit wies die Materialauswahl einen signifikanten Einfluss auf die Plaqueakkumulation auf. 
Tabelle 4: Ergebnisse (p-Werte) des allgemeinen linearen gemischten Modells für den Einfluss des Materials auf die Biofilmakkumulation (Titan als Referenzmaterial)

\begin{tabular}{|c|c|}
\hline Material & p-Wert \\
\hline BioHPP & $<0,001$ \\
\hline PEEK & $<0,001$ \\
\hline Zirkon & $<0,001$ \\
\hline
\end{tabular}

Tabelle 5: Paarvergleiche der gemessenen Biofilmmenge auf den Prüfmaterialien mit entsprechenden $\mathrm{p}$-Werten

\begin{tabular}{|c|c|c|c|c|}
\hline & BioHPP & PEEK & Titan & Zirkon \\
\hline BioHPP & & 0,953 & $<0,001$ & $<0,001$ \\
\hline PEEK & & & $<0,001$ & $<0,001$ \\
\hline Titan & & & & $<0,001$ \\
\hline Zirkon & & & & \\
\hline
\end{tabular}

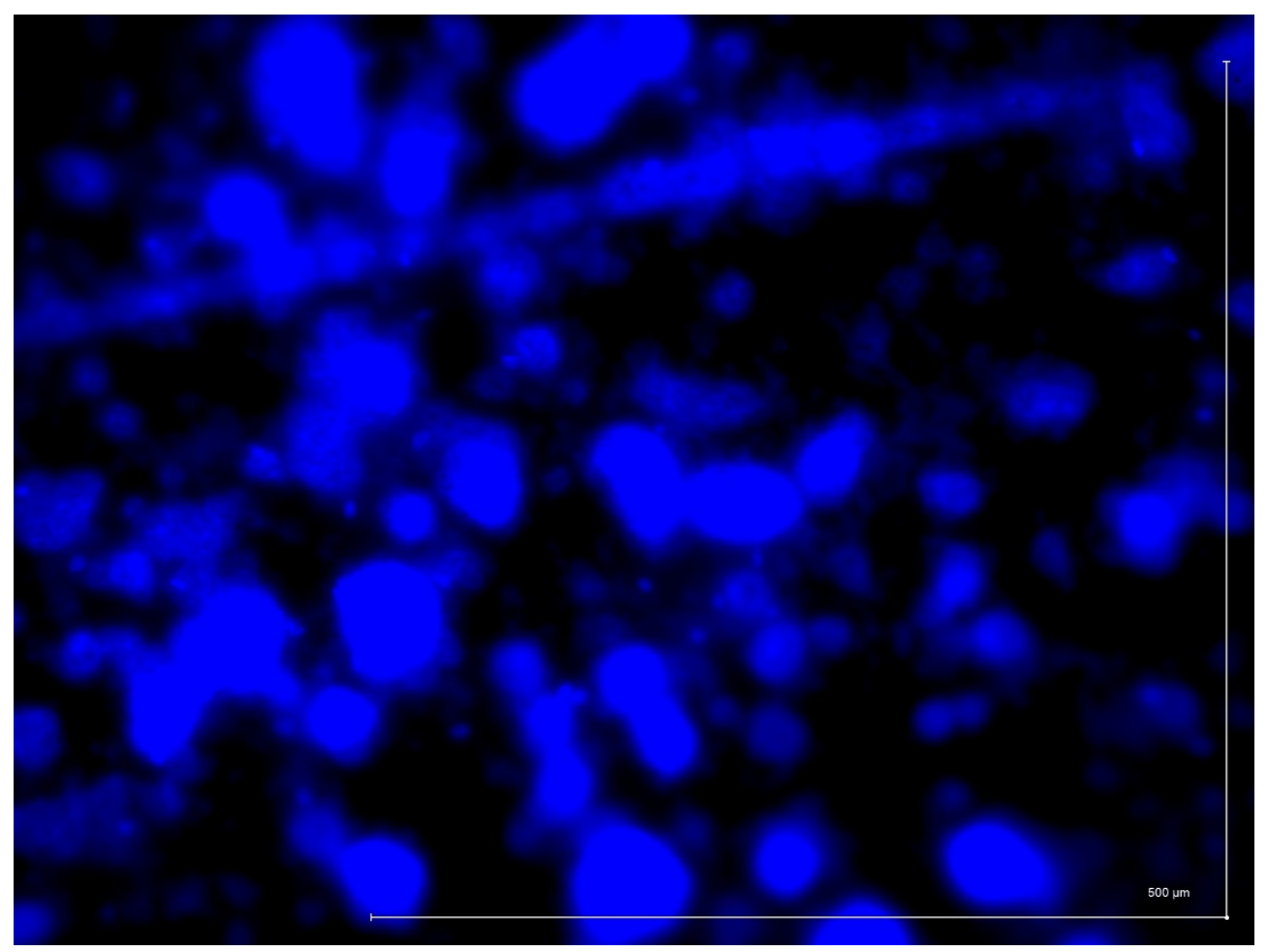

Abbildung 24: BioHPP, Fluoreszenzmikroskopische Aufnahme (20-fache Vergrößerung), Hoechst 33342-Färbung 


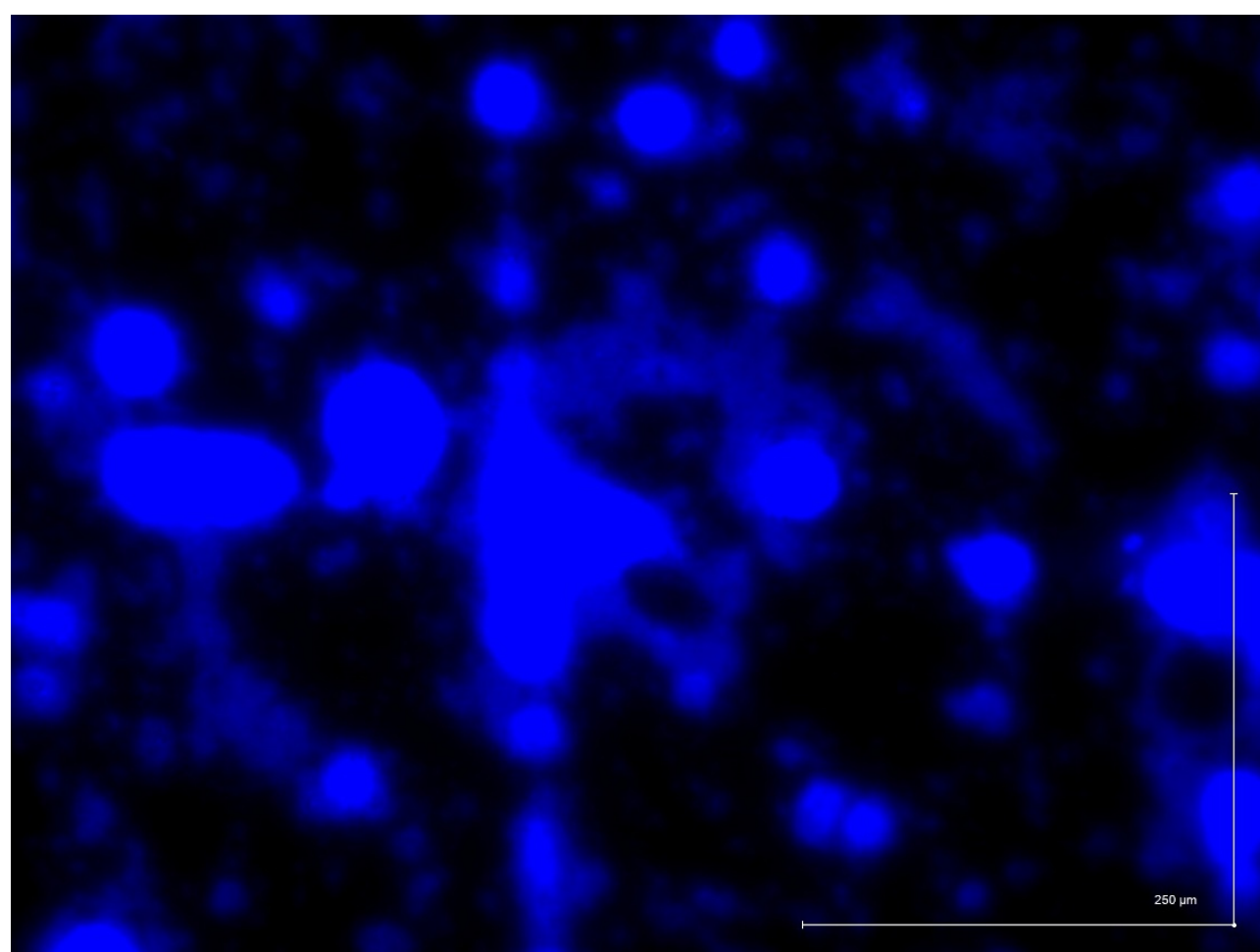

Abbildung 25: PEEK, Fluoreszenzmikroskopische Aufnahme (20-fache Vergrößerung), Hoechst 33342-Färbung

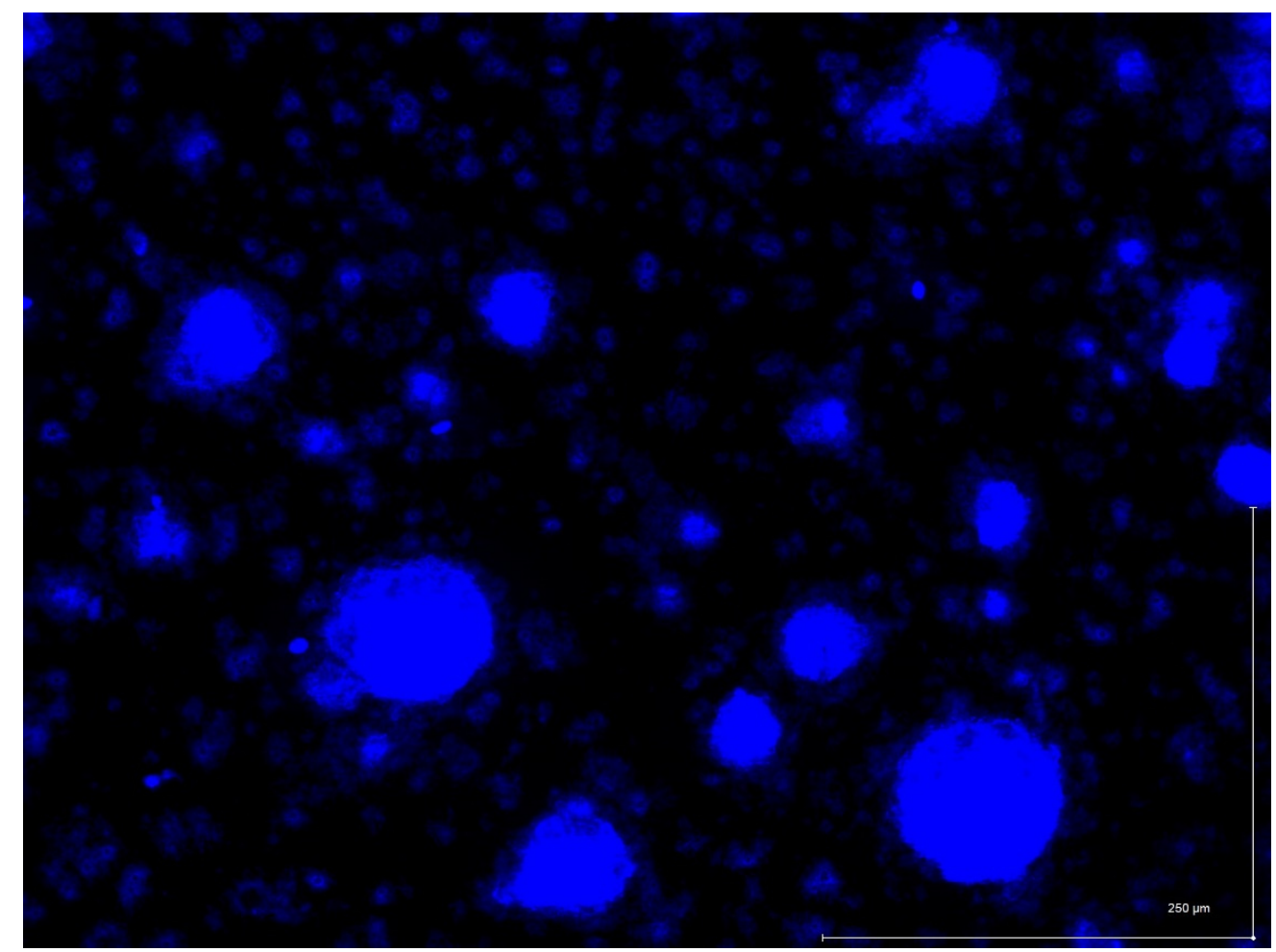

Abbildung 26: Titan, Fluoreszenzmikroskopische Aufnahme (20-fache Vergrößerung), Hoechst 33342-Färbung 


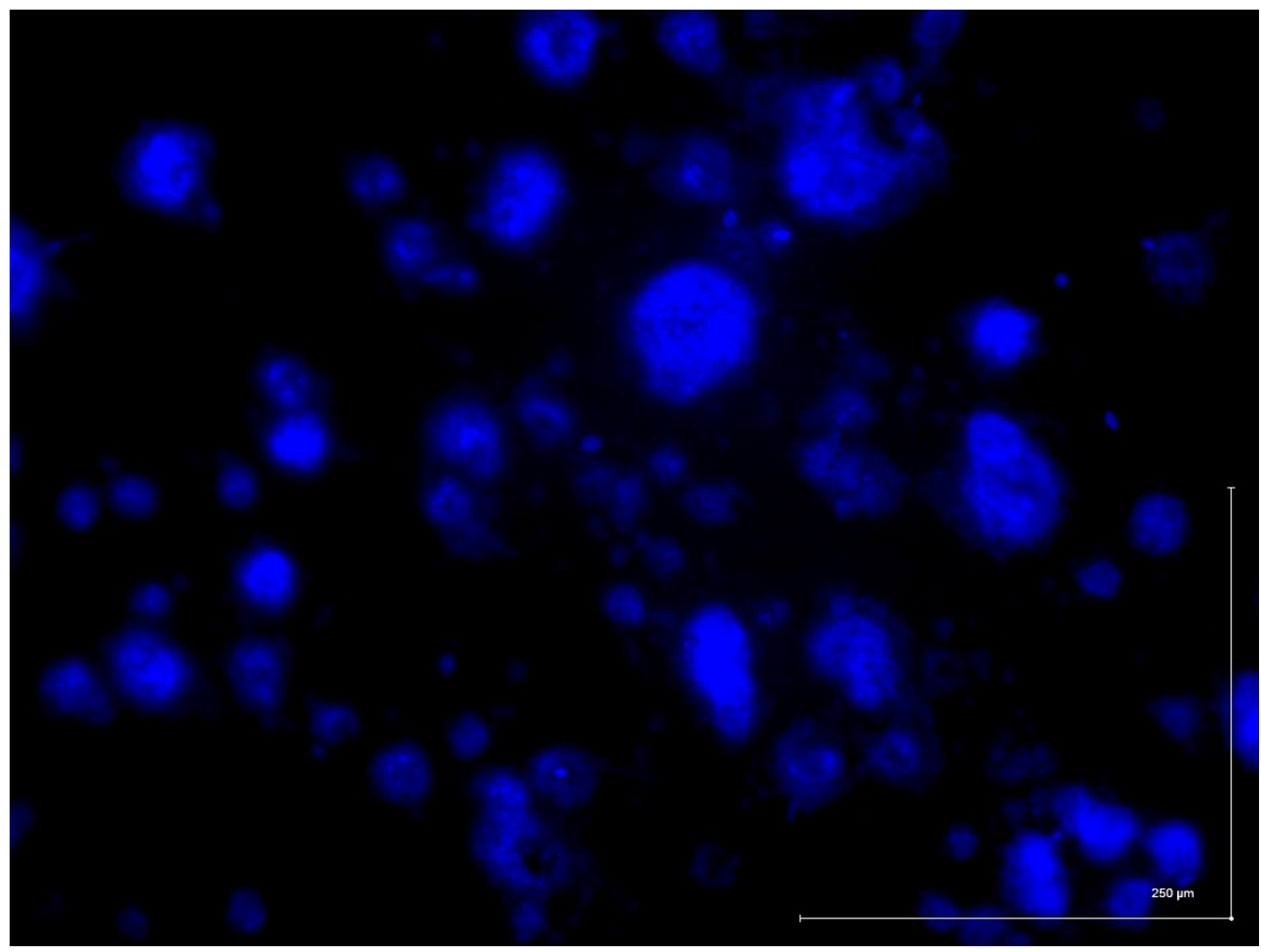

Abbildung 27: Zirkoniumdioxid, Fluoreszenzmikroskopische Aufnahme (20-fache Vergrößerung), Hoechst 33342-Färbung

\subsubsection{Biofilmakkumulation in Abhängigkeit von der Materialalterung}

Die Plaqueakkumulation für die einzelnen Materialien in Abhängigkeit vom Alterungszustand wird in Tabelle 6 und Abbildung 28 dargestellt. Eine lediglich tendenziell höhere Biofilmmenge wurde auf den Materialien im Ausgangszustand erfasst, jedoch konnte im allgemeinen linearen gemischten Modell kein signifikanter Einfluss der Materialalterung bestätigt werden $(\mathrm{p}=0,0503)$.

Tabelle 6: Verteilung der Biofilmakkumulation auf den einzelnen Materialoberflächen [\%] in Abhängigkeit vom Alterungszustand (Median, Q1, Q2)

\begin{tabular}{|c|c|c|}
\hline & Ausgangszustand & gealtert \\
\hline BioHPP & $18,2(12,0 / 33,6)$ & $15,8(8,4 / 30,4)$ \\
\hline PEEK & $19,9(8,3 / 27,6)$ & $16,4(12,5 / 24,7)$ \\
\hline Titan & $11,2(6,1 / 20,5)$ & $8,3(4,8 / 16,2)$ \\
\hline Zirkon & $4,6(3,2 / 14,6)$ & $3,8(2,6 / 10,8)$ \\
\hline
\end{tabular}




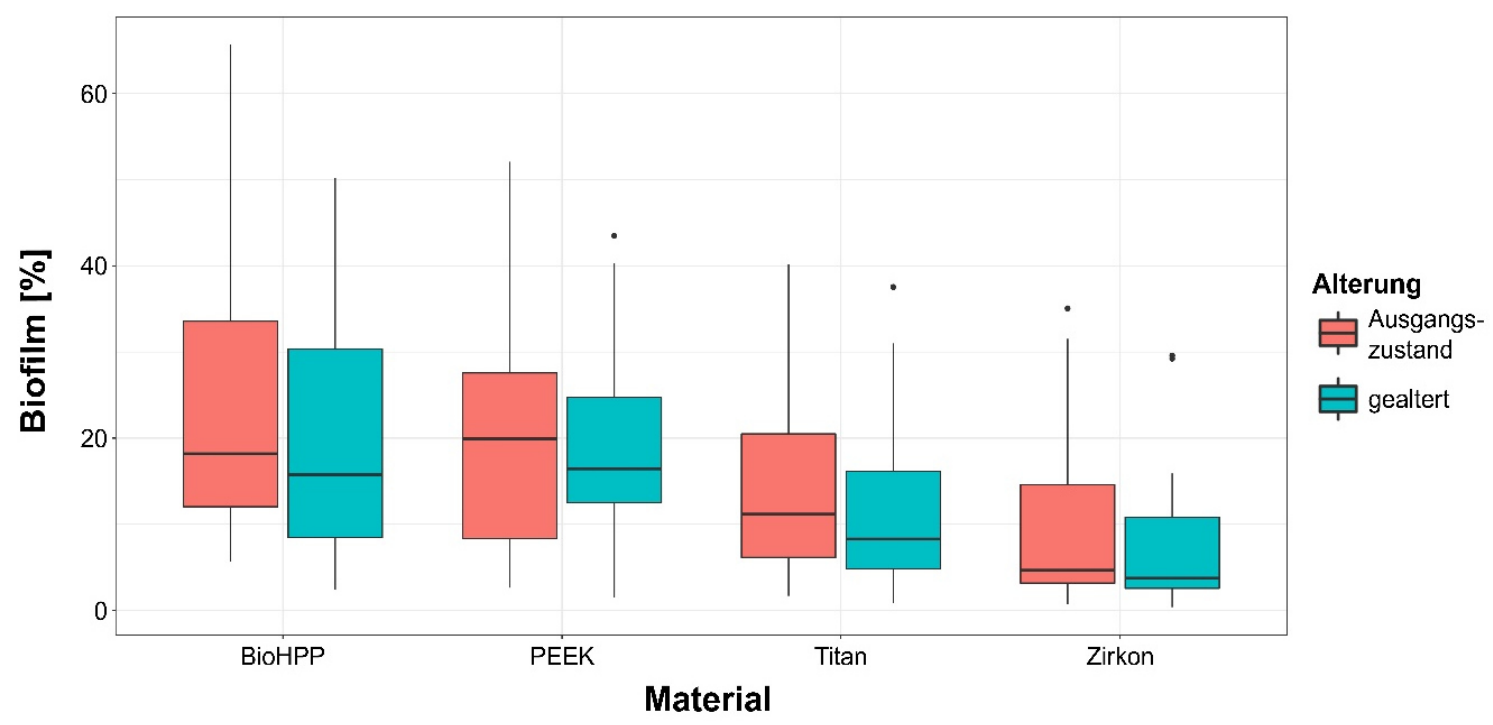

Abbildung 28: Verteilung der Biofilmakkumulation auf den einzelnen Materialoberflächen [\%] in Abhängigkeit vom Alterungszustand (Maximum, Q3, Median, Q1, Minimum)

\subsubsection{Positionsbedingte Biofilmakkumulation}

In Abbildung 29 sind die Ergebnisse für die Biofilmakkumulation in Abhängigkeit von der intraoralen Position dargestellt. Der Medianwert der Plaqueanlagerung betrug im posterioren Bereich (Molaren) 18,8 \% und im anterioren (Inzisiven) 8,9\%. Die intraorale Position der Probekörper stellte sich mit $\mathrm{p}=0,0123$ als signifikanter Einflussfaktor auf die Biofilmakkumulation dar.

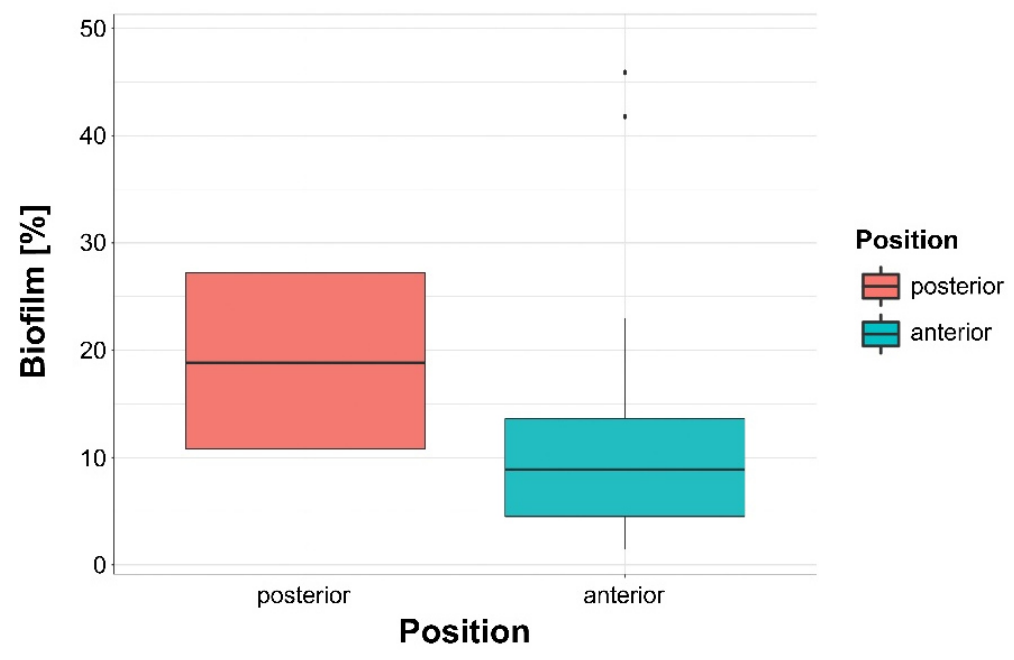

Abbildung 29: Verteilung der Biofilmakkumulation [\%] in Abhängigkeit von den intraoralen Positionen (Maximum, Q3, Median, Q1, Minimum) 


\subsubsection{Geschlechterspezifische Biofilmakkumulation}

Die geschlechterspezifische Plaqueakkumulation auf den verschiedenen Materialien wird in Tabelle 7 und Abbildung 30 dargestellt. Eine nur tendenziell höhere Biofilmmenge wurde bei den weiblichen Probandinnen erfasst, jedoch konnte im allgemeinen linearen gemischten Modell kein Einfluss des Geschlechts bestätigt werden $(p=0,079)$.

Tabelle 7: Verteilung der Biofilmakkumulation auf den einzelnen Materialoberflächen [\%] in Abhängigkeit vom Geschlecht (Median, Q1, Q2)

\begin{tabular}{|c|c|c|}
\hline & männlich & weiblich \\
\hline BioHPP & $17,7(9,3 / 23,4)$ & $21,5(14,9 / 34,9)$ \\
\hline PEEK & $15,5(11,4 / 21,5)$ & $21,2(17,0 / 25,3)$ \\
\hline Titan & $7,7(5,4 / 13,2)$ & $15,1(10,6 / 20,6)$ \\
\hline Zirkon & $3,6(3,0 / 8,4)$ & $8,6(3,2 / 15,1)$ \\
\hline
\end{tabular}

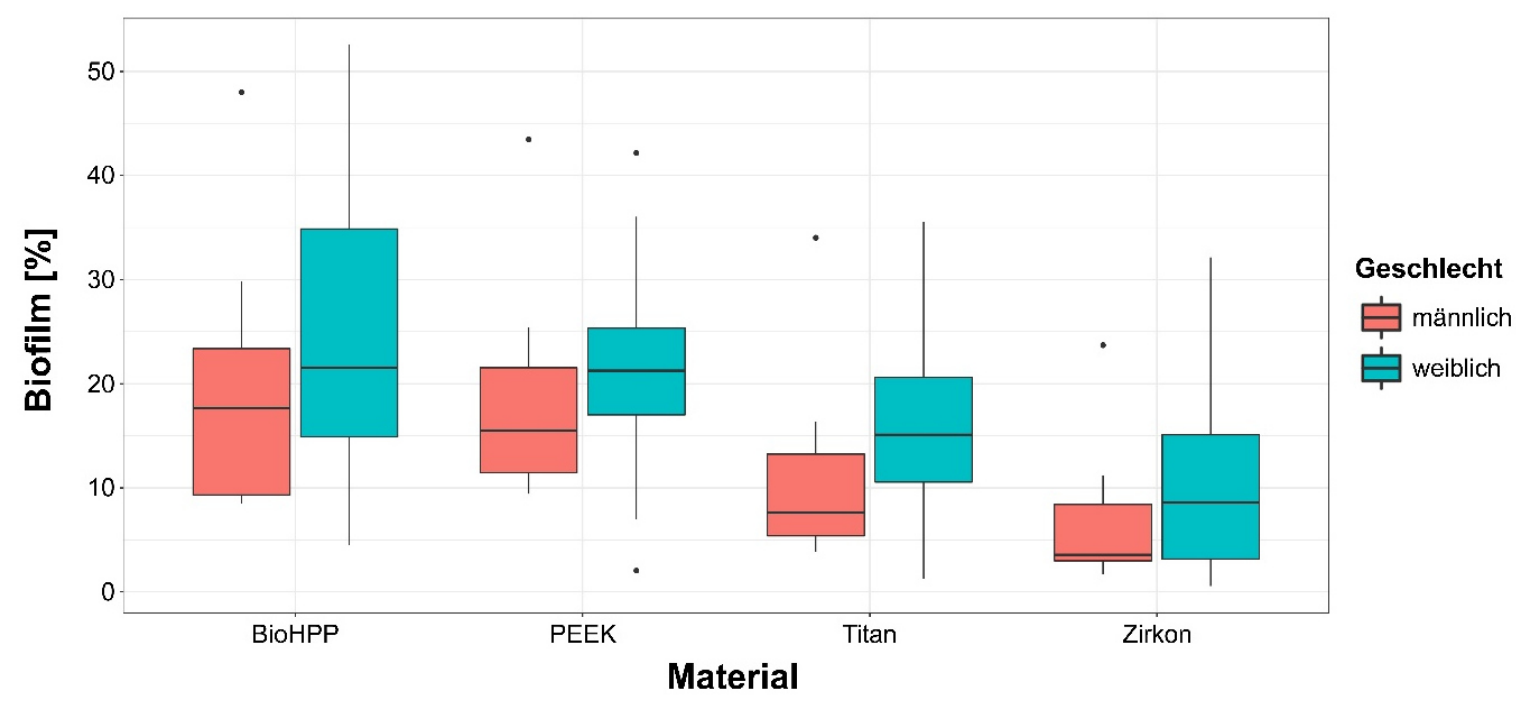

Abbildung 30: Verteilung der Biofilmakkumulation auf den einzelnen Materialoberflächen [\%] in Abhängigkeit vom Geschlecht (Maximum, Q3, Median, Q1, Minimum) 


\section{Diskussion}

\subsection{Diskussion der Methodik}

In der Literatur werden zahlreiche Studien im Zusammenhang mit der mikrobiellen Adhäsion und der Biofilmbildung auf unterschiedlichen dentalen Substraten beschrieben (Bürgers et al. 2009; 2010a; 2010b; Gosau et al. 2010; Wassmann et al. 2017; Zhang et al. 2011; Veerachamy et al. 2014; Busscher et al. 2010; Song et al. 2015; Yousif et al. 2015). Die Bildung von spezifischen Biofilmen auf oralen Hart- bzw. Weichgeweben und zahnärztlichen Restaurationen ist verantwortlich für diverse Pathogenitäten wie Karies, Parodontitis und Periimplantitis (Lewis et al. 2004; Arciola et al. 2015; Subramani et al. 2009; Pierce et al. 2017). Orale Biofilme können sowohl in vitro als auch in vivo untersucht werden (Lebeaux et al. 2013). In-vitro-Untersuchungen werden in künstlicher Umgebung unter standardisiertem Versuchsaufbau durchgeführt, was einerseits zum Ausschluss zahlreicher Störfaktoren und andererseits zu einer hohen Reproduzierbarkeit führt (Coenye und Nelis 2010; McBain 2009). In-vivo-Untersuchungen hingegen werden benötigt, um hochkomplexe Abläufe wie beispielsweise intraorale Stoffwechselprozesse innerhalb eines lebenden Organismus möglichst realitätsnah $\mathrm{zu}$ analysieren und um bereits in vitro entwickelte Strategien hinsichtlich ihrer Wirkung im Patienten abzusichern (Wimpenny 1997; Lebeaux et al. 2013; Coenye und Nelis 2010). Die Invivo-Methodik ist deutlich aufwendiger und wird durch viele individuelle, teilweise unkontrollierbare Faktoren beeinflusst.

In der Zahnmedizin erschweren die interindividuellen Unterschiede bezüglich Mundhygiene, Speichelflussrate und -zusammensetzung, Medikamenteneinnahme oder Grunderkrankungen die Vergleichbarkeit und Interpretation der Ergebnisse, weshalb die Festlegung von Ein- und Ausschlusskriterien vor Studiendurchführung von besonderer Relevanz ist (Jentsch et al. 2014; do Nascimento et al. 2013; Lebeaux et al. 2013). Aus diesem Grund erfolgte vor Durchführung der Untersuchung in Anlehnung an die Studien von Papavasileiou (2013) und Malinksi (2017) eine standardisierte klinische Voruntersuchung (Anamnese, Mundhygiene-Indizes etc.) der ProbandInnen. Die definierten Ausschlusskriterien umfassten eine vorhandene oder überstandene Tumorerkrankung mit Radiatio im Kopf-/Halsbereich, Xerostomie, eine antibiotische Therapie in den letzten zwei Monaten, keine Vollbezahnung und eine unzureichende Mundhygiene $(\mathrm{SBI}>10 \%, \quad \mathrm{API}>35 \%)$. All diese Kriterien beeinflussen die 
Zusammensetzung des oralen Mikrobioms und können die Studienergebnisse verfälschen (Sarapur und Shilpashree 2012; Bardow et al. 2001; Preoteasa et al. 2014). Die Vielzahl an unterschiedlichen und abweichenden Fragestellungen bezogen auf eine hohe Anzahl von unterschiedlichen Testmaterialien hat bisher die Etablierung eines Goldstandards in der Untersuchung von Potentialen zur Anlagerung von oralen Biofilmen bzw. antimikrobiellen Substratwirkungen verhindert (Lebeaux et al. 2013). Die vorliegende Invivo-Studie untersuchte die intraorale Biofilmbildung auf verschiedenen implantatprothetischen Werkstoffen und beschäftigte sich auch mit dem Einfluss der Positionierung von Probekörpern und dem Einfluss der Alterung von Testmaterialien auf die Anlagerung von oralen Biofilmen. Das Studiendesign mit in situ getragenen Schienen und mit integrierten Probekörpern der zu untersuchenden Werkstoffe orientierte sich an bereits in der Poliklinik für Zahnärztliche Prothetik der Universitätsmedizin Göttingen etablierten Untersuchungen (Wehle 2004; Malinski 2017).

\subsubsection{Probandenanzahl}

Die vorliegende Studie umfasste eine Gesamtzahl von 20 ProbandInnen (10 weibliche und 10 männliche). Der Einschluss von weiteren ProbandInnen hätte eventuell zu einer Verbesserung der statistischen Aussagekraft führen können. Die aufwendige Herstellung der Probekörper und Trägerschienen unterlag einem ausgesprochen zeitintensiven Prozess. Die Probandenzahl orientierte sich an ähnlichen Studien mit vergleichbarem Studienprofil (Bürgers et al. 2010a; Gosau et al. 2010; Malinski 2017; Papavasileiou et al. 2015; Scarano et al. 2013; Arweiler et al. 2004; Prada-López et al. 2015; Hannig et al. 2004). Zudem zeigt die Studienlage zahlreiche Forschungsarbeiten mit einer geringeren Personenanzahl. Beispielsweise untersuchten Arweiler et al. (2004) bei lediglich acht ProbandInnen die dreidimensionale Struktur und Vitalität des Biofilms. Dafür wurde über einen Zeitraum von 48 Stunden die intraorale Biofilmbildung an verschiedenen Positionen beobachtet. In einer Studie von Bürgers et al. (2010a), die sowohl eine Invitro- als auch eine In-vivo-Untersuchung beinhaltete, wurde die initiale Biofilmbildung auf zwei unterschiedlichen Titan-Implantatoberflächen bei sechs Versuchspersonen begutachtet. Prada-López et al. (2015) wählten für eine In-vivo-Studie 15 ProbandInnen aus, um die antibakterielle Wirkung auf den oralen Biofilm zweier antiseptischer Mundspüllösungen miteinander $\mathrm{zu}$ vergleichen. Scarano et al. (2004) untersuchten anhand von zehn StudienteilnehmerInnen die bakterielle Adhäsion auf Titan- und Zirkoniumdioxid-Probekörpern und verglichen diese miteinander. 


\subsubsection{In-vivo-Biofilmmodell}

Zur Gewinnung und anschließenden Quantifizierung des Biofilms ist es besonders wichtig, eine schonende Methode zu verwenden und somit einer Zerstörung der besonders feinen und empfindlichen Struktur des Biofilms entgegenzuwirken (Robinson et al. 1997). Für die Untersuchung der interzellulären Kommunikation und metabolischen Aktivität ist die Aufrechterhaltung der dreidimensionalen Struktur des Biofilms unabdingbar (Kuramitsu et al. 2007; Mahajan et al. 2013). In früheren In-vivo-Studien wurde die Plaque mit Handinstrumenten oder Papierspitzen mechanisch vom Zahn entfernt, wodurch es zu einer sofortigen Zerstörung der ursprünglichen Struktur des mikrobiellen Films kam (Arweiler et al. 2001; Netuschil et al. 1989). Die im nachfolgenden Abschnitt aufgeführten Untersuchungen beschäftigten sich mit dieser Problematik und entwickelten unterschiedliche Methoden zur schonenden Gewinnung dentaler Plaque. So nutzte Theilade (1964) für die Beobachtung der intraoralen Plaqueanlagerung dünne Kunststofffolien und befestigte diese an den Schneidezähnen der ProbandInnen. In den In-vivo-Studien von Brecx et al. $(1981 ; 1983)$ wurden dafür hingegen sogenannte Plast-Spray-Filme auf die Zähne gesprüht. Meyerowitz et al. (1991) entwarfen eine Trägervorrichtung ähnlich dem kieferorthopädischen Bracketsystem, das adhäsiv mittels der invasiven Säure-Ätz-Technik an die vestibulären Flächen der oberen Molaren angebracht wurde. Die drei aufgeführten Trägersysteme haben die Gemeinsamkeit, dass die benetzte Oberfläche ungeschützt vor exogenen Einflüssen in der Mundhöhle freilag und der Biofilm durch Scherkräfte von Zungen- oder Wangenbewegungen zerstört werden konnte. Außerdem bestand die Gefahr eines Ablösens und einer möglichen Aspiration der Trägermaterialien. Alle drei Methoden ließen sich nicht aus der Mundhöhle ausgliedern, wodurch einer angemessenen Mundhygiene während der Tragezeit nicht nachgegangen werden konnte. Zahlreiche Studien versuchten diese Probleme zu umgehen und nutzten herausnehmbare Trägersysteme. So stellten zum Beispiel Baier und Glantz (1978) oder Macpherson et al. (1990) zur Gewinnung der intraoralen Plaque herausnehmbare UnterkieferKunststoffschienen her. In der Studie von Leonhardt et al. (1995) bestanden die herausnehmbaren Trägersysteme aus Cobalt-Chrom und wurden im Oberkiefer eingesetzt. Auch Thomson et al. (1996) nutzten Modellgussschienen als Trägersysteme für die Analyse von intraoralen Stoffwechselprozessen. Analog zu den Studien von Gosau et al. (2010), Wehle (2004) und Malinski (2017) kamen in der vorliegenden klinischen Untersuchung tiefgezogene Kunststoffschienen als Trägersysteme zum 
Einsatz. Das Schienendesign stellte eine standardisierte und kostengünstige Variante zur intraoralen Fixation von Probekörpern dar. Durch den retentiven Einlass der Probekörper in die Kunststoffschienen konnte von invasiven Maßnahmen abgesehen werden. Zudem wurden die Probekörper bukkal in eine Fassung eingebracht, um die Substratoberflächen vor dem direkten mechanischen Abrieb durch Wange und Zunge und vor den Scherkräften des Speichels zu schützen (Gosau et al. 2010; van der Weijden et al. 2015). Das Ein- und Ausgliedern der Schiene im Oberkiefer war sowohl zur Nahrungsaufnahme als auch für Mundhygienemaßnahmen möglich ohne die Biofilmstruktur zu verändern.

\subsubsection{Intraorale Verweildauer}

Im Rahmen der Vorversuche für die vorliegende Studie wurde die Verweildauer der Probekörper in situ festgelegt. In der Literatur ist keine einheitliche Angabe zur intraoralen Exposition der Werkstoffe zu finden und variiert in Abhängigkeit von Fragestellung und Testmaterialien zwischen wenigen Sekunden und mehreren Tagen (Baier und Glantz 1978; Auschill et al. 2002). Der Grund für die individuelle Festlegung der intraoralen Expositionszeit ist die große Zeitspanne, in der die Biofilmbildung stattfindet: zwischen wenigen Minuten durch Anhaftung der frühkolonisierenden Keime und zwei Wochen bis zur Ausreifung der Plaque (Hellwig et al. 2013). Werden beispielsweise die initialen mikrobiellen Adhäsionsprozesse untersucht, ist eine kürzere Tragezeit von bis zu 24 Stunden sinnvoll (Bürgers et al. 2010a; do Nascimento et al. 2014; Wehle 2004; Malinski 2017). So können auch Unterschiede im initialen Adhäsionsverhalten besser beobachtet werden, weil bei längeren Tragezeiten und fehlender Mundhygiene alle Flächen komplett besiedelt wären. Vor allem kann dadurch der Einfluss des Substrats, d. h. Unterschiede im Potential zur Adhäsion von Biofilmen, besser differenziert werden, weil Adhäsionsphänomene wie Koadhäsion noch keine große Rolle spielen. Die durchgeführte Untersuchung beschäftigte sich mit der initialen Biofilmbildung auf implantatgetragenen Werkstoffen, sodass in Anlehnung an do Nascimento et al. (2014) und Scarano et al. (2004) eine Tragedauer von 24 Stunden festgelegt wurde. Um eine realistische Abschätzung auf die klinische Situation zuzulassen, ist es wichtig, auch die regelmäßige Mundhygiene mit einzuplanen. Diese sollte mindestens ein- bis zweimal täglich suffizient erfolgen; auch deswegen erscheinen Beobachtungszeiträume für die Anlagerung von Biofilmen zwischen 12 und 24 Stunden sinnvoll. 


\subsubsection{Rauheitsmessung}

In der vorliegenden Studie wurden die Rauheitsmessungen zur Ermittlung der Oberflächentopographie mittels der optischen Weitfeld-Konfokalmikroskopie durchgeführt. Diese Methodik ermöglichte, neben der schnellen und präzisen Erhebung der profil- $\left(\mathrm{R}_{\mathrm{a}}\right)$ und flächenbezogenen $\left(\mathrm{S}_{\mathrm{a}}\right)$ arithmetischen Mittenrauwerte, die dreidimensionale Darstellung der Oberflächentopographie. Der Parameter $\mathrm{R}_{\mathrm{a}}$ findet zur Bestimmung des Rauheitsprofils in der Literatur die häufigste Anwendung, beschreibt jedoch die Oberflächentopographie nicht vollständig und reagiert bei starken Diskrepanzen wenig sensitiv (Goodhand et al. 2016; Gadelmawla et al. 2002). Die flächenbezogene mittlere arithmetische Höhe $S_{a}$ stellt hingegen die gesamte Oberflächentopographie dar und kann zudem verlässlich durch optische Messverfahren erfasst werden (Haus 2014). Im Rahmen ähnlicher Forschungsprojekte der Poliklinik für Zahnärztliche Prothetik der Universitätsmedizin Göttingen fand ebenfalls die optische Weitfeld-Konfokalmikroskopie Anwendung und konnte sich seither erfolgreich etablieren (Schubert et al. 2019a; Elle 2018; Kurbad 2019). Um den Einfluss der Rauheit auf die mikrobielle Akkumulation auszuschließen, wurden bereits zu Beginn der Studie Rauheitsmessungen der Materialien nach Politur und artifizieller Alterung durchgeführt und deren Auswertung zeigte keine signifikanten Unterschiede. Als alternatives optisches Messverfahren kam zur Ermittlung der Oberflächenrauheit in ähnlichen Untersuchungen die Rasterelektronenmikroskopie zum Einsatz (Roehling et al. 2017; Scarano et al. 2004). Wie bereits im Abschnitt 2.2 beschrieben, könnten Rauheitsmessungen auch durch taktile Messmethoden erfolgen (Zhang et al. 2013; Wang et al. 2015; Crawford et al. 2012; Park et al. 2015). Für die zweidimensionale Rauheitsdarstellung und die Erfassung des arithmetischen Mittenrauwerts $\mathrm{R}_{\mathrm{a}}$ gilt das taktile Tastschnittverfahren in der Literatur als Standard (Kocher et al. 2002; Gevatter und Grünhaupt 2006; Keferstein und Marxer 2015). Diese Methodik zur Rauheitsmessung führten zahlreiche Forschungsgruppen mit einem ähnlichen Studiendesign zur vorliegenden Studie durch, um die zweidimensionale Topographie der Probekörper vor intraoraler Exposition zu analysieren (Bürgers et al. 2010a; 2010b; Scarano et al. 2004; Grössner-Schreiber et al. 2009; Rimondini et al. 2002; Hahnel et al. 2014). Taktile Messverfahren besitzen den Nachteil, dass sie zu einer Veränderung der Oberflächenstruktur führen können und deutlich zeitintensiver als optische Messverfahren sind (Tan 2016; Bhushan 2001). Bezüglich der Messgenauigkeit weisen die taktilen und optischen Methoden kaum Unterschiede auf (Vorburger et al. 2007). 


\subsubsection{Untersuchung des Biofilms / Versuchsauswertung}

In der durchgeführten Studie erfolgte die Visualisierung des Biofilms durch das Anfärben mittels des Fluorochroms Hoechst 33342 zur anschließenden Analyse unter einem Fluoreszenzmikroskop (Keyence BZ-X710). Der Farbstoff Hoechst 33342 ist zellmembrangängig und bindet an die DNA von vitalen und avitalen Zellen (Chazotte 2011; Zurek-Biesiada et al. 2013). Eine Alternative stellt das Fluorochrom DAPI (4',6Diamidin-2-phenylindol) dar, jedoch weist es im Vergleich zu Hoechst 33342 eine schlechtere Zellpermeabilität auf, weshalb die DAPI-Färbung hauptsächlich bei avitalen oder beschädigten Zellen Anwendung findet (Mulisch und Nixdorf-Bergweiler 2015). Beide Farbstoffe bieten eine relativ schnelle und einfache Visualisierung von Biofilmen, allerdings ohne eine Differenzierung zwischen einzelnen Bakterienarten oder dem Vitalitätszustandes der Mikroorganismen zu ermöglichen (Hannig et al. 2010). Das Studiendesign der vorliegenden Studie jedoch zielte lediglich auf die Quantifizierung des gesamten Biofilms ab, sodass von einer Unterscheidung zwischen intakter und beschädigter Zellmembran mittels einer Lebend/Tod-Färbung oder einer Analyse unterschiedlicher Bakterienstämme durch das FISH-Verfahren abgesehen wurde (Decker 2001; Al-Ahmad et al. 2009; Bottari et al. 2006; Wuertz et al. 2004). Diese Methoden eignen sich insbesondere bei Untersuchungen von antimikrobiell wirksamen Substanzen und Oberflächen und haben sich bereits im Rahmen zahlreicher Studien als sehr praktikabel erwiesen (Bürgers et al. 2009; Gosau et al. 2010; 2013; Azeredo et al. 2017). Sie könnten in entsprechenden Folgestudien Anwendung finden. Die angewandte Fluoreszenzmikroskopie, auch Epifluoreszenzmikroskopie genannt, ist eine Sonderform der Lichtmikroskopie, in dem Fluoreszenzfarbstoffe (Fluorochrome) durch UV- und kurzwelliges Licht angeregt werden und dadurch längerwelliges Licht emittieren (Cypionka 2010). Eine Alternative stellt die konfokale Laser-Scanning-Mikroskopie (CLSM) dar. Sie nutzt ebenfalls das Prinzip der Fluoreszenz, jedoch wird hierbei die Probenoberfläche mittels eines fokussierten Laserstrahls abgerastert, dabei die Fluorochrome angeregt und das reflektierte Licht hinter einer feinen Lochblende von einem Detektor erfasst. Laterales Streulicht wird somit eliminiert und die Auflösung der Aufnahmen erhöht (Cox und Sheppard 2004; Lichtman und Conchello 2005). Zudem können mit der CLSM einzelne Ebenen erfasst und $\mathrm{zu}$ einer dreidimensionalen Darstellung der mikrobiellen Struktur zusammengesetzt werden (Diaspro et al. 2013; Cypionka 2010). Eine weitere Methode zur Analyse von Biofilmen stellt die Rasterelektronenmikroskopie (REM) dar, bei der ein beschleunigter Elektronenstrahl die 
Oberfläche abtastet und so ebenfalls eine dreidimensionale Aufnahme der Oberflächenstruktur ermöglicht und zudem die Ultrastruktur der Mikroorganismen visualisiert (Hannig et al. 2010). Allerdings findet der Prozess im Hochvakuum statt und setzt eine elektrisch leitende Probenoberfläche voraus, weshalb eine aufwendige Vorbehandlung des Biofilms durch Fixierung, Dehydratation und Beschichtung mit einer leitenden Substanz erforderlich ist (Samson et al. 1979; Fischer et al. 2012). Hierbei kann es zur Beschädigung der ursprünglichen Biofilmstruktur kommen (Fischer et al. 2012). Außerdem ist mit dieser Methode keine Unterscheidung zwischen vitalen und avitalen Zellen möglich. $\mathrm{Da}$ in der vorliegenden Untersuchung die quantitative Biofilmakkumulation unabhängig von der Zellvitalität sowie Keimart von Interesse war, stellte eine Auswertung mittels des Farbstoffes Hoechst 33342 und Fluoreszenzmikroskopie eine zügige, unkomplizierte und vergleichsweise kosteneffektive Methode dar. Eine Limitation dieser Methode stellt die Vernachlässigung der dreidimensionalen Komponente der hochkomplexen Biofilmstruktur dar, sodass lediglich die zweidimensionale Analyse des Biofilms erfolgte und keine Differenzierung bezüglich der Pathogenität der Mikroorganismen möglich war (Magana et al. 2018; Azeredo et al. 2017).

\subsection{Diskussion der Ergebnisse}

\subsubsection{Rauheit}

Im Rahmen der vorliegenden Studie wurde die materialspezifische Biofilmakkumulation auf verschiedenen Werkstoffen untersucht und miteinander verglichen, weshalb die Bestimmung der Rauheitsparameter bereits vor Durchführung der Studie von besonderer Relevanz war. Die durch die Rauheitsmessungen ermittelten Medianwerte lagen bei allen Materialoberflächen sowohl für den Parameter $R_{a}$ als auch für den Parameter $S_{a}$ bei $<0,2 \mu \mathrm{m}$, sodass ein materialspezifischer Vergleich der Plaqueanlagerung adäquat durchgeführt werden konnte. Zudem konnte zwischen den einzelnen Materialien kein signifikanter Unterschied der Topographien ermittelt werden.

Zahlreiche vorausgegangene Studien beschreiben den direkten Einfluss der Oberflächenrauheit auf die Adhäsion und Reifung von dentalen Biofilmen (Elter et al. 2008; Rimondini et al. 1997). Beispielsweise verglichen Bürgers et al. (2010a) in vivo die 
Biofilmbildung auf säuregeätzten Titanoberflächen $\left(\mathrm{R}_{\mathrm{a}}=0,95 \mu \mathrm{m}\right)$ mit sandgestrahlten Titanoberflächen $\left(\mathrm{R}_{\mathrm{a}}=0,15 \mu \mathrm{m}\right)$ und konnten hierbei eine signifikant höhere mikrobielle Anlagerung auf der raueren Oberfläche feststellen. Diese Studie bestätigte neben zahlreichen weiteren Untersuchungen, dass die Topographie der Materialien die Biofilmakkumulation unmittelbar beeinflusst (Al-Ahmad et al. 2010; Scarano et al. 2004; Elter et al. 2008; Teughels et al. 2006). Größere topographische Unebenheiten führen zu einer verstärkten initialen Bakterienanlagerung, beschleunigen den Wechsel der reversiblen in die irreversible Adhäsion und beeinflussen die Quantität sowie Qualität des adhärierten Biofilms (Bürgers et al. 2010c). In der Literatur wird ein Schwellenwert von $\mathrm{R}_{\mathrm{a}}=0,2 \mu \mathrm{m}$ angegeben, unter dem Rauheiten von Titanoberflächen keinen weiteren Einfluss auf die mikrobielle Akkumulation aufweisen (Bollen et al. 1997; Quirynen et al. 1996).

\subsubsection{Bakterielle Akkumulation}

In der durchgeführten Untersuchung zeigte sich auf der Zirkoniumdioxidoberfläche die geringste Plaqueakkumulation mit einem Medianwert von 6,52 \% gefolgt von Titan mit $11,14 \%$. Der höchste quantitative Biofilm wurde auf den Materialien BioHPP $($ Medianwert $=19,71 \%) \quad$ und $\quad$ PEEK $\quad($ Medianwert $=17,81 \%) \quad$ gemessen. $\quad$ Ein signifikanter Unterschied konnte zwischen allen Materialien außer zwischen PEEK und BioHPP gemessen werden. Beide Werkstoffe (PEEK, BioHPP) sind PEEK-basierte Materialien, weshalb der nicht signifikante Unterschied in der mikrobiellen Adhäsion für einen materialabhängigen Einfluss spricht.

Während in der Literatur bereits zahlreiche vergleichbare Studien die Biofilmbildung auf Titan- und Zirkoniumdioxidoberflächen analysiert haben, ist der Umfang der Datenlage bezüglich PEEK-basierter Werkstoffe deutlich geringer. Dies ist auch erstaunlich, weil das Material von fast allen Herstellern als besonders biokompatibel und mit niedriger Tendenz zur Biofilmakkumulation angepriesen wird. Ein direkter Vergleich der Biofilmakkumulation zwischen dem Basismaterial PEEK und BioHPP ist bislang nicht durchgeführt worden. Ein Großteil der Studien beschäftigte sich lediglich mit dem Wachstum von Erregern, die bei orthopädischen Infektionen pathogene Veränderungen hervorrufen, da PEEK bereits seit langer Zeit in der Allgemeinmedizin ein breites Anwendungsspektrum bedient (Rochford et al. 2014; Barton et al. 1996). In der Zahnmedizin gilt PEEK jedoch eher als zukunftsträchtiges Material, weshalb sich bislang deutlich weniger Studien mit der oralen Biofilmakkumulation auf diesem Werkstoff 
befasst haben. So untersuchten Volpe et al. (2008) in einer In-vivo-Untersuchung die Konzentration und Variabilität von paropathogenen Keimen an Titan- und PEEKAbutments sowohl oberflächlich als auch zirkulär im Sulkus. Die Probenentnahme erfolgte lokalisiert mit einer Papierspitze, an der lediglich eine sehr kleine Bakterienmenge haften kann, sodass die Ergebnisse mit Vorsicht interpretiert werden müssen. Im Rahmen der Auswertung mittels Echtzeit-Polymerase-Kettenreaktion kam es weder zu einem quantitativen noch zu einem qualitativen Unterschied in der bakteriellen Akkumulation auf beiden Abutmentmaterialien (Volpe et al. 2008). Diese Auswertungsmethode eignet sich insbesondere für den Nachweis einzelner Bakterienstämme, jedoch weniger für die Bestimmung der prozentualen Oberflächenbesiedelung, die in der vorliegenden Studie im Vordergrund stand, wodurch die verschiedenen Ergebnisse zustande gekommen sein können (Azeredo et al. 2017). Die Datenlage $\mathrm{zu}$ In-vitro-Untersuchungen und dem Werkstoff PEEK hingegen ist umfangreicher. Beispielsweise verglichen Hahnel et al. (2014) die Biofilmbildung auf PEEK-, Titan- und Zirkoniumdioxid-Abutments in vitro. Hierbei kam es nach einer Expositionszeit von 20 Stunden $\mathrm{zu}$ einer signifikant niedrigeren Anlagerung lebender Mikroorganismen auf den PEEK- als auf den Titan- und Zirkoniumdioxid-Abutments. Nach 44 Stunden konnte hingegen kein signifikanter Unterschied zwischen den einzelnen Materialien mehr festgestellt werden (Hahnel et al. 2014). Im Gegensatz zur durchgeführten Studie wurden jedoch Probekörper mit unterschiedlicher Oberflächenrauheit verwendet: die Oberfläche der PEEK-Probekörper war im Vergleich zu den Titan- und Zirkoniumdioxid-Probekörpern signifikant glatter, was eine Beeinflussung der Ergebnisse bewirkt haben könnte und bereits durch zahlreiche Studien belegt wurde (Elter et al. 2008; Rimondini et al. 1997). Barkarmo et al. (2019) untersuchten, ebenfalls in vitro, die Biofilmbildung von häufig in der oralen Plaque anzutreffenden Keimen wie Streptococcus sanguinis, Streptococcus oralis, Enterococcus faecalis und Streptococcus gordonii auf vier unterschiedlichen Materialien. Hierzu zählten neben PEEK und sandgestrahltem PEEK noch Reintitan (cp-Ti) und eine Titanlegierung $\left(\mathrm{Ti}_{6} \mathrm{Al}_{4} \mathrm{~V}\right)$. Das sandgestrahlte PEEK wies im Vergleich zu den anderen Materialien sowohl in der mikrobiellen Akkumulation als auch in der Oberflächentopographie signifikant höhere Werte auf. Zwischen dem herkömmlichen PEEK, cp-Ti und $\mathrm{Ti}_{6} \mathrm{Al}_{4} \mathrm{~V}$ konnten weder in der Bakterienanlagerung noch in der Oberflächenrauheit signifikante Unterschiede gemessen werden. Somit bestätigten auch Barkarmo et al. (2019) in ihrer Studie den positiven Einfluss einer geringeren 
Oberflächenrauheit auf die Biofilmakkumulation. Da es sich bei einem oralen Biofilm um eine hochkomplexe Struktur handelt, die sich aus verschiedensten Erregern zusammensetzt und Barkarmo et al. (2019) nur einzelne Bakterien separat voneinander und mit einer Inkubationszeit von bis zu 120 Stunden unter Ausschluss intraoraler Störfaktoren kultivierten, ist eine Gegenüberstellung der Ergebnisse mit der vorliegenden Studie nur eingeschränkt möglich. Die in der durchgeführten Untersuchung ermittelten größeren Biofilmmengen auf den PEEK-Oberflächen können neben der Rauheit auch durch weitere oberflächenspezifische Eigenschaften beeinflusst worden sein. So beschreibt die Literatur, dass neben der Oberflächenrauheit auch die Hydrophobizität und die freie Oberflächenenergie eine Rolle bei der bakteriellen Adhäsion spielen (Quirynen et al. 1990; Quirynen und Bollen 1995; Rimondini et al. 1997). PEEK-Oberflächen besitzen im Vergleich zu Titan und Zirkoniumdioxid eine höhere freie Oberflächenenergie (Hahnel et al. 2014; Barkarmo et al. 2019). Eine Messung der freien Oberflächenenergie war in der vorliegenden Studie allerdings nicht möglich, da die Durchmesser der einzelnen Materialien zu klein waren und andere oberflächenspezifische Eigenschaften zur Beurteilung der Ergebnisse nicht hinzugezogen werden konnten.

In Bezug auf die Biofilmbildung auf Zirkoniumdioxid- und Titanoberflächen liegen zahlreiche vergleichbare Studien mit ähnlichen Ergebnissen vor. Rimondini et al. (2002) analysierten sowohl in vitro als auch in vivo die Adhäsion oraler Mikroorganismen auf Titan- und Zirkoniumdioxidoberflächen. Bei der Auswertung mittels Rasterelektronenmikroskopie wurde ebenfalls eine signifikant niedrigere Biofilmakkumulation auf Zirkoniumdioxid im Vergleich zu Titan erfasst (Rimondini et al. 2002). Sowohl Scarano et al. (2004) als auch do Nascimento et al. (2014) untersuchten, ähnlich dem vorliegenden Studiendesign, die bakterielle Anlagerung auf Probekörpern aus Titan und Zirkoniumdioxid in vivo mittels Kunststoffschienen bei einer Tragezeit von 24 Stunden. In beiden Studien wiesen die Zirkoniumdioxidoberflächen eine signifikant niedrigere mikrobielle Adhäsion auf. Das im Vergleich zu anderen Materialien niedrigere mikrobielle Adhäsionsverhalten der Zirkoniumdioxidoberfläche ist womöglich auf die spezifische chemische Beschaffenheit und die daraus hervorgehende elektrische Leitfähigkeit zurückzuführen (Al-Radha et al. 2012). Außerdem weist Zirkoniumdioxid gegenüber anderen Materialien die geringste Oberflächenenergie auf (Hahnel et al. 2014; Salihoglu et al. 2011; de Oliveira et al. 2012). Dennoch gibt es Studien, bei denen kein signifikanter Unterschied zwischen den an den 
Materialoberflächen anhaftenden Biofilmmassen gemessen werden konnte (Roehling et al. 2017; Souza et al. 2016).

Die unterschiedlichen Ergebnisse der Studien mit ähnlichen Forschungszielen lassen sich unter anderem damit begründen, dass zur Gewinnung von dentalem Biofilm verschiedenste (Labor-) Bedingungen Anwendung fanden. Ein grundlegender Unterschied liegt beispielsweise in der In-vitro-Durchführung unter optimalen Laborbedingungen oder der In-vivo-Ausführung unter Einbezug zahlreicher klinischer Aspekte. Zusätzlich stehen heutzutage eine Vielzahl von Auswertungsmethoden zur Verfügung, was den Vergleich der Studienergebnisse miteinander erschwert. Zur allgemeinen Quantifizierung des Biofilms beziehen sich einige Studien auf die Anzahl von Bakterien während in der vorliegenden Studie die Biofilmbedeckung der Probekörper in \% angegeben wurde. Durch den Vergleich der Medianwerte (in \%) konnten signifikante Unterschiede gut und übersichtlich dargestellt werden. Außerdem wurde die Komplexität des Biofilms nicht außer Acht gelassen, indem lediglich einzelne Bakterienstämme analysiert wurden. Diese Methodik hat sich bereits in vorausgegangenen Studien bewährt (Wehle 2004; Malinski 2017).

\subsubsection{Artifizielle Alterung}

In der durchgeführten Studie hatte die artifizielle Alterung mittels Thermolastwechselverfahren weder auf die mikrobielle Adhäsion noch auf die Oberflächenrauheit der Materialien einen signifikanten Einfluss. Festgestellt wurde lediglich eine tendenziell vergrößerte Rauheit der Oberflächen während die mikrobielle Ablagerung unsignifikant abnahm.

Da Rocha et al. (2020) und Rigolin et al. (2019) untersuchten in vitro sowohl die Biofilmbildung als auch die Oberflächenrauheit auf Titan- und Zirkoniumdioxidprobekörpern im Ausgangszustand und nach einem künstlichen Alterungsprozess mittels Autoklav. In der Studie durch da Roche et al. (2020) konnte ebenfalls kein Einfluss der künstlichen Alterung auf den Materialoberflächen feststellt werden. Rigolin et al. (2019) hingegen ermittelten nach Materialalterung eine verstärkte Biofilmreifung auf dem Zirkoniumdioxid und einer raueren Titanoberfläche. Die erhöhte Rauheit könnte auf eine verstärkte Bildung einer Titandioxid-Schicht zurückgeführt werden. Vergleichbare Studien für PEEK und weitere für Titan im direkten Vergleich zu Zirkoniumdioxid bezüglich Materialalterung im Zusammenhang mit der Biofilmakkumulation sind in der Literatur nicht angegeben. 
Gegebenenfalls waren die in der aktuellen Studie durchgeführten 5000 Zyklen im Thermocycler nicht ausreichend, um einen statistisch signifikanten Alterungseffekt und eine hieraus resultierende Veränderung der Biofilmanlagerung auf den Materialien zu verursachen. Da 10000 Zyklen eine intraorale Verweildauer von einem Jahr simulieren, entsprechen 5000 Zyklen theoretisch einer Expositionszeit von lediglich sechs Monaten (Gale und Darvell 1999; Türkmen et al. 2011). Außerdem werden die Materialien im Thermolastwechselverfahren einzig unterschiedlichen Wärmeausdehnungskoeffizienten und somit einer thermischen Belastung ausgesetzt. Die geringen Veränderungen der Oberflächentopographie nach dem Alterungsprozess können zudem auf die hohe Härte der Materialien zurückgeführt werden. Die tendenziell höhere Biofilmakkumulation auf den unbearbeiteten Probekörpern könnte auf eine „Veredelung“ der Materialoberflächen hinweisen, wie es auch bei der Abgabe von Restmonomeren bei Prothesenkunststoffen stattfindet. Es ist anzumerken, dass sowohl diese als auch weitere künstliche Alterungsverfahren nicht direkt auf die klinische Situation projiziert werden können, da intraoral neben der thermischen Beanspruchung vor allem chemische, biologische und physiologische Einflüsse auf die Materialien einwirken (Liebermann et al. 2016; Gupta et al. 2015; Gonzalez-Bonet et al. 2015).

\subsubsection{Position}

Ein signifikanter Unterschied $(p=0,0123)$ in der Biofilmakkumulation wurde in Abhängigkeit von der Lokalisation der Probekörper gemessen. Die Probekörper, die im Molarenbereich verankert wurden, wiesen eine stärkere mikrobielle Anlagerung auf (Medianwert $=18,84 \%$ ) als jene in Regio der Eckzähne (Medianwert $=8,89 \%$ ). Zahlreiche Studien berichten ebenfalls von einem Einfluss der intraoralen Lokalisation der Werkstoffe auf die Biofilmbildung (Sreenivasan et al. 2010; Sreenivasan und Prasad 2017; Haffajee et al. 2009; Quirynen et al. 1991). Sreenivasan et al. (2010) verglichen durch die Erhebung von Plaque- und Entzündungsindizes die Besiedlung von Probekörpern mit Mikroorganismen und analysierten die damit verbundenen Entzündungsprozesse im anterioren und posterioren Bereich der Mundhöhle. Auch sie beobachteten eine geringere Plaqueanlagerung in anterioren Bereichen der Oberkieferdentition. Außerdem konnte eine Korrelation höherer Entzündungswerte der Gingiva mit einer verstärkten Biofilmakkumulation im Seitenzahnbereich festgestellt werden (Sreenivasan und Prasad 2017). Weiterhin bestätigten mikrobiologische Analysen einer weiteren Studie pathogenere Keime im Molarenbereich und in der 
Unterkieferfront (Haffajee et al. 2009). Die höheren Biofilmmassen in diesen Regionen werden auf die in unmittelbarer Umgebung befindlichen Ausführungsgänge der Glandulae parotideae, submandibulares und sublinguales zurückgeführt. Durch ihre Lokalisation herrscht dort ein stetiger und verstärkter Kontakt von Speichelbestandteilen und den Zähnen, wodurch die Biofilmbildung beschleunigt wird (Palk et al. 2010; Haffajee et al. 2009; Newman et al. 1996).

Die geringere mikrobielle Belagerung der Probekörper im Bereich der Schneide- und Eckzähne des Oberkiefers lässt sich folglich durch die verringerte Exposition mit Speichelproteinen erklären. Zudem wird die Plaqueanlagerung durch die physiologische Bewegung der anliegenden Schleimhaut im Bereich der Oberlippe und der mimischen Muskulatur verringert und eine natürliche mechanische Reinigung der Bukkalflächen der Schneide- und Eckzähne des Oberkiefers unabsichtlich unterstützt (Haffajee et al. 2009). Aus den bereits vorhandenen und den in der vorliegenden Studie generierten Daten kann abgeleitet werden, dass ein Vergleich der Biofilmbildung auf verschiedenen Substraten mit abweichender Lokalisation der einzelnen Probekörper an unterschiedlichen Positionen im Mund nicht zulässig sein kann. Die Verwendung von geteilten Probekörpern - wie in der vorliegenden Studie - ist zwar deutlich aufwendiger, lässt dann aber einen Vergleich zwischen verschiedenen Testmaterialien zu.

\subsubsection{Geschlechterspezifische Unterschiede}

Das Probandenkollektiv umfasste jeweils 10 weibliche und 10 männliche TeilnehmerInnen, bei denen kein signifikanter Einfluss des Geschlechts auf die prozentuale Biofilmakkumulation auf den Probekörpern festgestellt werden konnte.

Die Studienlage bezüglich einer geschlechterspezifischen erhöhten Biofilmakkumulation ist als kontrovers $\mathrm{zu}$ beurteilen. Während einige Publikationen eine erhöhte Plaqueakkumulation bei Männern im Gegensatz zu Frauen feststellten (Micheelis und Bauch 1991; Micheelis und Borutta 1993), widerlegten wiederum andere Studien diese Annahme (Lukacs und Largaespada 2006). Gründe für eine erhöhte Biofilmbildung bei Männern können beispielsweise schlechtere Ernährungsgewohnheiten oder mangelnde Mundhygiene sein (Mamai-Homata et al. 2016; Albandar 2002; Furuta et al. 2011). Frauen hingegen haben im Vergleich zu Männern eine signifikant niedrigere Speichelflussrate (Percival et al. 1994; Eliasson et al. 2006). Durch die dadurch verringerte mechanische Reinigungswirkung sowie herabgesetzter antibakterieller 
Wirksamkeit des Speichelfluids könnte man eine erhöhte Biofilmakkumulation bei Frauen annehmen (Ferraro und Vieira 2010). Zur Gewährleistung ähnlicher Ausgangsbedingungen und somit einer geschlechterspezifischen Vergleichbarkeit, unterzogen sich im Rahmen der Studienvorbereitung alle ProbandInnen einer klinischen Voruntersuchung, bei der die Mundhygieneindizes SBI und API erhoben wurden. Die StudienteilnehmerInnen wurden vor Beginn der 24-stündigen Tragezeit über das adäquate Tragen der Schienen aufgeklärt: eine Entnahme sollte lediglich während der Mahlzeiten und zur Durchführung der häuslichen Mundhygiene erfolgen. Durch die exakte Planung der Studie und die detaillierte Instruktion der ProbandInnen vor Beginn der Tragezeit wurden, sofern bei klinischen Studien realisierbar, möglichst vergleichbare Ausgangsbedingungen geschaffen und eine nicht geschlechterspezifische Biofilmakkumulation auf den implantatgetragenen Werkstoffen erscheint evident.

\subsection{Schlussfolgerung}

Das angewandte In-vivo-Biofilmmodell und die Methodik zur Untersuchung des Biofilms auf unterschiedlichen implantatgetragenen Werkstoffen waren praktikabel und stellten sich im Vergleich zu anderen Vorgehensweisen bei gegebenem Versuchsdesign und der vorhandenen Fragestellung als adäquat dar. Die Ergebnisse der vorliegenden Studie zeigen, dass zwischen den untersuchten implantatprothetischen Materialien nach einer intraoralen Expositionszeit von 24 Stunden ein signifikanter Unterschied in der mikrobiellen Akkumulation vorliegt. Die Zirkoniumdioxidoberfläche wies hierbei im Vergleich zur Titanoberfläche und denen der Materialgruppe PEEK die geringste Biofilmmenge auf. Die größte mikrobielle Akkumulation wurde wiederum auf den Materialien PEEK und BioHPP registriert. Weiterhin wurde in der Untersuchung beobachtet, dass die Quantität des adhärierten Biofilms im Oberkiefer mit der intraoralen Positionierung der Probekörper korrelierte. Im posterioren Bereich der Oberkieferdentition lag eine signifikant größere bakterielle Adhäsion vor als im anterioren Bereich. 


\section{$5 \quad$ Zusammenfassung}

Die Bildung pathogener Biofilme auf Implantat-Abutments kann im periimplantären Gewebe eine Mukositis bzw. Periimplantitis hervorrufen und im schlechtesten Fall zum Implantatverlust führen. Deswegen sind implantatprothetische Materialien mit geringer Affinität zur mikrobiellen Anlagerungen vorteilhaft, weil diese das Risiko für periimplantäre Erkrankungen reduzieren und die Lebensdauer dentaler Implantate damit erhöhen können. Die vorliegende In-vivo-Studie verfolgte das Ziel, die Biofilmakkumulation auf vier verschiedenen Abutmentmaterialien (Titan, Zirkoniumdioxid, PEEK und BioHPP) zu untersuchen und miteinander zu vergleichen. Zusätzlich sollten die Einflüsse der Materialalterung und der intraoralen Positionierung der Probekörper auf die Biofilmakkumulation miteinbezogen werden. Hierfür wurden 80 Multiprobekörper aus jeweils den vier Testmaterialien hergestellt und alle Oberflächen mit einem standardisiertem Politurverfahren behandelt. Dann wurden die Hälfte der Probekörper einem artifiziellen Alterungsprozess mittels Thermocycler unterzogen. Zur Ermittlung der Oberflächentopographie und Rauheitsparameter $R_{a}$ und $S_{a}$ wurde die WeitfeldKonfokalmikroskopie verwendet. An der vorliegenden klinischen Studie nahmen 20 ProbandInnen (10 Frauen und 10 Männer) teil. JedeR ProbandIn erhielt eine individuell hergestellte Oberkieferschiene, mit jeweils zwei Multiprobekörpern im Ausgangszustand und zwei nach künstlichem Alterungsprozess, wovon jeweils zwei Probekörper bukkal an den Eckzähnen und zwei bukkal im Molarenbereich positioniert wurden. Die Tragedauer der Kunststoffschienen betrug 24 Stunden. Der akkumulierte Biofilm auf den Probekörpern wurde durch das Fluorochrom Hoechst 33342 angefärbt und im Fluoreszenzmikroskop visualisiert und anschließend quantifiziert. Abschließend wurden die gesammelten Daten statistisch ausgewertet. Die Rauheitsmessungen der Oberflächen ergaben sowohl beim profil- $\left(R_{a}\right)$ als auch beim flächenbezogenen $\left(S_{a}\right)$ Rauheitsparameter insgesamt Werte unter $0,2 \mu \mathrm{m}$. Die Varianzanalyse zeigte hierbei keine signifikanten Unterschiede zwischen den Materialien. Im allgemeinen linearen gemischten Modell konnten signifikante Einflüsse des Materials und der intraoralen Position der Probekörper auf die Biofilmbildung festgestellt werden.

Zusammenfassend zeigten sich im Rahmen der vorliegenden Studie die geringsten Biofilmmengen auf Zirkoniumdioxidoberflächen, wohingegen auf den PEEK-basierten Materialien (reines PEEK, BioHPP) die signifikant stärkste Anlagerung vorlag. Außerdem zeigten die Probekörper im posterioren Bereich eine höhere mikrobielle 
Besiedlung. Der Alterungszustand der Probekörper, das Geschlecht und das Alter der

ProbandInnen hatten keinen signifikanten Einfluss auf das Adhäsionsverhalten der Bakterien. 


\section{$6 \quad$ Literaturverzeichnis}

Abd El-Ghany OS, Sherief AH (2016): Zirconia based ceramics, some clinical and biological aspects: Review. Future Dental Journal 2, 55-64

Ahn SJ, Wen ZT, Burne RA (2007): Effects of oxygen on virulence traits of Streptococcus mutans. J Bacteriol 189, 8519-8527

Akagawa Y, Ichikawa Y, Nikai H, Tsuru H (1993): Interface histology of unloaded and early loaded partially stabilized zirconia endosseous implant in initial bone healing. J Prosthet Dent $\underline{69}, 599-604$

Al-Ahmad A, Follo M, Selzer AC, Hellwig E, Hannig M, Hannig C (2009): Bacterial colonization of enamel in situ investigated using fluorescence in situ hybridization. J Med Microbiol 토, 1359-1366

Al-Ahmad A, Wiedmann-Al-Ahmad M, Faust J, Bächle M, Follo M, Wolkewitz M, Hannig C, Hellwig E, Carvalho C, Kohal R (2010): Biofilm formation and composition on different implant materials in vivo. J Biomed Mater Res Part B Appl Biomater 95, 101-109

Al-Amleh B, Lyons K, Swain M (2010): Clinical trials in zirconia: a systematic review. J Oral Rehabil 37, 641-652

Albandar JM (2002): Global risk factors and risk indicators for periodontal diseases. Periodontol $2000 \underline{29}, 177-206$

Albertini M, López-Cerero L, O'Sullivan MG, Chereguini CF, Ballesta S, Ríos V, HerreroCliment M, Bullón P (2015): Assessment of periodontal and opportunistic flora in patients with peri-implantitis. Clin Oral Implants Res $\underline{26}$, 937-941

Albrektsson T, Isidor F: Consensus report of Session IV. In: Lang NP, Thorkild K (Hrsg.): Proceedings of the 1st European Workshop on Periodontology. Quintessence Publishing, Berlin 1994, 365-369

Albrektsson T, Wennerberg A (2004): Oral implant surfaces: Part 1 - review focusing on topographic and chemical properties of different surfaces and in vivo responses to them. Int J Prosthodont 17, 536-543

Al-Radha ASD, Dymock D, Younes C, O'Sullivan D (2012): Surface properties of titanium and zirconia dental implant materials and their effect on bacterial adhesion. J Dent $\underline{40}, 146-153$

Amaechi BT, Higham SM, Edgar WM, Milosevic A (1999): Thickness of acquired salivary pellicle as a determinant of the sites of dental erosion. J Dent Res $\underline{78}, 1821-1828$

An YH, Friedman RJ (1998): Concise review of mechanisms of bacterial adhesion to biomaterial surfaces. J Biomed Mater Res $\underline{43}$, 338-348

Andreiotelli M, Wenz HJ, Kohal R-J (2009): Are ceramic implants a viable alternative to titanium implants? A systematic literature review. Clin Oral Implants Res 20, 32-47 
Andrikopoulou E, Zoidis P, Artopoulou I-I, Doukoudakis A (2016): Modified PEEK resin bonded fixed dental prosthesis for a young cleft lip and palate patient. J Esthet Restor Dent $\underline{28}, 201-207$

Antonio PD, Lasalvia M, Perna G, Capozzi V (2012): Scale-independent roughness value of cell membranes studied by means of AFM technique. Biochim Biophys Acta 1818, 3141-3148

Anwar H, Dasgupta MK, Costerton JW (1990): Testing the susceptibility of bacteria in biofilms to antibacterial agents. Antimicrobial Agents and Chemotherapy $\underline{34}$, 2043-2046

Aparna MS, Yadav S (2008): Biofilms: microbes and disease. Braz J Infect Dis $\underline{12}, 526-530$

Arciola CR, Campoccia D, Ehrlich GD, Montanaro L (2015): Biofilm-based implant infections in orthopaedics. Adv Exp Med Biol $\underline{830}, 29-46$

Arciola CR, Campoccia D, Speziale P, Montanaro L, Costerton JW (2012): Biofilm formation in Staphylococcus implant infections. A review of molecular mechanisms and implications for biofilm-resistant materials. Biomaterials $\underline{33}, 5967-5982$

Armstrong WG (1968): Origin and nature of the acquired pellicle. Proc R Soc Med $\underline{61}, 923-930$

Arweiler NB, Hellwig E, Sculean A, Hein N, Auschill TM (2004): Individual vitality pattern of in situ dental biofilms at different locations in the oral cavity. Caries Res $\underline{38}, 442-447$

Arweiler NB, Netuschil L, Reich E (2001): Alcohol-free mouthrinse solutions to reduce supragingival plaque regrowth and vitality. A controlled clinical study. J Clin Periodontol $\underline{28}, 168-174$

Auschill TM, Arweiler NB, Brecx M, Reich E, Sculean A, Netuschil L (2002): The effect of dental restorative materials on dental biofilm. Eur J Oral Sci 110, 48-53

Aydin C, Yilmaz H, Ata SO (2010): Single-tooth zirconia implant located in anterior maxilla. A clinical report. N Y State Dent J $\underline{76}, 30-33$

Azeredo J, Azevedo NF, Briandet R, Cerca N, Coenye T, Costa AR, Desvaux M, Di Bonaventura G, Hébraud M, Jaglic Z et al. (2017): Critical review on biofilm methods. Crit Rev Microbiol 43, 313-351

Baier RE, Glantz PO (1978): Characterization of oral in vivo films formed on different types of solid surfaces. Acta Odontol Scand $\underline{36}, 289-301$

Barbieri M, Mencio F, Papi P, Rosella D, di Carlo S, Valente T, Pompa G (2017): Corrosion behavior of dental implants immersed into human saliva: preliminary results of an in vitro study. Eur Rev Med Pharmacol Sci 21, 3543-3548

Bardow A, Nyvad B, Nauntofte B (2001): Relationships between medication intake, complaints of dry mouth, salivary flow rate and composition, and the rate of tooth demineralization in situ. Arch Oral Biol 46, 413-423

Barkarmo S, Longhorn D, Leer K, Johansson CB, Stenport V, Franco-Tabares S, Kuehne SA, Sammons R (2019): Biofilm formation on polyetheretherketone and titanium surfaces. Clin Exp Dent Res $\underline{5}, 427-437$ 
Barnard AML, Salmond GPC (2004): Quorum Sensing: The complexities of chemical communication between bacteria. Complexus $\underline{2}, 87-101$

Barton AJ, Sagers RD, Pitt WG (1996): Bacterial adhesion to orthopedic implant polymers. J. Biomed. Mater. Res. $\underline{30}, 403-410$

Bayguinov PO, Oakley DM, Shih CC, Geanon DJ, Joens MS, Fitzpatrick JAJ (2018): Modern Laser Scanning Confocal Microscopy. Curr Protoc Cytom 포, e39

Berglundh T, Lindhe J, Ericsson I, Marinello CP, Liljenberg B, Thomsen P (1991): The soft tissue barrier at implants and teeth. Clin Oral Implants Res $\underline{2}, 81-90$

Berglundh T, Lindhe J, Jonsson K, Ericsson I (1994): The topography of the vascular systems in the periodontal and peri-implant tissues in the dog. J Clin Periodontol 21, 189-193

Berglundh T, Gislason O, Lekholm U, Sennerby L, Lindhe J (2004): Histopathological observations of human periimplantitis lesions. J Clin Periodontol $\underline{31}, 341-347$

Berglundh T, Lindhe J, Lang NP: Peri-implant Mucositis and Peri-implantitis. In: Lang NP, Lindhe J (Hrsg.): Clinical Periodontology and Implant Dentistry. 6. Auflage; WileyBlackwell, Hoboken 2015, 505-517

Beyth N, Bahir R, Matalon S, Domb AJ, Weiss EI (2008): Streptococcus mutans biofilm changes surface-topography of resin composites. Dent Mater 24, 732-736

Bhushan B: Surface Roughness Analysis and Measurement Techniques. In: Bhushan B (Hrsg.): Modern Tribology Handbook. CRC Press, Boca Raton 2001, 49-119

Bianco PD, Ducheyne P, Cuckler JM (1996): Local accumulation of titanium released from a titanium implant in the absence of wear. J Biomed Mater Res $\underline{31}$, 227-234

Blatz MB, Bergler M, Holst S, Block MS (2009): Zirconia abutments for single-tooth implants-rationale and clinical guidelines. J Oral Maxillofac Surg 67, 74-81

Bloomquist CG, Reilly BE, Liljemark WF (1996): Adherence, accumulation, and cell division of a natural adherent bacterial population. J Bacteriol $\underline{178}, 1172-1177$

Bollen CM, Papaioanno W, van Eldere J, Schepers E, Quirynen M, van Steenberghe D (1996): The influence of abutment surface roughness on plaque accumulation and peri-implant mucositis. Clin Oral Implants Res $\underline{7}, 201-211$

Bollen CM, Lambrechts P, Quirynen M (1997): Comparison of surface roughness of oral hard materials to the threshold surface roughness for bacterial plaque retention: A review of the literature. Dent Mater 13, 258-269

Bos R (1999): Physico-chemistry of initial microbial adhesive interactions - its mechanisms and methods for study. FEMS Microbiol Rev $\underline{23}, 179-229$

Bos R, van der Mei HC, Meinders JM, Busscher HJ (1994): A quantitative method to study coadhesion of microorganisms in a parallel plate flow chamber: Basic principles of the analysis. J Microbiol Methods 20, 289-305 
Bos R, van der Mei HC, Vries J de, Busscher HJ (1996): The role of physicochemical and structural surface properties in co-adhesion of microbial pairs in a parallel-plate flow chamber. Colloids Surf B Biointerfaces $\underline{7}, 101-112$

Bottari B, Ercolini D, Gatti M, Neviani E (2006): Application of FISH technology for microbiological analysis: current state and prospects. Appl Microbiol Biotechnol $\underline{73}$, 485494

Bradshaw DJ, Marsh PD, Watson GK, Allison C (1998): Role of Fusobacterium nucleatum and coaggregation in anaerobe survival in planktonic and biofilm oral microbial communities during aeration. Infect Immun $\underline{66}, 4729-4732$

Brägger U, Hugel-Pisoni C, Bürgin W, Buser D, Lang NP (1996): Correlations between radiographic, clinical and mobility parameters after loading of oral implants with fixed partial dentures. A 2-year longitudinal study. Clin Oral Implants Res $\underline{7}, 230-239$

Brecx M, Rönström A, Theilade J, Attström R (1981): Early formation of dental plaque on plastic films: 2. Electron microscopic observations. J Periodontal Res 16, 213-227

Brecx M, Theilade J, Attstrom R (1983): An ultrastructural quantitative study of the significance of microbial multiplication during early dental plaque growth. J Periodontal Res 18, 177-186

Brown SA, Hastings RS, Mason JJ, Moet A (1990): Characterization of short-fibre reinforced thermoplastics for fracture fixation devices. Biomaterials $\underline{11}, 541-547$

Bryers JD (1993): Bacterial biofilms. Curr Opin Biotechnol 4, 197-204

Buddecke E: Biochemische Grundlagen der Zahnmedizin. De Gruyter, Berlin 1981

Bürgers R, Eidt A, Frankenberger R, Rosentritt M, Schweikl H, Handel G, Hahnel S (2009): The anti-adherence activity and bactericidal effect of microparticulate silver additives in composite resin materials. Arch Oral Biol 54, 595-601

Bürgers R, Gerlach T, Hahnel S, Schwarz F, Handel G, Gosau M (2010a): In vivo and in vitro biofilm formation on two different titanium implant surfaces. Clin Oral Implants Res $\underline{21}$, $156-164$

Bürgers R, Hahnel S, Reichert TE, Rosentritt M, Behr M, Gerlach T, Handel G, Gosau M (2010b): Adhesion of Candida albicans to various dental implant surfaces and the influence of salivary pellicle proteins. Acta Biomater $\underline{6}, 2307-2313$

Bürgers R, Hahnel S, Rosentritt M, Handel G (2010c): Biofilmbildung auf dentalen Implantatoberflächen. DDZ $\underline{119}, 244-252$

Buser D, Nydegger T, Oxland T, Cochran DL, Schenk RK, Hirt HP, Sntivy D, Nolte LP (1999): Interface shear strength of titanium implants with a sandblasted and acid-etched surface: A biomechanical study in the maxilla of miniature pigs. J Biomed Mater Res $\underline{45}, 75-83$

Buser D, Schenk RK, Steinemann S, Fiorellini JP, Fox CH, Stich H (1991): Influence of surface characteristics on bone integration of titanium implants. A histomorphometric study in miniature pigs. J Biomed Mater Res 25, 889-902 
Buser D, Weber HP, Donath K, Fiorellini JP, Paquette DW, Williams RC (1992): Soft tissue reactions to non-submerged unloaded titanium implants in beagle dogs. J Periodontol $\underline{63}$, $225-235$

Busscher H, Weerkamp AH (1987): Specific and non-specific interactions in bacterial adhesion to solid substrata. FEMS Microbiol Lett $\underline{46}, 165-173$

Busscher HJ, van der Mei HC (1997): Physico-chemical interactions in initial microbial adhesion and relevance for biofilm formation. Adv Dent Res 11, 24-32

Busscher HJ, Cowan MM, Mei HC (1992): On the relative importance of specific and nonspecific approaches to oral microbial adhesion. FEMS Microbiol Lett $\underline{88}, 199-210$

Busscher HJ, Rinastiti M, Siswomihardjo W, van der Mei HC (2010): Biofilm formation on dental restorative and implant materials. J Dent Res $\underline{89}, 657-665$

Characklis WG (1981): Bioengineering report: Fouling biofilm development: A process analysis. Biotechnol Bioeng $\underline{23}, 1923-1960$

Chaturvedi TP (2009): An overview of the corrosion aspect of dental implants (titanium and its alloys). Indian J Dent Res $\underline{20}, 91-98$

Chazotte B (2011): Labeling nuclear DNA with Hoechst 33342. Cold Spring Harb Protoc, 8385

Cionca N, Hashim D, Mombelli A (2017): Zirconia dental implants: where are we now, and where are we heading? Periodontol $2000 \underline{73}, 241-258$

Coenye T, Nelis HJ (2010): In vitro and in vivo model systems to study microbial biofilm formation. J Microbiol Methods $\underline{83}, 89-105$

Costerton JW (1987): Bacterial biofilms in nature and disease. Annu Rev Microbiol 41, 435464

Costerton JW (1995): Overview of microbial biofilms. J Ind Microbiol 15, 137-140

Costerton JW, Lewandowski Z, DeBeer D, Caldwell D, Korber D, James G (1994): Biofilms, the customized microniche. J Bacteriol 176, 2137-2142

Costerton JW, Stewart PS, Greenberg EP (1999): Bacterial biofilms: A common cause of persistent infections. Science 284, 1318-1322

Covacci V, Bruzzese N, Maccauro G, Andreassi C, Ricci GA, Piconi C, Marmo E, Burger W, Cittadini A (1999): In vitro evaluation of the mutagenic and carcinogenic power of high purity zirconia ceramic. Biomaterials $\underline{20}, 371-376$

Cox G, Sheppard CJR (2004): Practical limits of resolution in confocal and non-linear microscopy. Microsc Res Tech $\underline{63}, 18-22$

Crawford RJ, Webb HK, Truong VK, Hasan J, Ivanova EP (2012): Surface topographical factors influencing bacterial attachment. Adv Colloid Interface Sci 179-182, 142-149

Cypionka H: Grundlagen der Mikrobiologie. 4. Auflage; Springer, Heidelberg 2010 
da Rocha JFSS, de Avila ED, Rigolin MSM, Barbugli PA, Marin DOM, Mollo Junior FA, Jorge $\mathrm{JH}$ (2020): Biological and physicochemical implications of the aging process on titanium and zirconia implant material surfaces. J Prosthet Dent

Davey ME, O'Toole G (2000): Microbial Biofilms: from Ecology to Molecular Genetics. Microbiol Mol Biol Rev $\underline{64}, 847-867$

de Avila ED, de Molon RS, Vergani CE, de Assis Mollo F, Salih V (2014): The Relationship between Biofilm and Physical-Chemical Properties of Implant Abutment Materials for Successful Dental Implants. Materials $\underline{7}, 3651-3662$

de Oliveira GR, Pozzer L, Cavalieri-Pereira L, de Moraes PH, Olate S, de Albergaría Barbosa JR (2012): Bacterial adhesion and colonization differences between zirconia and titanium implant abutments: An in vivo human study. J Periodontal Implant Sci 42, 217-223

Decker EM (2001): The ability of direct fluorescence-based, two-colour assays to detect different physiological states of oral streptococci. Lett Appl Microbiol 33, 188-192

Degidi M, Artese L, Scarano A, Perrotti V, Gehrke P, Piattelli A (2006): Inflammatory infiltrate, microvessel density, nitric oxide synthase expression, vascular endothelial growth factor expression, and proliferative activity in peri-implant soft tissues around titanium and zirconium oxide healing caps. J Periodontol $\underline{77}$, 73-80

Delgado-Ruiz R, Romanos G (2018): Potential Causes of Titanium Particle and Ion Release in Implant Dentistry: A Systematic Review. Int J Mol Sci 19, 3585

Diaspro A, Bianchini P, Cella Zanacchi F, Usai C: Confocal Laser Scanning Fluorescence Microscopy. In: Roberts GCK (Hrsg.): Encyclopedia of Biophysics. Springer, Berlin 2013, $362-366$

Diaz PI, Chalmers NI, Rickard AH, Kong C, Milburn CL, Palmer RJ, Kolenbrander PE (2006): Molecular characterization of subject-specific oral microflora during initial colonization of enamel. Appl Environ Microbiol 2, 2837-2848

Dirckx P (1997): Biofilm structure with labels. http://www.biofilm.montana.edu/multimedia/images/download.html?id=1097, abgerufen am: 23.06 .2020

do Nascimento C, da Rocha Aguiar C, Pita MS, Pedrazzi V, de Albuquerque RF, Ribeiro RF (2013): Oral biofilm formation on the titanium and zirconia substrates. Microsc Res Tech $\underline{76}, 126-132$

do Nascimento C, Pita MS, Fernandes FHNC, Pedrazzi V, Albuquerque Junior RF de, Ribeiro RF (2014): Bacterial adhesion on the titanium and zirconia abutment surfaces. Clin Oral Implants Res 25, 337-343

Donachie MJ: Titanium: A technical guide. 2. Auflage; ASM International, Materials Park 2000

Donlan RM (2002): Biofilms: Microbial life on surfaces. Emerging Infect Dis $\underline{8}, 881-890$

Donlan RM, Costerton JW (2002): Biofilms: Survival mechanisms of clinically relevant microorganisms. Clin Microbiol Rev 15, 167-193 
Douglas CW (1983): The binding of human salivary $\alpha$-amylase by oral strains of streptococcal bacteria. Arch Oral Biol 28, 567-573

Douglas CW (1994): Bacterial-protein interactions in the oral cavity. Adv Dent Res $\underline{8}, 254-262$

Duan K, Sibley CD, Davidson CJ, Surette MG: Chemical interactions between organisms in microbial communities. In: Collin M, Schuch R (Hrsg.): Bacterial Sensing and Signaling. 1. Auflage; Karger, Basel 2009, 1-17

Dunne WM (2002): Bacterial adhesion: Seen any good biofilms lately? Clin Microbiol Rev $\underline{15}$, $155-166$

Edgerton M, Lo SE, Scannapieco FA (1996): Experimental salivary pellicles formed on titanium surfaces mediate adhesion of streptococci. Int J Oral Maxillofac Implants 11, 443449

Eke PI, Braswell LD, Fritz ME (1998): Microbiota associated with experimental peri-implantitis and periodontitis in adult Macaca mulatta monkeys. J Periodontol $\underline{69}, 190-194$

Elias CN, Rocha FA, Nascimento AL, Coelho PG (2012): Influence of implant shape, surface morphology, surgical technique and bone quality on the primary stability of dental implants. J Mech Behav Biomed Mater 16, 169-180

Eliasson L, Birkhed D, Osterberg T, Carlén A (2006): Minor salivary gland secretion rates and immunoglobulin A in adults and the elderly. Eur J Oral Sci 114, 494-499

Eliasson L, Carlén A (2010): An update on minor salivary gland secretions. Eur J Oral Sci 118 , $435-442$

Elle HJ: In-vitro-Untersuchung zur initialen Biofilmbildung auf dentalen Kompositmaterialien. Med. Diss. Göttingen 2018

Ellen RP, Veisman H, Buivids IA, Rosenberg M (1994): Kinetics of lactose-reversible coadhesion of Actinomyces naeslundii WVU 398A and Streptococcus oralis 34 on the surface of hexadecane droplets. Oral Microbiol Immunol 9, 364-371

Elter C, Heuer W, Demling A, Hannig M, Heidenblut T, Bach FW, Stiesch-Scholz M (2008): Supra- and subgingival biofilm formation on implant abutments with different surface characteristics. Int J Oral Maxillofac Implants $\underline{23}$, 327-334

Embery G, Heaney TG, Stanbury JB (1986): Studies on the organic polyanionic constituents of human acquired dental pellicle. Arch Oral Biol 31, 623-625

Esfahanizadeh N, Mirmalek SP, Bahador A, Daneshparvar H, Akhoundi N, Pourhajibagher M (2018): Formation of biofilm on various implant abutment materials. Gen Dent $\underline{66}, 39-44$

Esposito M, Hirsch JM, Lekholm U, Thomsen P (1998): Biological factors contributing to failures of osseointegrated oral implants: (I). Success criteria and epidemiology. Eur J Oral Sci $\underline{106}, 527-551$

Ferraro M, Vieira AR (2010): Explaining gender differences in caries: A multifactorial approach to a multifactorial disease. Int J Dent 2010, 649643 
Ferreira SD, Silva GLM, Cortelli JR, Costa JE, Costa FO (2006): Prevalence and risk variables for peri-implant disease in Brazilian subjects. J Clin Periodontol 33, 929-935

Figuero E, Graziani F, Sanz I, Herrera D, Sanz M (2014): Management of peri-implant mucositis and peri-implantitis. Periodontol 2000 66, 255-273

Fischer ER, Hansen BT, Nair V, Hoyt FH, Dorward DW (2012): Scanning electron microscopy. Curr Protoc Microbiol 25, 2B.2.1-2B.2.47

Fisher SJ, Prakobphol A, Kajisa L, Murray PA (1987): External radiolabelling of components of pellicle on human enamel and cementum. Arch Oral Biol 32, 509-517

Flemming HC, Wingender J (2001a): Relevance of microbial extracellular polymeric substances (EPSs) - Part I: Structural and ecological aspects. Water Sci Technol $\underline{43}, 1-8$

Flemming H-C, Wingender J (2001b): Biofilme - die bevorzugte Lebensform der Bakterien: Flocken, Filme und Schlämme. Biol Unserer Zeit $\underline{31}$, 169-180

Fuqua WC, Winans SC, Greenberg EP (1994): Quorum sensing in bacteria: The LuxR-LuxI family of cell density-responsive transcriptional regulators. J Bacteriol $\underline{176}, 269-275$

Fürst MM, Salvi GE, Lang NP, Persson GR (2007): Bacterial colonization immediately after installation on oral titanium implants. Clin Oral Implants Res $\underline{18}, 501-508$

Furuta M, Ekuni D, Irie K, Azuma T, Tomofuji T, Ogura T, Morita M (2011): Sex differences in gingivitis relate to interaction of oral health behaviors in young people. J Periodontol $\underline{82}$, $558-565$

Fux CA, Stoodley P, Hall-Stoodley L, Costerton JW (2003): Bacterial biofilms: A diagnostic and therapeutic challenge. Expert Rev Anti Infect Ther 1, 667-683

Gadelmawla ES, Koura MM, Maksoud TMA, Elewa IM, Soliman HH (2002): Roughness parameters. J Mater Process Technol $\underline{123}, 133-145$

Gale MS, Darvell BW (1999): Thermal cycling procedures for laboratory testing of dental restorations. J Dent 27, 89-99

Gehrke P, Dhom G, Brunner J, Wolf D, Degidi M, Piattelli A (2006): Zirconium implant abutments: Fracture strength and influence of cyclic loading on retaining-screw loosening. Quintessence Int 37, 19-26

Gehrke P, Jaladi N, Spintzyk S, Fischer C, Scheideler L, Geis-Gerstorfer J, Rupp F (2018): Einfluss unterschiedlicher Reinigungsverfahren auf die Biokompatibilität von Titan-, Zirkonoxid- und PEEK-Abutmentmaterialien. Quintessenz $\underline{69}$, 1432-1440

Gevatter HJ, Grünhaupt U: Handbuch der Mess- und Automatisierungstechnik in der Produktion. 2. Auflage; Springer, Berlin 2006

Gibbons RJ, Moreno EC, Spinell DM (1976): Model delineating the effects of a salivary pellicle on the adsorption of Streptococcus miteor onto hydroxyapatite. Infect Immun 14, 11091112 
Gibbons RJ, Nygaard M (1970): Interbacterial aggregation of plaque bacteria. Arch Oral Biol $\underline{15}, 1397-1400$

Gonzalez-Bonet A, Kaufman G, Yang Y, Wong C, Jackson A, Huyang G, Bowen R, Sun J (2015): Preparation of dental resins resistant to enzymatic and hydrolytic degradation in oral environments. Biomacromolecules $\underline{16}$, 3381-3388

Goodhand MN, Walton K, Blunt L, Lung HW, Miller RJ, Marsden R (2016): The limitations of using "Ra" to describe surface roughness. J Turbomach $\underline{138}, 101003$

Gosau M, Hahnel S, Schwarz F, Gerlach T, Reichert TE, Bürgers R (2010): Effect of six different peri-implantitis disinfection methods on in vivo human oral biofilm. Clin Oral Implants Res $\underline{21}, 866-872$

Gosau M, Bürgers R, Vollkommer T, Holzmann T, Prantl L (2013): Effectiveness of antibacterial copper additives in silicone implants. J Biomater Appl 28, 187-198

Gosavi S, Gosavi S, Alla R (2013): Titanium: A miracle metal in dentistry. Trends Biomater Artif Organs 27, 42-46

Gotfredsen K, Nimb L, Hjorting-hansen E, Jensen JS, Holmen A (1992): Histomorphometric and removal torque analysis for TiO2-blasted titanium implants: An experimental study on dogs. Clin Oral Implants Res $\underline{3}, 77-84$

Grössner-Schreiber B, Teichmann J, Hannig M, Dörfer C, Wenderoth DF, Ott SJ (2009): Modified implant surfaces show different biofilm compositions under in vivo conditions. Clin Oral Implants Res 20, 817-826

Gruica B, Wang HY, Lang NP, Buser D (2004): Impact of IL-1 genotype and smoking status on the prognosis of osseointegrated implants. Clin Oral Implants Res $\underline{15}$, 393-400

Guindy JS, Schiel H, Schmidli F, Wirz J (2004): Corrosion at the marginal gap of implantsupported suprastructures and implant failure. Int J Oral Maxillofac Implants $\underline{19}, 826-831$

Gupta N, Tripathi AM, Saha S, Dhinsa K, Garg A (2015): Effect of saliva on the tensile bond strength of different generation adhesive systems: An in-vitro study. J Clin Diagn Res $\underline{9}$, ZC91-4

Haffajee AD, Teles RP, Patel MR, Song X, Yaskell T, Socransky SS (2009): Factors affecting human supragingival biofilm composition. II. Tooth position. J Periodontal Res $\underline{44}, 520$ 528

Hahnel S, Wieser A, Lang R, Rosentritt M (2014): Biofilm formation on the surface of modern implant abutment materials. Clin Oral Implants Res $\underline{26}$, 1297-1301

Hall-Stoodley L, Stoodley P (2002): Developmental regulation of microbial biofilms. Curr Opin Biotechnol 13, 228-233

Hammer BK, Bassler BL (2003): Quorum sensing controls biofilm formation in Vibrio cholerae. Mol Microbiol 50, 101-104 
Hand AR, Pathmanathan D, Field RB (1999): Morphological features of the minor salivary glands. Arch Oral Biol 44, 3-10

Hannig C, Hannig M (2009): The oral cavity - a key system to understand substratumdependent bioadhesion on solid surfaces in man. Clin Oral Investig 13, 123-139

Hannig C, Huber K, Lambrichts I, Gräser J, D'Haen J, Hannig M (2007): Detection of salivary alpha-amylase and lysozyme exposed on the pellicle formed in situ on different materials. $\mathrm{J}$ Biomed Mater Res A $\underline{83}, 98-103$

Hannig C, Follo M, Hellwig E, Al-Ahmad A (2010): Visualization of adherent microorganisms using different techniques. J Med Microbiol $\underline{59}, 1-7$

Hannig M (1997): Transmission electron microscopic study of in vivo pellicle formation on dental restorative materials. Eur J Oral Sci 105, 422-433

Hannig M (1999): Transmission electron microscopy of early plaque formation on dental materials in vivo. Eur J Oral Sci 107, 55-64

Hannig M (2002): The protective nature of the salivary pellicle. Int Dent J $\underline{52}, 417-423$

Hannig M, Joiner A (2006): The structure, function and properties of the acquired pellicle. Monogr Oral Sci 19, 29-64

Hannig M, Hannig C (2007): Der initiale orale Biofilm - pathogen oder protektiv? Oralprophylaxe \& Kinderzahnheilkunde $\underline{2}, 73-82$

Hannig M, Fiebiger M, Güntzer M, Döbert A, Zimehl R, Nekrashevych Y (2004): Protective effect of the in situ formed short-term salivary pellicle. Arch Oral Biol 49, 903-910

Happe A, Körner G, Rothamel D (2011): Zur Problematik von submukösen Zementresten bei implantologischen Suprastrukturen und der Indikation individueller Abutments. Implantologie 19, 161-169

Harris LG, Richards RG (2004): Staphylococcus aureus adhesion to different treated titanium surfaces. J Mater Sci: Mater Med 15, 311-314

Haus J: Optische mikroskopie: Funktionsweise und Kontrastierverfahren. 1. Auflage; WileyVCH, Weinheim 2014

Hay DI (1973): The interaction of human parotid salivary proteins with hydroxyapatite. Arch Oral Biol $\underline{18}, 1517-1529$

Hector MP, Linden RWA: Reflexes of salivary secretion. In: Garrett JR, Ekström J, Anderson LC (Hrsg.): Neural mechanisms of salivary gland secretion. Karger, Basel 1999, 196-217

Heitz-Mayfield L (2008): Peri-implant diseases: Diagnosis and risk indicators. J Clin Periodontol $\underline{35}, 292-304$

Heitz-Mayfield L, Teles RP, Lang NP: Peri-implant Infections. In: Lang NP, Lindhe J (Hrsg.): Clinical Periodontology and Implant Dentistry. 6. Auflage; Wiley-Blackwell, Hoboken 2015, 222-237 
Hellwig E, Klimek J, Attin T: Einführung in die Zahnerhaltung. 6. Auflage; Dt. Zahnärzte-Verl., Köln 2013

Hermann JS, Cochran DL (2005): Biologische Prinzipien in der oralen Implantologie. Implantologie 13, 109-123

Heukelekian H, Heller A (1940): Relation between food concentration and surface for bacterial growth. J Bacteriol $\underline{40}, 547-558$

Holst S, Blatz MB, Hegenbarth E, Wichmann M, Eitner S (2005): Prosthodontic considerations for predictable single-implant esthetics in the anterior maxilla. J Oral Maxillofac Surg $\underline{63}$, $89-96$

Hoyle BD, Jass J, Costerton JW (1990): The biofilm glycocalyx as a resistance factor. J Antimicrob Chemother $\underline{26}, 1-5$

Huang R, Li M, Gregory RL (2011): Bacterial interactions in dental biofilm. Virulence 2 , 435444

Hultin M, Gustafsson A, Hallstrom H, Johansson LA, Ekfeldt A, Klinge B (2002): Microbiological findings and host response in patients with peri-implantitis. Clin Oral Implants Res $\underline{13}, 349-358$

Humphrey SP, Williamson RT (2001): A review of saliva: Normal composition, flow, and function. J Prosthet Dent $\underline{85}, 162-169$

Ikeda H, Yamaza T, Yoshinari M, Ohsaki Y, Ayukawa Y, Kido MA, Inoue T, Shimono M, Koyano K, Tanaka T (2000): Ultrastructural and immunoelectron microscopic studies of the peri-implant epithelium-implant (Ti-6Al-4V) interface of rat maxilla. J Periodontol 71 , 961-973

Ionescu A, Wutscher E, Brambilla E, Schneider-Feyrer S, Giessibl FJ, Hahnel S (2012): Influence of surface properties of resin-based composites on in vitro Streptococcus mutans biofilm development. Eur J Oral Sci $\underline{120}, 458-465$

Javed F, Al-Hezaimi K, Salameh Z, Almas K, Romanos GE (2011): Proinflammatory cytokines in the crevicular fluid of patients with peri-implantitis. Cytokine $\underline{53}, 8-12$

Javed F, Ahmed HB, Crespi R, Romanos GE (2013): Role of primary stability for successful osseointegration of dental implants: Factors of influence and evaluation. Interv Med Appl Sci $\underline{5}, 162-167$

Jemt T (1986): Modified single and short-span restorations supported by osseointegrated fixtures in the partially edentulous jaw. J Prosthet Dent $\underline{55}$, 243-247

Jensen Kjeilen JC, Brodin P, Aars H, Berg T (1987): Parotid salivary flow in response to mechanical and gustatory stimulation in man. Acta Physiol Scand 131, 169-175

Jentsch HFR, Eckert FR, Eschrich K, Stratul SI, Kneist S (2014): Antibacterial action of Chlorhexidine/thymol containing varnishes in vitro and in vivo. Int J Dent Hyg $\underline{12}, 168$ 173 
Jorge JRP, Barão VA, Delben JA, Faverani LP, Queiroz TP, Assunção WG (2013): Titanium in dentistry: Historical development, state of the art and future perspectives. J Indian Prosthodont Soc $\underline{13}, 71-77$

Karoussis IK, Salvi GE, Heitz-Mayfield LJA, Brägger U, Hämmerle CHF, Lang NP (2003): Long-term implant prognosis in patients with and without a history of chronic periodontitis: A 10-year prospective cohort study of the ITI Dental Implant System. Clin Oral Implants Res 14, 329-339

Katzer A, Marquardt H, Westendorf J, Wening JV, Foerster G von (2002): Polyetheretherketone - cytotoxicity and mutagenicity in vitro. Biomaterials $23,1749-1759$

Keferstein CP, Marxer M: Fertigungsmesstechnik. Springer Vieweg, Wiesbaden 2015

Kelly JR, Denry I (2008): Stabilized zirconia as a structural ceramic: an overview. Dent Mater 24, 289-298

Keselowsky BG, Collard DM, García AJ (2003): Surface chemistry modulates fibronectin conformation and directs integrin binding and specificity to control cell adhesion. J Biomed Mater Res A 66, 247-259

Khammissa RAG, Feller L, Meyerov R, Lemmer J (2012): Peri-implant mucositis and periimplantitis: Bacterial infection. SADJ $\underline{67}, 70,72-74$

Kielbassa AM: Speichel, orale Mikrobiologie und Bioadhäsion. In: Hugger A, Türp JC, Kerschbaum T (Hrsg.): Curriculum orale Physiologie. Quintessenz, Berlin 2006, 143-158

Klausen M, Aaes-Jørgensen A, Molin S, Tolker-Nielsen T (2003): Involvement of bacterial migration in the development of complex multicellular structures in Pseudomonas aeruginosa biofilms. Mol Microbiol 50, 61-68

Klinge B, Hultin M, Berglundh T (2005): Peri-implantitis. Dent Clin North Am 49, 661-676

Klinger A, Steinberg D, Kohavi D, Sela MN (1997): Mechanism of adsorption of human albumin to titanium in vitro. J. Biomed. Mater. Res. $\underline{36}$, 387-392

Kocher T, Langenbeck N, Rosin M, Bernhardt O (2002): Methodology of three-dimensional determination of root surface roughness. J Periodontal Res 37, 125-131

Koeck B, Ackermann KL, Haunfelder D, Diedrich P, Al-Nawas B, Behneke A, Behneke N, Beschnidt SM, Besimo C, Kirsch A et al.: Implantologie. 2. Auflage; Elsevier, Amsterdam 2005

Kohal RJ, Att W, Bächle M, Butz F (2008): Ceramic abutments and ceramic oral implants. An update. Periodontol 2000 47, 224-243

Kolbeck C, Sereno N, Rosentritt M, Handel G (2013): Biofilm formation on polyetheretherketone surfaces and cleaning options. J Dent Res (Spec Iss 92A): 2353

Kolenbrander PE, London J: Ecological significance of coaggregation among oral bacteria. In: Marshall KC (Hrsg.): Advances in Microbial Ecology. Springer US, Boston 1992, 183-217 
Kolenbrander PE, London J (1993): Adhere today, here tomorrow: Oral bacterial adherence. J Bacteriol 175, 3247-3252

Kolenbrander PE, Palmer RJ, Periasamy S, Jakubovics NS (2010): Oral multispecies biofilm development and the key role of cell-cell distance. Nat Rev Microbiol $\underline{8}, 471-480$

Kronström M, Svenson B, Hellman M, Persson GR (2001): Early implant failures in patients treated with Brånemark System titanium dental implants: A retrospective study. Int J Oral Maxillofac Implants 16, 201-207

Kuboki Y, Teraoka K, Okada S (1987): X-ray photoelectron spectroscopic studies of the adsorption of salivary constituents on enamel. J Dent Res $\underline{66}, 1016-1019$

Kuramitsu HK, He X, Lux R, Anderson MH, Shi W (2007): Interspecies interactions within oral microbial communities. Microbiol Mol Biol Rev 71, 653-670

Kurbad O: Wirkung physiko-chemischer Oberflächencharakteristika auf Zytotoxizität verschiedener dentaler Komposite. Med. Diss. Göttingen 2019

Kurtz SM: PEEK biomaterials handbook. William Andrew, Norwich 2012

Kuula H, Könönen E, Lounatmaa K, Konttinen YT, Könönen M (2004): Attachment of oral gram-negative anaerobic rods to a smooth titanium surface: An electron microscopy study. Int J Oral Maxillofac Implants $\underline{19}, 803-809$

Lamkin MS, Arancillo AA, Oppenheim FG (1996): Temporal and compositional characteristics of salivary protein adsorption to hydroxyapatite. J Dent Res $\underline{75}, 803-808$

Lane N (2015): The unseen world: Reflections on Leeuwenhoek (1677) 'Concerning little animals'. Phil Trans R Soc Lond B $\underline{370}, 1-11$

Lang NP, Berglundh T (2011): Periimplant diseases - Where are we now?: Consensus of the Seventh European Workshop on Periodontology. J Clin Periodontol 38, 178-181

Lang NP, Wilson TG, Corbet EF (2000): Biological complications with dental implants: Their prevention, diagnosis and treatment. Clin Oral Implants Res 11, 146-155

Lang NP, Bosshardt DD, Lulic M (2011a): Do mucositis lesions around implants differ from gingivitis lesions around teeth? J Clin Periodontol $\underline{38}, 182-187$

Lang NP, Salvi GE, Huynh-Ba G, Ivanovski S, Donos N, Bosshardt DD (2011b): Early osseointegration to hydrophilic and hydrophobic implant surfaces in humans. Clin Oral Implants Res $\underline{22}, 349-356$

Lange DA, Jennings HM, Shah SP (1993): Analysis of surface roughness using confocal microscopy. J Mater Sci $\underline{28}, 3879-3884$

Lasserre JF, Brecx MC, Toma S (2018): Oral microbes, biofilms and their role in periodontal and peri-implant diseases. Materials $\underline{11}$

Leach R (Hrsg.): Optical measurement of surface topography. Springer, Berlin 2011

Lebeaux D, Chauhan A, Rendueles O, Beloin C (2013): From in vitro to in vivo models of bacterial biofilm-related infections. Pathogens $2,288-356$ 
Lee BC, Jung GY, Kim DJ, Han JS (2011): Initial bacterial adhesion on resin, titanium and zirconia in vitro. J Adv Prosthodont $\underline{3}, 81-84$

Lendenmann U, Grogan J, Oppenheim FG (2000): Saliva and dental pellicle - a review. Adv Dent Res $\underline{14}, 22-28$

Leonhardt A, Berglundh T, Ericsson I, Dahlén G (1992): Putative periodontal pathogens on titanium implants and teeth in experimental gingivitis and periodontitis in beagle dogs. Clin Oral Implants Res $\underline{3}, 112-119$

Leonhardt A, Adolfsson B, Lekholm U, Wikström M, Dahlén G (1993): A longitudinal microbiological study on osseointegrated titanium implants in partially edentulous patients. Clin Oral Implants Res $\underline{4}, 113-120$

Leonhardt A, Olsson J, Dahlén G (1995): Bacterial colonization on titanium, hydroxyapatite, and amalgam surfaces in vivo. J Dent Res $\underline{74}, 1607-1612$

Lewis K (2001): Riddle of biofilm resistance. Antimicrob Agents Chemother 45, 999-1007

Lewis MW, Holder-Ballard C, Selders RJ, Scarbecz M, Johnson HG, Turner EW (2004): Comparison of the use of a toothpick holder to dental floss in improvement of gingival health in humans. J Periodontol $\underline{75}, 551-556$

Li J, Helmerhorst EJ, Troxler RF, Oppenheim FG (2004): Identification of in vivo pellicle constituents by analysis of serum immune responses. J Dent Res $\underline{83}, 60-64$

Li YH, Lau PC, Lee JH, Ellen RP, Cvitkovitch DG (2001): Natural genetic transformation of Streptococcus mutans growing in biofilms. J Bacteriol 183, 897-908

Li Z, Nair SK (2012): Quorum sensing: How bacteria can coordinate activity and synchronize their response to external signals? Protein Sci 21, 1403-1417

Lichtman JW, Conchello JA (2005): Fluorescence microscopy. Nat Methods 2 , 910-919

Liebermann A, Wimmer T, Schmidlin PR, Scherer H, Löffler P, Roos M, Stawarczyk B (2016): Physicomechanical characterization of polyetheretherketone and current esthetic dental CAD/CAM polymers after aging in different storage media. J Prosthet Dent 115, 321-8.e2

Liljemark WF, Bloomquist CG, Reilly BE, Bernards CJ, Townsend DW, Pennock AT, LeMoine JL (1997): Growth dynamics in a natural biofilm and its impact on oral disease management. Adv Dent Res 11, 14-23

Lima DP, Diniz DG, Moimaz SAS, Sumida DH, Okamoto AC (2010): Saliva: Reflection of the body. Int J Infect Dis $\underline{14}$, e184-8

Lima EMCX, Koo H, Vacca Smith AM, Rosalen PL, Del Bel Cury AA (2008): Adsorption of salivary and serum proteins, and bacterial adherence on titanium and zirconia ceramic surfaces. Clin Oral Implants Res $\underline{19}, 780-785$

Limoli DH, Jones CJ, Wozniak DJ (2015): Bacterial Extracellular Polysaccharides in Biofilm Formation and Function. Microbiol Spectr $\underline{3}, 1-30$ 
Lindhe J, Berglundh T, Ericsson I, Liljenberg B, Marinello C (1992): Experimental breakdown of peri-implant and periodontal tissues: A study in the beagle dog. Clin Oral Implants Res $\underline{3}, 9-16$

Lindhe J, Meyle J (2008): Peri-implant diseases: Consensus Report of the Sixth European Workshop on Periodontology. J Clin Periodontol 35, 282-285

Liskmann S, Vihalemm T, Salum O, Zilmer K, Fischer K, Zilmer M (2007): Characterization of the antioxidant profile of human saliva in peri-implant health and disease. Clin Oral Implants Res $\underline{18}, 27-33$

Listgarten MA, Lai CH (1999): Comparative microbiological characteristics of failing implants and periodontally diseased teeth. J Periodontol $\underline{70}, 431-437$

Listgarten MA, Buser D, Steinemann SG, Donath K, Lang NP, Weber HP (1992): Light and transmission electron microscopy of the intact interfaces between non-submerged titaniumcoated epoxy resin implants and bone or gingiva. J Dent Res $\underline{71}, 364-371$

Lops D, Bressan E, Chiapasco M, Rossi A, Romeo E (2013): Zirconia and titanium implant abutments for single-tooth implant prostheses after 5 years of function in posterior regions. Int J Oral Maxillofac Implants $\underline{28}, 281-287$

Lukacs JR, Largaespada LL (2006): Explaining sex differences in dental caries prevalence: saliva, hormones, and "life-history" etiologies. Am J Hum Biol 18, 540-555

Mabilleau G, Bourdon S, Joly-Guillou ML, Filmon R, Baslé MF, Chappard D (2006): Influence of fluoride, hydrogen peroxide and lactic acid on the corrosion resistance of commercially pure titanium. Acta Biomater 2, 121-129

Macpherson LM, MacFarlane TW, Stephen KW (1990): An intra-oral appliance study of the plaque microflora associated with early enamel demineralization. J Dent Res $\underline{69}, 1712$ 1716

Magana M, Sereti C, Ioannidis A, Mitchell CA, Ball AR, Magiorkinis E, Chatzipanagiotou S, Hamblin MR, Hadjifrangiskou M, Tegos GP (2018): Options and limitations in clinical investigation of bacterial biofilms. Clin Microbiol Rev $\underline{31}, 435-444$

Mahajan A, Singh B, Kashyap D, Kumar A, Mahajan P (2013): Interspecies communication and periodontal disease. Sci World J, 765434

Malinski F: Die in vivo antibakterielle Wirkung von Kupfer in einem zahnärztlichen ZinkoxidPhosphatzement. Med. Diss. Göttingen 2017

Malmstrom HS, Fritz ME, Timmis DP, van Dyke TE (1990): Osseo-integrated implant treatment of a patient with rapidly progressive periodontitis. A case report. J Periodontol $\underline{61}, 300-304$

Mamai-Homata E, Koletsi-Kounari H, Margaritis V (2016): Gender differences in oral health status and behavior of Greek dental students: A meta-analysis of 1981, 2000, and 2010 data. J Int Soc Prev Community Dent $\underline{6}, 60-68$

Marsh PD (2004): Dental plaque as a microbial biofilm. Caries Res $\underline{38}, 204-211$ 
Marsh PD, Bradshaw DJ (1995): Dental plaque as a biofilm. J Ind Microbiol 15, 169-175

Marsh PD, Martin MV, Callaway AS: Orale Mikrobiologie. Georg Thieme Verlag, Stuttgart 2003

Marsh PD, Moter A, Devine DA (2011): Dental plaque biofilms: Communities, conflict and control. Periodontol 2000 55, 16-35

Marshall PA, Loeb GI, Cowan MM, Fletcher M (1989): Response of microbial adhesives and biofilm matrix polymers to chemical treatments as determined by interference reflection microscopy and light section microscopy. Appl Environ Microbiol 55, 2827-2831

Mayhall CW (1970): Concerning the composition and source of the acquired enamel pellicle of human teeth. Arch Oral Biol 15, 1327-1341

McBain AJ: Chapter 4 In vitro biofilm models: An Overview. In: Laskin AI, Gadd GM, Sariaslani S (Hrsg.): Advances in Applied Microbiology: Volume 69. 1. Auflage; Elsevier, Amsterdam 2009, 99-132

Mese H, Matsuo R (2007): Salivary secretion, taste and hyposalivation. J Oral Rehabil $\underline{34}$, 711723

Meurman JH, Frank RM (1991): Progression and surface ultrastructure of in vitro caused erosive lesions in human and bovine enamel. Caries Res $\underline{25}, 81-87$

Meyerowitz C, Featherstone JD, Billings RJ, Eisenberg AD, Fu J, Shariati M, Zero DT (1991): Use of an intra-oral model to evaluate $0.05 \%$ sodium fluoride mouthrinse in radiationinduced hyposalivation. J Dent Res $\underline{70}$, 894-898

Meza-Siccha AS, Aguilar-Luis MA, Silva-Caso W, Mazulis F, Barragan-Salazar C, Del ValleMendoza J (2019): In vitro evaluation of bacterial adhesion and bacterial viability of Streptococcus mutans, Streptococcus sanguinis, and Porphyromonas gingivalis on the abutment surface of titanium and zirconium dental implants. Int J Dent $\underline{2019}, 4292976$

Micheelis W, Bauch J: Mundgesundheitszustand und -verhalten in der Bundesrepublik Deutschland: Ergebnisse des nationalen IDZ-Survey 1989. Deutscher Ärzte-Verlag, Köln 1991

Micheelis W, Borutta A: Mundgesundheitszustand und -verhalten in Ostdeutschland: Ergebnisse des IDZ-Ergänzungssurvey 1992. Deutscher Ärzte-Verlag, Köln 1993

Miller MB, Bassler BL (2001): Quorum sensing in bacteria. Annu Rev Microbiol 55, 165-199

Mishra S, Chowdhary R (2019): PEEK materials as an alternative to titanium in dental implants: A systematic review. Clin Implant Dent Relat Res 21, 208-222

Miyazaki T, Nakamura T, Matsumura H, Ban S, Kobayashi T (2013): Current status of zirconia restoration. J Prosthodont Res $\underline{57}$, 236-261

Mombelli A, Lang NP (1998): The diagnosis and treatment of peri-implantitis. Periodontol $2000 \underline{17}, 63-76$ 
Mombelli A, Müller N, Cionca N (2012): The epidemiology of peri-implantitis. Clin Oral Implants Res $\underline{23}, 67-76$

Monroe D (2007): Looking for chinks in the armor of bacterial biofilms. PLoS Biol $\underline{5}$, e307

Moon IS, Berglundh T, Abrahamsson I, Linder E, Lindhe J (1999): The barrier between the keratinized mucosa and the dental implant. An experimental study in the dog. J Clin Periodontol 26, 658-663

Morrison C, Macnair R, MacDonald C, Wykman A, Goldie I, Grant MH (1995): In vitro biocompatibility testing of polymers for orthopaedic implants using cultured fibroblasts and osteoblasts. Biomaterials $\underline{16}, 987-992$

Mouhyi J, Dohan Ehrenfest, David M., Albrektsson T (2012): The peri-implantitis: Implant surfaces, microstructure, and physicochemical aspects. Clin Implant Dent Relat Res $\underline{14}$, $170-183$

Mulisch M, Nixdorf-Bergweiler B: Fluoreszenzfärbungen. In: Mulisch M, Welsch U (Hrsg.): Romeis - Mikroskopische Technik. Springer, Berlin 2015, 283-298

Müller R, Gröger G, Hiller K-A, Schmalz G, Ruhl S (2007): Fluorescence-based bacterial overlay method for simultaneous in situ quantification of surface-attached bacteria. Appl Environ Microbiol 73, 2653-2660

Murer H: Magen-Darm-Trakt. In: Deetjen P, Speckmann EJ, Hescheler J (Hrsg.): Physiologie. 4. Auflage; Elsevier Urban \& Fischer, München 2005, 592-632

Najeeb S, Zafar MS, Khurshid Z, Siddiqui F (2016): Applications of polyetheretherketone (PEEK) in oral implantology and prosthodontics. J Prosthodont Res $\underline{60,}$ 12-19

Nakamura K, Kanno T, Milleding P, Ortengren U (2010): Zirconia as a dental implant abutment material: A systematic review. Int J Prosthodont 23, 299-309

Netuschil L, Reich E, Brecx M (1989): Direct measurement of the bactericidal effect of chlorhexidine on human dental plaque. J Clin Periodontol $\underline{16}$, 484-488

Neugebauer J, Adler S, Weiß S, Pfeifer K, Kistler F, Kistler S (2014): Vor- und Nachteile bei der Verwendung von individuellen Abutments. ZWR $\underline{123}$, 556-559

Newman F, Beeley JA, MacFarlane TW (1996): Adherence of oral microorganisms to human parotid salivary proteins. Electrophoresis 17, 266-270

Newman HN (1974): Diet, attrition, plaque and dental disease. Br Dent J 136, 491-497

Nguyen-Hieu T, Borghetti A, Aboudharam G (2012): Peri-implantitis: From diagnosis to therapeutics. J Investig Clin Dent $\underline{3}, 79-94$

Nyvad B, Fejerskov O (1987): Scanning electron microscopy of early microbial colonization of human enamel and root surfaces in vivo. Scand J Dent Res $\underline{95}$, 287-296

Ohkubo C, Hanatani S, Hosoi T (2008): Present status of titanium removable dentures - a review of the literature. J Oral Rehabil $\underline{35}, 706-714$ 
Osman RB, Swain MV (2015): A critical review of dental implant materials with an emphasis on titanium versus zirconia. Materials $\underline{8}, 932-958$

O'Toole GA, Kolter R (1998): Flagellar and twitching motility are necessary for Pseudomonas aeruginosa biofilm development. Mol Microbiol $\underline{30}$, 295-304

O'Toole G, Kaplan HB, Kolter R (2000): Biofilm formation as microbial development. Annu Rev Microbiol 54, 49-79

Ottria L, Lauritano D, Andreasi Bassi M, Palmieri A, Candotto V, Tagliabue A, Tettamanti L (2018): Mechanical, chemical and biological aspects of titanium and titanium alloys in implant dentistry. J Biol Regul Homeost Agents $\underline{32}, 81-90$

Overman PR (2000): Biofilm: A new view of plaque. JCDP 1, 18-29

Paddock SW, Eliceiri KW (2014): Laser scanning confocal microscopy: History, applications, and related optical sectioning techniques. Methods Mol Biol 1075, 9-47

Palk L, Sneyd J, Shuttleworth TJ, Yule DI, Crampin EJ (2010): A dynamic model of saliva secretion. J Theor Biol 266, 625-640

Papaioannou W, Quirynen M, van Steenberghe D (1996): The influence of periodontitis on the subgingival flora around implants in partially edentulous patients. Clin Oral Implants Res $\underline{7}, 405-409$

Papavasileiou D: In-vivo-Untersuchung zur periimplantären Biofilmbildung auf Befestigungszementen für festsitzenden implantatgetragenen Zahnersatz. Med. Diss. Regensburg 2013

Papavasileiou D, Behr M, Gosau M, Gerlach T, Buergers R (2015): Peri-implant biofilm formation on luting agents used for cementing implant-supported fixed restorations: A preliminary in vivo study. Int J Prosthodont 28 , 371-373

Park JB, Yang SM, Ko Y (2015): Evaluation of the surface characteristics of various implant abutment materials using confocal microscopy and white light interferometry. Implant Dent $\underline{24}, 650-656$

Pedersen AM, Bardow A, Beier Jensen S, Nauntofte B (2002): Saliva and gastrointestinal functions of taste, mastication, swallowing and digestion. Oral Diseases $\underline{8}, 117-129$

Percival RS, Challacombe SJ, Marsh PD (1994): Flow rates of resting whole and stimulated parotid saliva in relation to age and gender. J Dent Res $\underline{73}$, 1416-1420

Persson GR, Renvert S (2014): Cluster of bacteria associated with peri-implantitis. Clin Implant Dent Relat Res 16, 783-793

Persson LG, Lekholm U, Leonhardt A, Dahlén G, Lindhe J (1996): Bacterial colonization on internal surfaces of Brånemark system implant components. Clin Oral Implants Res $\underline{7}, 90$ 95 
Pierce CG, Vila T, Romo JA, Montelongo-Jauregui D, Wall G, Ramasubramanian A, LopezRibot JL (2017): The Candida albicans biofilm matrix: Composition, structure and function. J Fungi $\underline{3}, 1-10$

Pier-Francesco A, Adams RJ, Waters MGJ, Williams DW (2006): Titanium surface modification and its effect on the adherence of Porphyromonas gingivalis: An in vitro study. Clin Oral Implants Res 17, 633-637

Pontoriero R, Tonelli MP, Carnevale G, Mombelli A, Nyman SR, Lang NP (1994): Experimentally induced peri-implant mucositis. A clinical study in humans. Clin Oral Implants Res $\underline{5}, 254-259$

Prada-López I, Quintas V, Casares-De-Cal MA, Suárez-Quintanilla JA, Suárez-Quintanilla D, Tomás I (2015): Ex vivo vs. in vivo antibacterial activity of two antiseptics on oral biofilm. Front Microbiol $\underline{6}, 655$

Preoteasa E, Tâncu AM, Iosif L, Melescanu Imre M, Murariu-Măgureanu C, Preoteasa CT (2014): Salivary changes related to systemic diseases in the edentulous patients. J Med Life 7, 577-580

Proctor GB, Carpenter GH (2007): Regulation of salivary gland function by autonomic nerves. Auton Neurosci 133, 3-18

Quirynen M, van Steenberghe D (1993): Bacterial colonization of the internal part of two-stage implants. An in vivo study. Clin Oral Implants Res $\underline{4}, 158-161$

Quirynen M, Bollen CML (1995): The influence of surface roughness and surface-free energy on supra- and subgingival plaque formation in man. J Clin Periodontol 22, 1-14

Quirynen M, Marechal M, Busscher HJ, Weerkamp AH, Darius PL, van Steenberghe D (1990): The influence of surface free energy and surface roughness on early plaque formation: An in vivo study in man. J Clin Periodontol 17, 138-144

Quirynen M, Dekeyser C, van Steenberghe D (1991): The influence of gingival inflammation, tooth type, and timing on the rate of plaque formation. J Periodontol $\underline{62}, 219-222$

Quirynen M, Bollen CM, Papaioannou W, van Eldere J, van Steenberghe D (1996): The influence of titanium abutment surface roughness on plaque accumulation and gingivitis: Short-term observations. Int J Oral Maxillofac Implants 11, 169-178

Quirynen M, Soete M de, van Steenberghe D (2002): Infectious risks for oral implants: A review of the literature. Clin Oral Implants Res $\underline{13}, 1-19$

Rai R, Gupta R (2013): In vitro evaluation of the effect of two finishing and polishing systems on four esthetic restorative materials. J Conserv Dent $\underline{16}, 564-567$

Ramenzoni LL, Attin T, Schmidlin PR (2019): In vitro effect of modified polyetheretherketone (PEEK) implant abutments on human gingival epithelial keratinocytes migration and proliferation. Materials $\underline{12}, 1401$ 
Rasperini G, Maglione M, Cocconcelli P, Simion M (1998): In vivo early plaque formation on pure titanium and ceramic abutments: A comparative microbiological and SEM analysis. Clin Oral Implants Res $\underline{9}, 357-364$

Reddy CA, Beveridge TJ, Breznak JA, Marzluf GA, Schmidt TM, Snyder LR (Hrsg.): Methods for general and molecular microbiology. 3. Auflage; ASM Press, Washington, DC 2007

Reinhardt B, Beikler T: Dental implants. In: Shen JZ, Kosmač T (Hrsg.): Advanced ceramics for dentistry. Elsevier, Amsterdam 2014, 51-75

Rickard AH, Gilbert P, High NJ, Kolenbrander PE, Handley PS (2003): Bacterial coaggregation: An integral process in the development of multi-species biofilms. Trends Microbiol 11, 94-100

Rigolin MSM, Barbugli PA, Jorge JH, Reis MRD, Adabo GL, Casemiro LA, Martins CHG, Lima OJ de, Mollo Junior FdA (2019): Effect of the aging of titanium and zirconia abutment surfaces on the viability, adhesion, and proliferation of cells and the adhesion of microorganisms. J Prosthet Dent 122, 564.e1-564.e10

Rimondini L, Farè S, Brambilla E, Felloni A, Consonni C, Brossa F, Carrassi A (1997): The effect of surface roughness on early in vivo plaque colonization on titanium. J Periodontol $\underline{68}, 556-562$

Rimondini L, Cerroni L, Carrassi A, Torricelli P (2002): Bacterial colonization of zirconia ceramic surfaces: An in vitro and in vivo study. Int J Oral Maxillofac Implants 17, 793-798

Rinke S, Bürgers R, Ziebolz D, Rödiger M (2015): Clinical outcome of double crown-retained implant overdentures with zirconia primary crowns. J Adv Prosthodont $\underline{7}$, 329-337

Robinson C, Kirkham J, Percival R, Shore RC, Bonass WA, Brookes SJ, Kusa L, Nakagaki H, Kato K, Nattress B (1997): A method for the quantitative site-specific study of the biochemistry within dental plaque biofilms formed in vivo. Caries Res $\underline{31}, 194-200$

Rochford ETJ, Poulsson AHC, Salavarrieta Varela J, Lezuo P, Richards RG, Moriarty TF (2014): Bacterial adhesion to orthopaedic implant materials and a novel oxygen plasma modified PEEK surface. Colloid Surface B $\underline{113}$, 213-222

Rodrigues DC, Valderrama P, Wilson TG, Palmer K, Thomas A, Sridhar S, Adapalli A, Burbano M, Wadhwani C (2013): Titanium corrosion mechanisms in the oral environment: A retrieval study. Materials $\underline{6}, 5258-5274$

Roehling S, Astasov-Frauenhoffer M, Hauser-Gerspach I, Braissant O, Woelfler H, Waltimo T, Kniha H, Gahlert M (2017): In vitro biofilm formation on titanium and zirconia implant surfaces. J Periodontol $\underline{88}, 298-307$

Rogge S, Kielbassa A (2004): Periimplantäre Erkrankungen: Periimplantitisprophylaxe und Implantatpflege. Dentalhygiene Journal $\underline{1}, 12-15$

Romaní AM, Fund K, Artigas J, Schwartz T, Sabater S, Obst U (2008): Relevance of polymeric matrix enzymes during biofilm formation. Microb Ecol 56, 427-436 
Rosentritt M, Ilie N, Lohbauer U (Hrsg.): Werkstoffkunde in der Zahnmedizin: Moderne Materialien und Technologien. Georg Thieme Verlag, Stuttgart 2018

Rowe MC, Withers HL, Swift S (2010): Uropathogenic Escherichia coli forms biofilm aggregates under iron restriction that disperse upon the supply of iron. FEMS Microbiol Lett $\underline{307}, 102-109$

Rupp F, Haupt M, Eichler M, Doering C, Klostermann H, Scheideler L, Lachmann S, Oehr C, Wendel HP, Decker E et al. (2012): Formation and photocatalytic decomposition of a pellicle on anatase surfaces. J Dent Res $\underline{91}$, 104-109

Rutar A, Lang NP, Buser D, Burgin W, Mombelli A (2001): Retrospective assessment of clinical and microbiological factors affecting periimplant tissue conditions. Clin Oral Implants Res 12, 189-195

Rytömaa I, Meurman JH, Koskinen J, Laakso T, Gharazi L, Turunen R (1988): In vitro erosion of bovine enamel caused by acidic drinks and other foodstuffs. Scand J Dent Res $\underline{96}, 324$ 333

Sagomonyants KB, Jarman-Smith ML, Devine JN, Aronow MS, Gronowicz GA (2008): The in vitro response of human osteoblasts to polyetheretherketone (PEEK) substrates compared to commercially pure titanium. Biomaterials $29,1563-1572$

Salihoglu U, Boynuegri D, Engin D, Duman AN, Gokalp P, Balos K (2011): Bacterial adhesion and colonization differences between zirconium oxide and titanium alloys: An in vivo human study. Int J Oral Maxillofac Implants 26, 101-107

Samson RA, Stalpers JA, Verkerke W (1979): A simplified technique to prepare fungal specimens for scanning electron microscopy. Cytobios $\underline{24}, 7-11$

Sander M: A Practical Guide to the Assessment of Surface Texture. Mahr Feinprüf, Göttingen 1991

Sanderink RBA, Bernhardt H, Knoke M, Meyer J, Weber C, Weiger R (Hrsg.): Curriculum orale Mikrobiologie und Immunologie. Quintessenz, Berlin 2004

Sanz M, Alandez J, Lazaro P, Calvo JL, Quirynen M, van Steenberghe D (1991): Histopathologic characteristics of peri-implant soft tissues in Brånemark implants with 2 distinct clinical and radiological patterns: A histometric and ultrastructural study. Clin Oral Implants Res $\underline{2}, 128-134$

Sarapur S, Shilpashree HS (2012): Salivary pacemakers: A review. Dent Res J $\underline{9}, 20-25$

Sauer K, Cullen MC, Rickard AH, Zeef LAH, Davies DG, Gilbert P (2004): Characterization of nutrient-induced dispersion in Pseudomonas aeruginosa PAO1 biofilm. J Bacteriol $\underline{186}$, $7312-7326$

Scarano A, Piattelli M, Caputi S, Favero GA, Piattelli A (2004): Bacterial adhesion on commercially pure titanium and zirconium oxide disks: an in vivo human study. $\mathrm{J}$ Periodontol 75, 292-296 
Scarano A, Tripodi D, Carinci F, Piccolomini R, D'Ercole S (2013): Biofilm formation on titanium alloy and anatase- Bactercline ${ }^{\circledR}$ coated titanium healing screws: An in vivo human study. J Osseointegration $\underline{5}, 8-12$

Scarano A, Crocetta E, Quaranta A, Lorusso F (2018): Influence of the thermal treatment to address a better osseointegration of Ti6Al4V dental implants: Histological and histomorphometrical study in a rabbit model. Biomed Res Int 2018, 2349698

Schalock PC, Menné T, Johansen JD, Taylor JS, Maibach HI, Lidén C, Bruze M, Thyssen JP (2012): Hypersensitivity reactions to metallic implants - diagnostic algorithm and suggested patch test series for clinical use. Contact Derm $\underline{66}$, 4-19

Scheie AA (1994): Mechanisms of dental plaque formation. Adv Dent Res $\underline{8}, 246-253$

Schliephake H, van den Berghe P, Neukam FW (1991): Osseointegration of titanium fixtures in onlay grafting procedures with autogenous bone and hydroxylapatite. An experimental histometric study. Clin Oral Implants Res $\underline{2}, 56-61$

Schliephake H, Lehmann H, Kunz U, Schmelzelsen H (1993): Ultrastructural findings in soft tissues adjacent to titanium plates used in jaw fracture treatment. Int J Oral Maxillofac Surg $22,20-25$

Schroeder A, van der Zypen E, Stich H, Sutter F (1981): The reactions of bone, connective tissue, and epithelium to endosteal implants with titanium-sprayed surfaces. J Maxillofac Surg $\underline{9}, 15-25$

Schubert A, Wassmann T, Holtappels M, Kurbad O, Krohn S, Bürgers R (2019a): Predictability of microbial adhesion to dental materials by roughness parameters. Coatings $\underline{9}, 456$

Schubert T, Hofele M, Bernthaler T, Schneider G, Riegel H (2019b): Surface analysis of laser polished additively manufactured 316L stainless steel using ZEISS Smartproof 5. https://applications.zeiss.com/C125792900358A3F/0/0DDDDC68AD1700E5C125847A00 4B6E93/\$FILE/EN_42_13_300_Surface_Analysis_Laser_Polished_Steed.pdf, abgerufen am: 02.04.2020

Schuth M, Buerakov W: Handbuch optische Messtechnik: Praktische Anwendungen für Entwicklung, Versuch, Fertigung und Qualitätssicherung. Hanser, München 2017

Schwarz F, Jepsen S, Herten M, Sager M, Rothamel D, Becker J (2006a): Influence of different treatment approaches on non-submerged and submerged healing of ligature induced periimplantitis lesions: An experimental study in dogs. J Clin Periodontol 33, 584-595

Schwarz F, Papanicolau P, Rothamel D, Beck B, Herten M, Becker J (2006b): Influence of plaque biofilm removal on reestablishment of the biocompatibility of contaminated titanium surfaces. J Biomed Mater Res A $\underline{77}$, 437-444

Schwarz F, Sahm N, Becker J (2008): Aktuelle Aspekte zur Therapie periimplantärer Entzündungen. Quintessenz 59, 521-530

Schwitalla A, Müller WD (2013): PEEK dental implants: A review of the literature. J Oral Implantol 39, 743-749 
Schwitalla A, Spintig T, Kallage I, Wagner R, Müller WD (2014): Polyetheretherketon (PEEK) - ein vielversprechender Werkstoff für die Zukunft. umwelt-medizin-gesellschaft 27, 255261

Sculean A, Gruber R, Bosshardt DD (2014): Soft tissue wound healing around teeth and dental implants. J Clin Periodontol 41, 6-22

Severino VO, Napimoga MH, Lima Pereira SA de (2011): Expression of IL-6, IL-10, IL-17 and IL-8 in the peri-implant crevicular fluid of patients with peri-implantitis. Arch Oral Biol $\underline{56}, 823-828$

Seymour GJ, Berglundh T, Trombelli L: Pathogenesis of periodontitis. In: Lang NP, Lindhe J (Hrsg.): Clinical Periodontology and Implant Dentistry. 6. Auflage; Wiley-Blackwell, Hoboken 2015, 256-269

Shafie HR (Hrsg.): Clinical and laboratory manual of dental implant abutments. WileyBlackwell, Hoboken 2014

Siewert B, Parra M (2013): Eine neue Werkstoffklasse in der Zahnmedizin. Z Zahnärztl Impl $\underline{29}, 148-159$

Skillman LC, Sutherland IW, Jones MV (1999): The role of exopolysaccharides in dual species biofilm development. J Appl Microbiol $\underline{\text { 85, }}$ 13-18

Slavkin HC (1997): Biofilms, microbial ecology and Antoni van Leeuwenhoek. J Am Dent Assoc 128, 492-495

Sogn JA, Gibbons WA, Randall EW (1973): Study of nitrogen-15-labeled amino acids and peptides by nuclear magnetic resonance spectroscopy. Biochemistry 12, 2100-2105

Song F, Koo H, Ren D (2015): Effects of material properties on bacterial adhesion and biofilm formation. J Dent Res 94, 1027-1034

Souza JCM, Ponthiaux P, Henriques M, Oliveira R, Teughels W, Celis JP, Rocha LA (2013): Corrosion behaviour of titanium in the presence of Streptococcus mutans. J Dent $\underline{41}, 528$ 534

Souza JCM, Mota RRC, Sordi MB, Passoni BB, Benfatti CAM, Magini RS (2016): Biofilm formation on different materials used in oral rehabilitation. Braz Dent J $\underline{27}, 141-147$

Sreenivasan PK, Prasad KVV (2017): Distribution of dental plaque and gingivitis within the dental arches. J Int Med Res $\underline{45}, 1585-1596$

Sreenivasan PK, DeVizio W, Prasad KVV, Patil S, Chhabra KG, Rajesh G, Javali SB, Kulkarni RD (2010): Regional differences within the dentition for plaque, gingivitis, and anaerobic bacteria. J Clin Dent 21, 13-19

Stawarczyk B, Beuer F, Wimmer T, Jahn D, Sener B, Roos M, Schmidlin PR (2013): Polyetheretherketone - a suitable material for fixed dental prostheses? J Biomed Mater Res Part B Appl Biomater 101, 1209-1216 
Steinberg D, Klinger A, Kohavi D, Sela MN (1995): Adsorption of human salivary proteins to titanium powder. I. Adsorption of human salivary albumin. Biomaterials $\underline{16}, 1339-1343$

Steinberg D, Sela MN, Klinger A, Kohavi D (1998): Adhesion of periodontal bacteria to titanium, and titanium alloy powders. Clin Oral Implants Res $\underline{9}, 67-72$

Stewart PS, Costerton JW (2001): Antibiotic resistance of bacteria in biofilms. The Lancet $\underline{358}$, $135-138$

Stoodley P, DeBeer D, Lewandowski Z (1994): Liquid flow in biofilm systems. Appl Environ Microbiol $\underline{60}, 2711-2716$

Stoodley P, Wilson S, Hall-Stoodley L, Boyle JD, Lappin-Scott HM, Costerton JW (2001): Growth and detachment of cell clusters from mature mixed-species biofilms. Appl Environ Microbiol 67, 5608-5613

Stout KJ (Hrsg.): Development of methods for the characterisation of roughness in three dimensions. Butterworth-Heinemann, Oxford 2002

Subramani K (2010): Titanium surface modification techniques for implant fabrication - from microscale to the nanoscale. JBBTE $\underline{5}, 39-56$

Subramani K, Jung RE, Molenberg A, Hammerle CHF (2009): Biofilm on dental implants: A review of the literature. Int J Oral Maxillofac Implants 24, 616-626

Sutherland IW (2001a): Biofilm exopolysaccharides: A strong and sticky framework. Microbiology 147, 3-9

Sutherland IW (2001b): The biofilm matrix - an immobilized but dynamic microbial environment. Trends Microbiol $\underline{9}, 222-227$

Tan Ö (2016): Rauheit berührungslos messen. J Oberfl Techn $\underline{56}, 20-23$

Tanner A, Maiden MF, Lee K, Shulman LB, Weber HP (1997): Dental implant infections. Clin Infect Dis 25 Suppl 2, S213-7

Teughels W, van Assche N, Sliepen I, Quirynen M (2006): Effect of material characteristics and/or surface topography on biofilm development. Clin Oral Implants Res 17, 68-81

Theilade J (1964): Electron microscopic study of calculus attachment to smooth surfaces. Acta Odontol Scand 22, 379-387

Thoma DS, Jones AA, Dard M, Grize L, Obrecht M, Cochran DL (2011): Tissue integration of a new titanium-zirconium dental implant: A comparative histologic and radiographic study in the canine. J Periodontol $\underline{82}, 1453-1461$

Thomson ME, Thomson CW, Chandler NP (1996): In vitro and intra-oral investigations into the cariogenic potential of human milk. Caries Res $\underline{30}, 434-438$

Tomasi C, Derks J (2012): Clinical research of peri-implant diseases - quality of reporting, case definitions and methods to study incidence, prevalence and risk factors of peri-implant diseases. J Clin Periodontol 39, 207-223 
Tonetti MS (1999): Determination of the success and failure of root-form osseointegrated dental implants. Adv Dent Res $\underline{13}, 173-180$

Truninger TC, Stawarczyk B, Leutert CR, Sailer TR, Hämmerle CHF, Sailer I (2012): Bending moments of zirconia and titanium abutments with internal and external implant-abutment connections after aging and chewing simulation. Clin Oral Implants Res $\underline{23}, 12-18$

Tsigarida AA, Dabdoub SM, Nagaraja HN, Kumar PS (2015): The influence of smoking on the peri-implant microbiome. J Dent Res $\underline{94}, 1202-1217$

Türkmen C, Durkan M, Cimilli H, Öksüz M (2011): Tensile bond strength of indirect composites luted with three new self-adhesive resin cements to dentin. J Appl Oral Sci $\underline{19}$, 363-369

Turkoglu P, Kose A, Sen D: Abutment selection for anterior implant-supported restorations. In: Ahmad Almasri M (Hrsg.): An Update of Dental Implantology and Biomaterial. InTechOpen, London 2019

Urban RM, Jacobs JJ, Tomlinson MJ, Gavrilovic J, Black J, Peoc'h M (2000): Dissemination of wear particles to the liver, spleen, and abdominal lymph nodes of patients with hip or knee

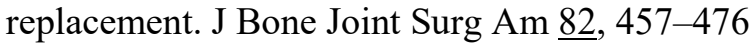

Vacca Smith AM, Bowen WH (2000): The effects of milk and kappa-casein on salivary pellicle formed on hydroxyapatite discs in situ. Caries Res 34, 88-93

van Brakel R, Cune MS, van Winkelhoff AJ, de Putter C, Verhoeven JW, van der Reijden W (2011): Early bacterial colonization and soft tissue health around zirconia and titanium abutments: an in vivo study in man. Clin Oral Implants Res 22, 571-577

van der Weijden F, Slot DE, Echeverria JJ, Lindhe J: Mechanical supragingival plaque control. In: Lang NP, Lindhe J (Hrsg.): Clinical Periodontology and Implant Dentistry. 6. Auflage; Wiley-Blackwell, Hoboken 2015, 677-716

van Leeuwenhoek A (1684): An abstract of a letter from Mr. Anthony Leewenhoeck at Delft, dated Sep. 17. 1683. Containing some microscopical observations, about animals in the scurf of the teeth, the substance call'd worms in the nose, the cuticula consisting of scales. Phil Trans $\underline{14}, 568-574$

van Loosdrecht MC, Norde W, Zehnder AJ (1990): Physical chemical description of bacterial adhesion. J Biomater Appl $\underline{5}, 91-106$

van Rensburg BGJ: Mundbiologie. Quintessenz, Berlin 1994

Veerachamy S, Yarlagadda T, Manivasagam G, Yarlagadda PK (2014): Bacterial adherence and biofilm formation on medical implants: A review. Proc Inst Mech Eng H 228, 1083-1099

Volpe S, Verrocchi D, Andersson P, Gottlow J, Sennerby L (2008): Comparison of early bacterial colonization of PEEK and titanium healing abutments using real-time PCR. Applied Osseointegration Research, 54-56

Vorburger TV, Rhee HG, Renegar TB, Song JF, Zheng A (2007): Comparison of optical and stylus methods for measurement of surface texture. Int J Adv Manuf Technol $\underline{33}, 110-118$ 
Walz A, Stühler K, Wattenberg A, Hawranke E, Meyer HE, Schmalz G, Blüggel M, Ruhl S (2006): Proteome analysis of glandular parotid and submandibular-sublingual saliva in comparison to whole human saliva by two-dimensional gel electrophoresis. Proteomics $\underline{6}$, $1631-1639$

Wang D, Haapasalo M, Gao Y, Ma J, Shen Y (2018): Antibiofilm peptides against biofilms on titanium and hydroxyapatite surfaces. Bioact Mater $\underline{3}, 418-425$

Wang JJ, Sanderson BJS, Wang H (2007): Cyto- and genotoxicity of ultrafine TiO2 particles in cultured human lymphoblastoid cells. Mutat Res $\underline{628}, 99-106$

Wang RR, Fenton A (1996): Titanium for prosthodontic applications: A review of the literature. Quintessence Int 27, 401-408

Wang Y, Lee SM, Dykes G (2015): The physicochemical process of bacterial attachment to abiotic surfaces: Challenges for mechanistic studies, predictability and the development of control strategies. Crit Rev Microbiol 41, 452-464

Wassmann T, Kreis S, Behr M, Buergers R (2017): The influence of surface texture and wettability on initial bacterial adhesion on titanium and zirconium oxide dental implants. Int J Implant Dent $\underline{3}, 32$

Waters CM, Bassler BL (2005): Quorum sensing: Cell-to-cell communication in bacteria. Annu Rev Cell Dev Biol 21, 319-346

Wehle J: Klinische Studie zur initialen In-vivo-Plaqueakkumulation auf verschiedenen dentalen Werkstoffen. Med. Diss. Göttingen 2004

Welander M, Abrahamsson I, Berglundh T (2008): The mucosal barrier at implant abutments of different materials. Clin Oral Implants Res $\underline{19}, 635-641$

Wenz LM, Merritt K, Brown SA, Moet A, Steffee AD (1990): In vitro biocompatibility of polyetheretherketone and polysulfone composites. J Biomed Mater Res $\underline{24}$, 207-215

Williams DF, McNamara A, Turner RM (1987): Potential of polyetheretherketone (PEEK) and carbon fibre reinforced peek in medical applications. J Mater Sci Lett $\underline{6}, 188-190$

Wilson V (2013): An insight into peri-implantitis: A systematic literature review. Prim Dent J $\underline{2}$, $69-73$

Wimpenny JW (1997): The validity of models. Adv Dent Res 11, 150-159

Wolinsky LE, de Camargo PM, Erard JC, Newman MG (1989): A study of in vitro attachment of Streptococcus sanguis and Actinomyces viscosus to saliva-treated titanium. Int J Oral Maxillofac Implants $\underline{4}, 27-31$

Wuertz S, Okabe S, Hausner M (2004): Microbial communities and their interactions in biofilm systems: An overview. Water Sci Technol 49, 327-336

Xiao GQ, Corle TR, Kino GS (1988): Real-time confocal scanning optical microscope. Appl Phys Lett $\underline{53}, 716-718$ 
Xing R, Lyngstadaas SP, Ellingsen JE, Taxt-Lamolle S, Haugen HJ (2015): The influence of surface nanoroughness, texture and chemistry of TiZr implant abutment on oral biofilm accumulation. Clin Oral Implants Res 26, 649-656

Yao Y, Grogan J, Zehnder M, Lendenmann U, Nam B, Wu Z, Costello CE, Oppenheim FG (2001): Compositional analysis of human acquired enamel pellicle by mass spectrometry. Arch Oral Biol 46, 293-303

Yeo IS, Kim HY, Lim KS, Han JS (2012): Implant surface factors and bacterial adhesion: A review of the literature. Int J Artif Organs $\underline{35}, 762-772$

Yildirim M, Edelhoff D, Hanisch O, Spiekermann H (2000): Ceramic abutments - a new era in achieving optimal esthetics in implant dentistry. Int J Periodontics Restorative Dent 20, 8191

Yoshinari M, Oda Y, Kato T, Okuda K, Hirayama A (2000): Influence of surface modifications to titanium on oral bacterial adhesion in vitro. J Biomed Mater Res 52, 388-394

Yousif A, Jamal MA, Raad I (2015): Biofilm-based central line-associated bloodstream infections. Adv Exp Med Biol 830, 157-179

Yu F, Addison O, Baker SJ, Davenport AJ (2015): Lipopolysaccharide inhibits or accelerates biomedical titanium corrosion depending on environmental acidity. Int J Oral Sci 7, 179186

Zaffe D, Bertoldi C, Consolo U (2003): Element release from titanium devices used in oral and maxillofacial surgery. Biomaterials 24, 1093-1099

Zahradnik RT, Moreno EC, Burke EJ (1976): Effect of salivary pellicle on enamel subsurface demineralization in vitro. J Dent Res 55, 664-670

Zhang L, Gowardman J, Rickard CM (2011): Impact of microbial attachment on intravascular catheter-related infections. Int J Antimicrob Agents $\underline{38}, 9-15$

Zhang R, Wan Y, Ai X, Liu Z, Zhang D (2017): Corrosion resistance and biological activity of $\mathrm{TiO} 2$ implant coatings produced in oxygen-rich environments. Proc Inst Mech Eng H 231 , $20-27$

Zhang X, Wang L, Levänen E (2013): Superhydrophobic surfaces for the reduction of bacterial adhesion. RSC Adv. $\underline{3}, 12003$

Zitzmann NU, Berglundh T (2008): Definition and prevalence of peri-implant diseases. J Clin Periodontol $\underline{35}, 286-291$

Zitzmann NU, Berglundh T, Marinello CP, Lindhe J (2001): Experimental peri-implant mucositis in man. J Clin Periodontol 28, 517-523

Zitzmann NU, Walter C, Berglundh T (2006): Ätiologie, Diagnostik und Therapie der Periimplantitis - eine Übersicht. DZZ $\underline{61}, 642-649$

Zoidis P, Papathanasiou I (2016): Modified PEEK resin-bonded fixed dental prosthesis as an interim restoration after implant placement. J Prosthet Dent 116, 637-641 
Zoidis P, Papathanasiou I, Polyzois G (2016): The use of a modified poly-ether-ether-ketone (PEEK) as an alternative framework material for removable dental prostheses. A clinical report. J Prosthodont $\underline{25}$, 580-584

Zurek-Biesiada D, Kędracka-Krok S, Dobrucki JW (2013): UV-activated conversion of Hoechst 33258, DAPI, and Vybrant DyeCycle fluorescent dyes into blue-excited, green-emitting protonated forms. Cytometry A $\underline{83}, 441-451$ 


\section{Danksagung}

Ein ganz besonderer Dank gilt meinem Doktorvater Herrn Professor Dr. Ralf Bürgers für die Überlassung des Themas, der hervorragenden und konstruktiven Betreuung sowie Unterstützung bei der Erstellung dieser Arbeit. Des Weiteren danke ich der „AG Biofilme und Orales Mikrobiom“, insbesondere Herrn Dr. Torsten Wassmann und MTA Frau S. Kiecke für die Einweisung, Einarbeitung und kompetente Betreuung bei der Versuchsdurchführung. Außerdem möchte ich mich bei Frau Z̈̈ Johanna Maria Leding für die unermüdliche Unterstützung und das stilistische Lektorat bedanken. 